You are kindly invited to attend the public defence of my PhD thesis

\section{The development of a sole diet} based on the composition of ragworm

On Tuesday, 6 June, 2017

at 16:00 in the Aula of Wageningen University, General Foulkesweg 1a, Wageningen.
The defence ceremony will be followed by a reception in the Aula.

Jeroen Kals Jeroen.Kals@wur.n 0610131556

Paranymphs Maarten Kals Paul Hendrix 


\section{Jeroen Kals}

\section{The development of \\ a sole diet based on the \\ composition of ragworm}




\section{The development of a sole diet based on the composition of ragworm}

Jeroen Kals 


\section{Thesis committee}

\section{Promotor}

Prof. Dr Johan A.J. Verreth

Professor of Aquaculture and Fisheries

Wageningen University \& Research

\section{Co-promotors}

Dr Johan W. Schrama

Associate professor, Aquaculture and Fisheries Group

Wageningen University \& Research

Dr Robbert J.W. Blonk

Director R\&D, Hendrix Genetics Aquaculture BV

Boxmeer, The Netherlands

\section{Other members}

Prof. Dr Hans Komen, Wageningen University \& Research

Dr Mark Bayley, Aarhus University, Denmark

Prof. Patrick Kestemont, Université de Namur, Belgium

Dr Arjen J. Roem, Nutreco/Skretting, Boxmeer, The Netherlands

This research was conducted under the auspices of the Graduate School, Wageningen Institute of Animal Sciences (WIAS). 


\title{
The development of a sole diet based on the composition of ragworm
}

\section{Jeroen Kals}

\author{
Thesis \\ submitted in fulfilment of the requirements for the degree of doctor \\ at Wageningen University \\ by the authority of the Rector Magnificus, \\ Prof. Dr A.P.J. Mol, \\ in the presence of the \\ Thesis Committee appointed by the Academic Board \\ to be defended in public \\ on Tuesday 6 June 2017 \\ at 4 p.m. in the Aula.
}




\section{Jeroen Kals}

The development of a sole diet based on the composition of ragworm,

136 pages.

$\mathrm{PhD}$ thesis, Wageningen University, Wageningen, the Netherlands (2017)

With references, with summary in English

ISBN: 978-94-6343-180-4

DOI: http://10.18174/412951 
For myself and anyone interested in the subject 



\begin{abstract}
Scientifically, this study aimed to validate the potential of ragworm to alleviate anaemia in common sole and to identify the dietary requirements of common sole to alleviate this anaemia. At the same time it was aimed to explain part of the difference in growth between sole fed a commercial pellet and sole fed ragworm. Practically, this study aimed to develop a diet that achieves similar growth rates in sole as when fed ragworm. Sole fed commercial pellets developed nutritional anaemia. Feeding ragworm or mussel alleviates this nutritional anaemia. It is suggested that the ability of mussel or ragworm (meal) to alleviate anaemia and improve growth in sole can be explained by heme iron and high $\mathrm{B}_{12}$ levels. Yet, iron absorption in sole is high and independent of iron source. Still, heme increases the absorption of copper. The high absorption of iron and copper in sole fed heme does not affect the haematocrit (Hct) and haemoglobin $(\mathrm{Hb})$ levels, which indicates the anaemia in sole is not an iron or a copper deficiency anaemia. The Hct and $\mathrm{Hb}$ levels in sole are affected by dietary $\mathrm{B}_{12}$. Yet, the applied levels are unable to alleviate the anaemia in sole induced by feeding commercial pellets. More options to alleviate the nutritional anaemia in common sole are discussed. Nutrients as vitamin C, B1, B2, B5 and a possible role of dietary EPO are discussed. It is suggested that the slow growth of pellet-fed sole might be due to the low Hct and $\mathrm{Hb}$ levels, which hampers the uptake of oxygen, and thus also the overall metabolic capacity, including the scope for growth. Discussed is a $7^{\circ} \mathrm{C}$ difference in the "optimal" temperature between sole fed ragworm and the $2^{\text {nd }}$ generation pellet and that the "worm effect" is dependent on temperature. However, the growth rate of sole fed the $3^{\text {rd }}$ generation pellet at $18.4^{\circ} \mathrm{C}$ was comparable to the growth rate of sole fed ragworm, which could not have been the consequence of increasing Hct and $\mathrm{Hb}$ levels as these were comparable to levels found in sole fed commercial pellets. Yet, $\mathrm{B}_{12}$ levels in blood plasma of sole are up to 200 times those of other (fish) species. Hence, we inferred on the possibility of a specific metabolic function of $\mathrm{B}_{12}$ in respiration in sole. In addition, the economic and practical impact of the improved growth rate in sole culture is discussed. Finally, several suggestions for future research are given.
\end{abstract}





\section{Contents}

\section{Chapter 1}

General Introduction 11

\section{Chapter 2}

Feeding ragworm (Nereis virens Sars) increases haematocrit and haemoglobin levels in common sole (Solea solea L.)

\section{Chapter 3}

Mussel (Mytilus edulis L.) and ragworm (Nereis virens, Sars) both alleviate anaemia in common sole (Solea, solea L.) 27

\section{Chapter 4}

Feeding ragworm (Nereis virens Sars) to common sole (Solea solea L.) alleviates nutritional anaemia and stimulates growth.

\section{Chapter 5}

The relation between ragworm meal inclusion level, haematocrit level and growth of common sole (Solea solea L.). 51

\section{Chapter 6}

Effect of different iron sources on the alleviation of nutritional anaemia in common sole (Solea solea). 65

\section{Chapter 7}

Effect of vitamin $\mathrm{B}_{12}$ and taurine on the alleviation of nutritional anaemia in common sole, (Solea, solea L.) 


\section{Chapter 8}

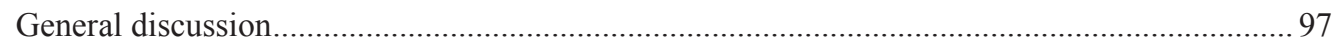

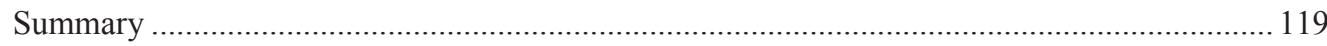

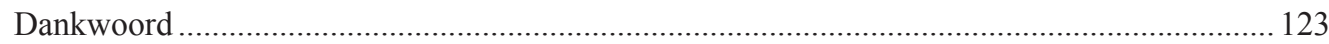

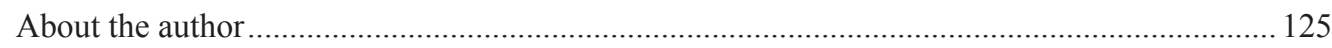

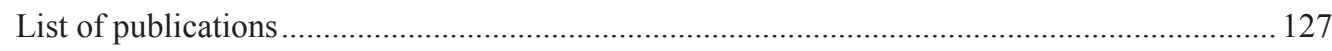




\section{Chapter 1}

\section{General Introduction}

The aquaculture production of common sole (Solea solea L.) does not meet its potential when using currently available commercial feeds as sole grows about $70 \%$ faster on ragworm (Nereis virens, Sars) than on commercial feeds (Ende, Kroeckel, Schrama, Schneider \& Verreth 2014). Moreover, ragworm appears to be an excellent feed to support long term growth of sole over a wide range of size classes (Ende, Kroeckel, Schrama \& Verreth 2009; Kals, Ruizeveld de Winter \& Schiphouwer 2009'; Kals, Capelle \& Hemsing $2009^{\mathrm{b}}$; Ende et al. 2014). This suggests a mismatch between the nutritional requirements of sole and the dietary composition of the commercial feeds. It is therefore assumed that the composition of ragworm reflects the dietary requirements of common sole. The essential question remains which compound(s) within ragworm are essential for meeting the soles nutrient requirements and thus explain the high nutritional value of ragworm for sole. Therefore, this thesis takes ragworm as a benchmark to identify this component.

\section{Nutritional value and requirements}

In general terms, the nutritional value of an ingredient and or feed formulation for meeting the requirements of fish are related to dietary composition, attractivity, palatability and digestibility. Only a balanced combination of these categories will lead to healthy fish and full expression of the sole's growth potential. The dietary requirements for common sole have not yet been established for most nutrients. However, for protein, the dietary requirements have been confirmed for Senegalese sole (Solea senegalensis Kaup 1858) with levels ranging from 50-60\% (Aragao, Conceição, Dias, Marques, Gomes \& Dinis 2003; Rema, Conceição, Evers, Castro-Cunha, Dinis \& Dias 2008) and common sole with a level of 57\% (Gatta, Parma, Guarniero, Mandrioli, Sirri, Fontanillas \& Bonaldo 2010). Ragworm contains levels of 
protein varying between $50-74 \%$ (Ende et al. 2009; Kals et al. $2009^{\mathrm{b}}$ ), thereby fulfilling the requirements of sole for dietary protein.

For dietary fat there are indications that levels in current available feeds for sole are too high. Borges, Oliveira, Casal, Dias, Conceição \& Valente (2009) suggest a maximum dietary level of $8 \%$ for Senegalese sole for both optimal growth and nutrient utilization. Fat levels found in ragworm do differ depending on season, diet and origin. Approximate fat levels found for wild, farmed and intensively farmed ragworms are 3-7\%, 6-8\% and 13-20\% on dry matter basis, respectively (Craig, Olive, Pinon \& Rutherford 2005; Ende et al. 2014; Kals et al. $2009^{\mathrm{b}}$ ).

Fish do not have specific requirements for dietary carbohydrates and are able to grow on diets without carbohydrates. The ability of fish to utilize dietary carbohydrates varies among species and more or less corresponds to the feeding habits of the species (NRC 2011). As common sole is a polychaete-mollusc feeder with sometimes crustaceans found in their alimentary tract (De Groot 1971), carbohydrates form only a limited part of their natural diet. However, in nature, sole will ingest some carbohydrates as chitin and glycogen (Jobling 2004). One of the reasons for the inclusion of carbohydrates in current commercial feeds is their binding or matrix forming properties. Sole might have difficulties digesting carbohydrates, i.e. the carbohydrate matrix of the pellet, thereby lowering the bioavailability of the other nutrients.

Information concerning mineral and vitamin requirements in fish is limited (NRC 2011). Quantitative requirements are known for some species among which sole is not included. In addition to the variability between fish species, requirements of minerals and vitamins are affected by size, age and growth rate as well as environmental factors, the form in which minerals and vitamins are provided and the interrelationships (e.g. antagonism) between nutrients (Prabhu, Schrama \& Kaushik 2014).

The basic metabolic functions of the various minerals are the same for aquatic and terrestrial animals with the exception of osmoregulation, ionic and acid base balance (NRC 2011). Because the requirements of fish in general are poorly known, fish feeds usually are fortified with mineral and vitamin pre-mixes under the assumption that the supplementation will be adequate to meet the requirements (Jobling 2004). However, from a quantitative point of view, this assumption might be questionable. Moreover, from a qualitative, point of view, the bioavailability of the sources used are often not considered. As ragworm is an excellent feed for sole their vitamin content could reflect requirements. For minerals this reflection is somewhat more difficult, as minerals can be absorbed from the water. 
Flavour, or the combination of biochemical signals, is assumed crucial to make a feed attractive. Sole is known for its low feeding motivation under farm conditions when fed commercial pellets. Barata, Hubert, Conceição, Velez, Rema, Hubbard \& Canário (2009) found that addition of a polychaete homogenate to dry feed enhanced pellet ingestion in Senegalese sole. Therefore, it was hypothesized that adding a ragworm extract to a commercial pellet would increase long term feed intake and that the current difference in growth, found in sole fed ragworm compared to conventional diets, is explained by a mismatch in attractivity/palatability.

\section{Processing and nutritional value}

Fish feed ingredients contain thermolabile components (e.g. flavours, proteins, vitamins and organically bound minerals). Most fish feed processing methods (e.g. extrusion/ steam pelleting) contain at least one heat step. Hence, processing will affect the properties of feed ingredients and consequently of the final feed. The undifferentiated alimentary tract of sole with its alkaline environment and low pepsin like activity (Clark, MacDonald \& Stark 1985; Groot de 1971; Yúfera \& Darías 2007) might make sole sensitive to the effect of heat on thermolabile components. This supports the hypothesis that sole might encounter problems digesting heat processed proteins or possibly other thermolabile compounds. Therefore, before the start of this $\mathrm{PhD}$ study, an exploratory experiment was carried out to sharpen our hypotheses on the effect of a heat treatment (i.e. boiling), as the major difference between raw $v s$. processed feeds. Feeding boiled ragworm had a negative effect on feed intake and growth, compared to feeding fresh or frozen ragworm. Consequently, heat negatively affects the nutritive value of ragworm (unpublished data). Hence, it was decided that in this $\mathrm{PhD}$ study, cold extrusion $\left(\mathrm{T}<50^{\circ} \mathrm{C}\right)$ is used to reduce biochemical reactions and minimize the nutritional change of the feed ingredients and the final feed.

\section{Haematocrit levels in common sole}

During the exploratory experiments before the start of this $\mathrm{PhD}$, I became aware that common sole develops an anaemia when fed commercial pellets. Low haematocrit (Hct) levels of around $10 \%$ were found in fish fed commercial pellets under both experimental as intensive production conditions. In contrast, sole in outdoor ponds stocked with ragworm (Nereis virens Sars), show Hct levels of about 24\% (unpublished data) confirming the findings of Palstra, Blok, Kals, Blom, Tuinhof-Koelma, Dirks, Forlenza \& Blonk (2015). The Hct values of sole fed fresh ragworm were about twice as high as the values of sole fed 
commercial pellets. The Hct values of sole fed boiled ragworm were significantly lower than sole fed fresh or frozen ragworm (unpublished data). Low Hct values do point to a physiological state of anaemia. Anaemia is strictly defined as a decrease in red blood cell mass (Lydyard, Cole, Holton, Irving, Porakishvili, Venkatesan \& Ward 2010) and according to Thrall, Weiser, Allison \& Campbell (2012) fish are anaemic when Hct values are $<20 \%$. In addition, low growth rates were associated with low Hct values. A negative relation between anaemia and growth performance is shown in sheep, pigs, fish and humans (Bhatia \& Seshadri 1993; El-Zibdeh \& Furuichi 1996; Green, Graham \& Morgan 1997; Jiang, Jiang, Zhu \& Jiang 2009). The mechanism behind this relation is that higher Hct levels facilitate oxygen uptake in the cardiovascular system. As common sole fed ragworm grows about $70 \%$ faster compared to sole fed commercial feeds (Ende et al. 2014) and have Hct levels almost double those of sole fed commercial pellets, it is expected that the increase of Hct will have a significant effect on the metabolic performance (e.g. feed intake, feed efficiency and growth) of sole. Therefore, in my opinion, it is crucial to investigate the observed anaemia in sole fed commercial pellets. As a consequence, this became the focus of this $\mathrm{PhD}$ study.

\section{Problem definition and aims of the study}

Based on our observations during the preliminary, exploratory experiments, the goal of the current thesis was set to validate the potential of ragworm to alleviate anaemia in sole, to define the type of anaemia and to identify the dietary requirements of common sole to prevent anaemia and achieve optimal growth. In addition it is aimed to explain part of the difference in growth between sole fed a conventional diet and ragworm. The practical aim as a result of the scientific aims is the development of a diet based on the composition of ragworm that will give a comparable growth performance compared to sole fed fresh ragworm,

\section{Outline of thesis}

In chapter 2 the aim was to test and validate if a change in diet from commercial pellets to ragworm increases Hct and haemoglobin (Hb) levels and alleviate anaemia in common sole. We also determined the rate of increase and the time needed to develop a new steady state of these blood parameters.

Based on the fact that growth rates of sole fed mussel (Mytilus edulis L.) are comparable to growth rates of sole fed ragworm (Fonds, Drinkwaard, Resink, Eysink \& Toet (1989); Ende et al. 2014) we expected that also mussel will alleviate anaemia in sole. In 
chapter 3 we therefore hypothesized that feeding mussel to sole will result in similar Hct and $H b$ values as feeding ragworm. Additionally, as we wanted to gain insight into which dietary components could be of importance to explore the alleviation of anaemia in sole, we analysed the nutritional components of the diets.

In chapter 4 we studied the type of anaemia found in common sole. As an anaemia can also be caused by an inflammatory response to infection or a combination of this with a nutritional deficiency we tested if the anaemia in sole fed pellets is caused by an inflammatory response to infection. In addition, as low growth rates were associated with low Hct values we tested if feeding ragworm to sole will positively affect the sole's metabolic performance as reflected in feed intake, feed efficiency and growth.

As feeding solely fresh ragworm or a pellet completely made of ragworm meal, is neither technical nor economically viable the aim in chapter $\mathbf{5}$ was to determine the minimal amount of freeze dried ragworm meal in the diet, needed to keep growth and Hct values comparable to those of sole fed fresh ragworm.

In chapter 4 we provided evidence that common sole fed commercial pellets suffers from a nutritional anaemia. This suggests that components important for the recovery of anaemia (erythropoiesis or the production of red blood cells) are present in ragworm and mussel, but missing in current commercial feeds.

Many nutritional factors can play a role in a nutritional anaemia (Kraemer \& Zimmermann 2007). However, in most cases iron is deficient in a nutritional anaemia (Latham 1997; Kraemer \& Zimmermann 2007). Yet, despite the fact that the intake of iron in sole fed boiled ragworm was lower than in sole fed commercial pellets, sole fed boiled ragworm recovered from their anaemia, while sole fed commercial pellets stayed anaemic. Similarly, the intake of copper, cobalt, chrome, manganese, selenium and zinc was comparable or higher in sole fed commercial pellets compared to sole fed boiled ragworm (unpublished data). This suggests that the higher Hct in sole fed boiled ragworm is not due to a higher intake of dietary iron or the other minerals mentioned. However, a factor which cannot be excluded to be involved in anaemia is the bioavailability of minerals (e.g. the source). For example the bioavailability of iron depends on the form in which it is presented to the fish (heme vs. non heme iron). The absorption of heme iron differs from that of non heme iron, as the absorption of heme iron has its own pathway, which is independent of intestinal pH (Kraemer \& Zimmermann 2007). Therefore, the alkaline character of the sole's intestine (Clark et al. 1985; Yúfera et al. 2007) might negatively affect the sole's ability to absorb non heme iron, leading to low Hct and Hb levels. 
Consequently, in chapter $\mathbf{6}$ we tested if the nutritional anaemia in sole fed commercial pellets is caused by an iron deficiency and could be alleviated by adding heme iron into the diet, the form of iron in which most of the iron occurs in ragworm.

The influence of vitamins as folic acid and menadione on the observed anaemia can be eliminated. In the exploratory experiment focused on the effect of a heat treatment on the nutritive value of ragworm the intake of both was comparable or higher in sole fed commercial pellets than sole fed boiled ragworm, while the Hct level of sole fed boiled ragworm was about $45 \%$ higher (unpublished data). Though, a vitamin $\mathrm{B}_{12}$ deficiency could be an obvious factor responsible for the nutritional anaemia observed in sole fed commercial pellets. $B_{12}$ is essential for erythropoiesis (Koury \& Ponka 2004). The requirement of $B_{12}$ for sole is, as far as we know, hitherto unknown. Based on the high levels of $\mathrm{B}_{12}$ in mussel and ragworm (chapter 4) we hypothesized that sole needs high dietary levels of $B_{12}$ to alleviate or prevent anaemia, which is the first hypothesis of chapter 7 . The link between taurine and $\mathrm{B}_{12}$ (Scott \& Weir 1981) and the fact that taurine can affect Hct and Hb levels (Salze \& Davis 2015; Anand, Rajakumar, Felix \& Balasubramanian 2010; Takagi, Murata, Goto, Hayashi, Hatate, Endo, Yamashita \& Ukawa 2006; Sirdah, El-Agouza \& Abu Shahla 2002) makes taurine a co-factor. The second hypothesis of chapter 7 is therefore that there is interaction between taurine and $B_{12}$ regarding the occurrence of anaemia in sole.

In chapter 8 the overall results of this thesis are discussed and integrated with the latest results, explaining what has been achieved. Moreover, the practical implications are discussed and suggestions for further research are given. 


\section{References}

Anand P., Rajakumar D., Felix A.J. \& Balasubramanian T. (2010). Effects of oral administration of antioxidant taurine on haematological parameters in Wistar rats. Pak. Journal of Biological Sciences. 13, 785-793.

Aragao C., Conceiçoa L.E.C., Dias J., Marques A.C., Gomes E. \& Dinis M.T. (2003). Soy protein concentrate as a protein source for Senegalese sole (Solea senegalensis Kaup 1858) diets: effects on growth and amino acid metabolism of postlarvae. Aquaculture Research 34,1443-1452

Bhatia D. \& Seshadri S. (1993). Growth performance in anemia and following iron supplementation. Indian paediatrics. 30 (2), 195-200.

Barata E.N., Hubert F., Conceição L.E.C., Velez Z., Rema P., Hubbard P.C. \& Canário A.V.M. (2009). Prey odour enhances swimming activity and feed intake in the Senegalese sole. Aquaculture 293,100-107.

Borges P., Oliveira B., Casal S., Dias J., Conceição L. \& Valente L.M.P. (2009). Dietary lipid level affects growth performance and nutrient utilisation of Senegalese sole (Solea senegalensis) juveniles. British Journal of Nutrition 102 (7):1007-14. doi: 10.1017/S0007114509345262.

Clark J., MacDonald N. \& Stark, J.R. (1985). Metabolism in marine flatfish. II. Protein digestion in Dover sole (Solea solea L.). Comparative Biochemistry and Physiology 81B, 217-222.

Craig S., Olive P.J.W., Pinon E. \& Rutherford G. (2005). Enhancing polychaete products for enhanced hatchery performance. Presentation at WAS Bali.

El-Zibdeh M., Ide K. \& Furuichi M. (1996). Effects of the Deletion of Mg or Fe from Semi Purified Diets on Growth and Efficiency of Feed Utilization of Yellow Croaker Nibea albiflora. Journal of the Faculty of Agriculture, Kyushu University. 40 (3-4), pp. 391-397.

Ende S.S.W., Kroeckel S., Schrama J.W. \& Verreth J.A.J. (2009). Comparing feed intake, utilization of protein and energy for growth and body composition in S. Solea fed natural and commercial diets. IMARES report C045/09.

Ende S.S.W., Kroeckel S., Schrama J.W., Schneider O. \& Verreth J.A.J. (2014). Feed intake, growth, and nutrient retention of common sole (Solea, solea L.) fed natural pray and an artificial feed. Aquaculture Research 1-8.

Fonds M., B. Drinkwaard J.W., Resink G.G.J., EysinkW. \& Toet. (1989). Measurements of metabolism, food intake, and growth of Solea solea (L.) fed with mussle meat or with dry food. In: Aquaculture-A biotechnology in progress. Eds. N. De Pauw, E. Jaspers, H. Ackefors, N. Wilkins (Eds). European Aquaculture Society, Bredene, Belgium.

Gatta P.P., Parma L., Guarniero I., Mandrioli L., Sirri R.,Fontanillas R. \& Bonaldo A. (2010). Growth, feed utilization and liver histology of juvenile common sole (Solea solea L.) fed isoenergetic diets with increasing protein levels. Aquaculture Research 42, 313-321.

Green L.E., Graham M. \& Morgan K.L., (1997). Preliminary study of the effect of iron dextran on a nonregenerative anaemia of housed lambs. Veterinary Record 140, 219-222.

Groot S.J. de (1971). On the interrelationship between morphology of the alimentary tract, food and feeding behaviour in flatfishes (Pisces : Pleuronectiformes). Netherlands Journal of Sea Research 5, 121-196.

Jiang J.F., Jiang J.B., Zhu H.S. \& Jiang M.I. (2009). Combined treatment with vitamin A and iron to prevent piglet anemia. Journal of Swine Health and Production. 17, 22-27.

Jobling M. (2004). Ongrowing to market size. In. Culture of Cold-Water Marine Fish. Moksness, E. Kjørsvik, E., Olsen, Y. (Eds) Blackwell Publishing Ltd. Oxford, UK.

Kals J., Ruizeveld de Winter S. \& Schiphouwer M. (2009) ${ }^{\text {a }}$. Doorkweek Tong. IMARES Report C046/09.

Kals J., Capelle J. \& Hemsing V. (2009) $)^{\mathrm{b}}$. Conversie zagervoer-zagers-tong. IMARES Report C041/09.

Koury M.J \& Ponka P. (2004). New insights into erythropoiesis: The Roles of Folate, Vitamin B12, and Iron. Annual Review of Nutrition 24, 105-131.

Kraemer K. \& Zimmermann M.B. (2007). Nutritional anemia . SIGHT AND LIFE Press. c/o SIGHT AND LIFE / DSM Nutritional Products Ltd. Internet: www.sightandlife.org

Latham M.C. (1997). Human Nutrition in the Developing World 1997 Food and Agriculture Organization of the United Nations Rome, Italy.

Lydyard P.M., Cole M.F., Holton J., Irving W.L., Porakishvili N., Venkatesan P. \& Ward N.K. (2010). Case studies in infectious disease. 609 p. Garland Science, Taylor and Francis Group, New York \& London.

NRC (2011). Nutrient requirements of fish and shrimp. Ed. by Committee on the Nutrient Requirements of Fish and Shrimp. National Academies Press 376 pp.

Palstra A.P., Blok M.C., Kals J., Blom E., Tuinhof-Koelma N., Dirks R.P., Forlenza M. \& Blonk R.J.W. (2015). In- and outdoor reproduction of first generation common sole Solea solea under a natural photothermal regime: temporal progression of sexual maturation assessed by monitoring plasma steroids and gonadotropin mRNA expression. General and Comparative Endocrinology 15, 221:183-92. doi: 10.1016/j.ygcen.2014.12.004. 
Rema P., Conceiçao L.E.C., Evers F., Castro-Cunha M., Dinis M.T. \& Dias. J. (2008). Optimal dietary protein levels in juvenile Senegalese sole (Solea, senegalensis). Aquaculture Nutrition, 14, 263-269.

Prabhu P.A.J., Schrama J.W. \& Kaushik S.J. (2014). Mineral requirements of fish: a systematic review. Reviews in Aquaculture. 8, 172-219.

Salze P.G. \& Davis D.A. (2015). Taurine: a critical nutrient for future fish feeds. Aquaculture 437, $215-229$. http://dx.doi.org/10.1016/j.aquaculture.2014.12.006.

Scott J.M. \& Wier D.G. (1981). The methyl folate trap. The Lancet 2, 337-340.

Sirdah M.M., El-Agouza I.M.A. \& Abu Shahla, A.N.K.(2002). Possible ameliorative effect of taurine in the treatment of iron-deficiency anaemia in female university students of Gaza, Palestine. European Journal of Haematology 69, 236-242

Takagi S., Murata H., Goto T., Hayashi M., Hatate H., Endo M., Yamashita H. \& Ukawa, M. (2006). Hemolytic suppression roles of taurine in yellowtail Seriola quinqueradiata fed non-fishmeal diet based on soybean protein. Fisheries Science. 72 (3), 546-555.

Thrall M.A., Weiser G., Allison R.W. \& Campbell T.W. (2012). Veterinary Hematology and Clinical Chemistry. 2nd ed. 792 p. Wiley-Blackwell Oxford, UK.

Yúfera M. \& Darías M.J. (2007). Changes in the gastrointestinal pH from larvae to adult in Senegal sole (Solea senegalensis). Aquaculture 267, 94-99. 


\section{Chapter 2}

Feeding ragworm (Nereis virens Sars) increases haematocrit and haemoglobin levels in common sole (Solea solea L.)

Jeroen Kals

Robbert J.W. Blonk

Henk van der Mheen

Johan W. Schrama

Johan A.J. Verreth

Published in Aquaculture Research: DOI: 10.1111/are.12767 


\begin{abstract}
The aim of this study was to test if haematocrit (Hct) and haemoglobin (Hb) will increase when the diet of common sole is changed from commercial pellets (CPEL) to ragworm (RW). Also, the time needed to develop a new steady state for Hct and $\mathrm{Hb}$ was determined. The experiment consisted of two treatments: in the first treatment, sole was fed RW and sampled over a period of 26 days. In the second treatment, sole was fed CPEL and only sampled at day 26. Sole used for the experiment were raised on CPEL and were moderate anaemic with Hct and $\mathrm{Hb}$ values of $9.8 \%$ and $16.3 \mathrm{~g} \mathrm{l}^{-1}$, respectively. In sole fed RW during the experiment, Hct and $\mathrm{Hb}$ started to rise within eight to ten days and animals recovered from anaemia within 16 to 21 days. In this treatment, Hct rose from $9.8 \%$ to $19.0 \%$, and $\mathrm{Hb}$ levels rose from $16.3 \mathrm{~g}^{-1}$ to $39.7 \mathrm{~g} \mathrm{l}^{-1}$. Sole fed CPEL during the experiment stayed anaemic. Here, Hct (8.8\%, p>0.05) and $\mathrm{Hb}\left(11.7 \mathrm{~g} \mathrm{l}^{-1}, \mathrm{p}>0.05\right)$ were not different from levels at the start of the experiment.
\end{abstract}

Keywords: anemia; hematocrit; haemoglobin; Nereis virens; recovery; Solea solea 


\section{Introduction}

Common sole (Solea solea L.), kept under intensive production conditions has lower haematocrit (Hct) levels than when kept in outdoor ponds feeding on natural food (Palstra, Blok, Kals, Blom, Tuinhof-Koelma, Dirks, Forlenza \& Blonk 2015). Preliminary findings indicate average Hct levels of $10.2 \pm 2.7 \%$ for sole fed commercial pellets (CPEL) under intensive production conditions. In contrast, sole in outdoor ponds stocked with ragworm (Nereis virens Sars), show Hct levels of $23.9 \pm 4.7 \%$ (unpublished data) confirming the findings of Palstra et al. (2015). Based on the feeding ecology of sole we hypothesise that feeding ragworm (RW) increases Hct and possibly haemoglobin ( $\mathrm{Hb}$ ) levels. Therefore, the aim of this study was to test if a change in diet from CPEL to RW increases Hct and Hb levels in sole. We also aimed to determine the rate of increase and the time needed to develop a new steady state of these blood parameters.

\section{Materials and methods}

This experiment was approved by the Ethical Committee for Animal Experiments and conducted at IMARES, Yerseke, The Netherlands. It consisted of a nine day acclimatisation period during which all fish were fed CPEL and a 26 day experimental period, and contained two treatments using individual fish as the experimental unit. After acclimatisation, 24 soles were sacrificed to establish starting values of Hct and Hb. Further, 120 soles were randomly divided over 12 tanks (10 soles per tank). During the experimental period, 11 tanks (110 individuals) were fed RW (protein 73\%, lipids 6\%, ash 13\%, iron $490 \mathrm{mg} \mathrm{kg}^{-1}$, copper $11 \mathrm{mg}$ ) and these tanks were sampled at 11 subsequent moments. At each sampling moment, e.g. day $2,4,6,8,10,13,16,19,21,23$ and 26 one tank was emptied and all 10 fish were used to sample blood. In the $12^{\text {th }}$ tank ten individuals were fed CPEL (protein 63\%, lipids $14 \%$, ash $12 \%$, iron $250 \mathrm{mg} \mathrm{kg}^{-1}$, copper $13 \mathrm{mg}$ ) as a control group. This tank was only sampled at day 26. In this way densities could be kept constant along with the duration of the experiment. Soles were fed by hand to satiation twice a day (8:30 and 16:30). Fresh ragworms (Topsy Baits, Wilhelmina polder, The Netherlands) were chopped and sieved for one minute to drain excess fluids prior to weighing. At the start of the experiment, the mean bodyweight of the soles was $69 \pm 14 \mathrm{~g}$. All 12 tanks $\left(0.4 \mathrm{~m}^{2}, 130\right.$ 1) belonged to one recirculation system and received a continuous flow of $4.11 \mathrm{~min}^{-1}$ fresh filtered seawater. Husbandry conditions were: photoperiod 12L:12D, light intensity 11-15 lux, temperature $19.2 \pm 1.3^{\circ} \mathrm{C}$, oxygen $8.3 \pm 0.3 \mathrm{mg}$ $1^{-1}, \mathrm{pH} 7.9 \pm 0.03$, TAN $0.0 \pm 0.0 \mathrm{mg} \mathrm{l}^{-1}, \mathrm{NO}_{2}^{-} 0.01 \pm 0.0 \mathrm{mg} \mathrm{l}^{-1}, \mathrm{NO}_{3}^{-} 2.1 \pm 1.4 \mathrm{mg} \mathrm{l}^{-1}$, flow $4.1 \pm 0.2$ 
$1 \mathrm{~min}^{-1}$ and salinity $25-30 \mathrm{~g}^{-1}$, and stayed within pre-set limits. Temperature and oxygen were measured daily. Flow, $\mathrm{pH}, \mathrm{TAN}, \mathrm{NO}_{2}{ }^{-}, \mathrm{NO}_{3}{ }^{-}$were measured weekly.

During sampling, soles were sacrificed using an overdose of phenoxy ethanol (1:1000). All sacrificed soles were sampled for blood. Blood was obtained by caudal venous puncture using a heparinized syringe $(0.6 \mathrm{~mm} / 30 \mathrm{~mm}$ needle $)$, transferred into tubes, stored on ice and processed within approximately 15 minutes. Hct was determined by centrifuging blood samples for five minutes at 11,000 rpm (SpinCrit microhematocrit centrifuge, Indianapolis, US). The $\mathrm{Hb}$ content of the blood was determined using the method described by Kampen \& Zijlstra (1961). Data were analysed using one way ANOVA to test for time effects.

Homogeneity of variance was tested using Levene's test. For all tests, a probability $\mathrm{p}<0.05$ was considered significant. When significantly different, means were compared using the Tukey HDS test. Curves were fit by regression analysis using CurveExpert (Microsoft Corporation).

\section{Results}

No mortality occurred during the experiment. Sole, which were raised on CPEL had an average Hct level of $9.8 \% \pm 3.6$ and $\mathrm{Hb}$ level of $16.3 \mathrm{~g} \mathrm{l}^{-1} \pm 6.6$ at day 0 . At the end of the experiment, the average Hct level of sole fed RW rose to $19.0 \%$ and the average $\mathrm{Hb}$ level more than doubled to $39.7 \mathrm{~g} \mathrm{l}^{-1}$, when compared to day $0(\mathrm{P}<0.05$, Table 2.1). In contrast, the $\mathrm{Hct}$ and $\mathrm{Hb}$ levels at day 26 of sole fed CPEL stayed low with $8.8 \% \pm 3.3$ and $11.7 \pm 5.5 \mathrm{~g} \mathrm{l}^{-1}$, respectively $(\mathrm{P}>0.05$, Table 2.1$)$.

Table 2.1. Levels of Haematocrit (Hct) and values of Haemoglobin (Hb) and standard deviations in sole after 0 and 26 day feeding of either commercial pellet (CPEL) or ragworm (RW).

\begin{tabular}{lcccc}
\hline Diet & Day & $\mathbf{N}$ & $\mathbf{H e t}(\mathbf{\%})$ & $\mathbf{H b}\left(\mathbf{g ~ I}^{-1}\right)$ \\
\hline$--^{\mathrm{a}}{ }^{-1}$ & 0 & 24 & $9.8^{\mathrm{a}} \pm 3.6$ & $16.3^{\mathrm{a}} \pm 6.6$ \\
$\mathrm{CPEL}$ & 26 & 10 & $8.8^{\mathrm{a}} \pm 3.3$ & $11.7^{\mathrm{a}} \pm 5.5$ \\
$\mathrm{RW}$ & 26 & 10 & $19.0^{\mathrm{b}} \pm 4.9$ & $39.7^{\mathrm{b}} \pm 10.2$ \\
$\begin{array}{l}{ }^{a b} \text { Means within columns with a common superscript are not significantly different using the Tukey post hoc test } \\
(P<0.05) .\end{array}$
\end{tabular}

In the experimental sole fed RW, both the Hct and $\mathrm{Hb}$ levels differed between sampling moments over time $(\mathrm{P}<0.001$; Fig. 1A). The change in Hct and $\mathrm{Hb}$ had a sigmoidal shape, which fitted best with the Morgan-Mercer-Flodin growth model. However, the 
response kinetics were slightly different between $\mathrm{Hct}$ and $\mathrm{Hb}$. From day eight onwards, the Hct values started to become higher than at day $0(\mathrm{P}<0.05)$, whereas the $\mathrm{Hb}$ values became significantly higher from day ten onwards. Similarly, the increase levelled off earlier for Hct (day 16) than for $\mathrm{Hb}$ (day 18 to 20; Fig. 1A). Despite this slight difference in kinetics, the Hct and $\mathrm{Hb}$ levels were highly correlated $(\mathrm{R}=0.92, \mathrm{P}<0.05$; Fig. $1 \mathrm{~B})$.

$A$

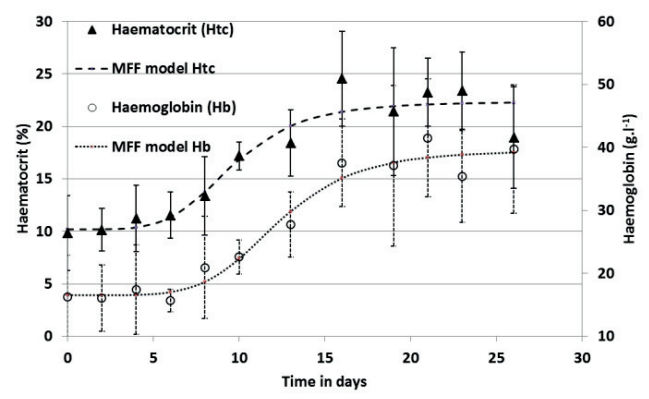

B

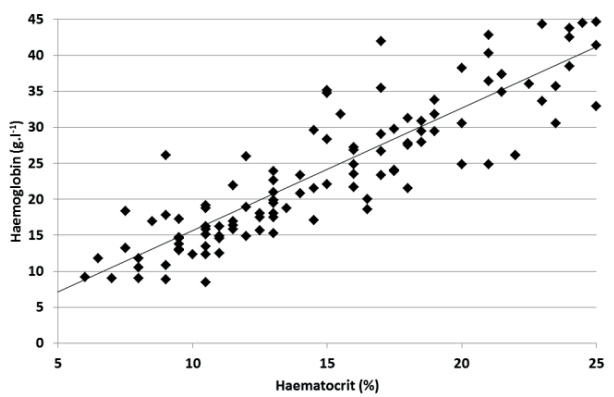

Figure 2.1A: Recovery pattern of sole fed ragworm for Hct $\left(Y=\left(10.20 * 51019+22.4 * X^{4.79}\right) /\left(51019+X^{4.79}\right), R^{2}\right.$ $=0.66)$ and $\mathrm{Hb}\left(Y=\left(16.54 * 675168+39.6 * X^{5.35}\right) /\left(675168+X^{5.35}\right), R^{2}=0.64\right) .2 .1 B$ : The relation between haematocrit (\%) and haemoglobin $\left(g l^{-1}\right) y=1.7205 x-1.785, R^{2}=0.84$

\section{Discussion}

The results show a clear effect of RW on Hct and $\mathrm{Hb}$ levels of common sole that were previously fed CPEL. To our knowledge this is the first record of such a dietary effect in fish. To validate the results we measured Hct levels in a study of Mas-Muñoz (2013) evaluating the interaction between rearing environment and behaviour of common sole. The experiment was run with four tanks per treatment, 20 soles per tank of which eight were sampled for Hct. Average Hct values of sole fed CPEL vs. RW were $10.5 \% \pm 1.8$ vs. $19.2 \% \pm 0.7(\mathrm{p}<0.001)$ (unpublished data). This result confirmed the data of our study.

Hct levels show a wide variety between fish species. However, within a fish species the range of Hct levels for normocythemia tend to be relatively narrow (Gallaugher \& Farrell 1998). Soles, different species of flounder (e.g. Platichthys flesus L., Pseudopleuronectes americanus (Walbaum) and turbot (Scophthalmus maximus L.) are benthic flatfishes. The average $\mathrm{Hct}$ and $\mathrm{Hb}$ levels between flounder species and turbot range between 16-26\% and 45-61 $\mathrm{g} \mathrm{l}^{-1}$, respectively (Gallaugher \& Farrell 1998). According to Wood, McMahon \& 
McDonald (1979), the normal Hct level of healthy flounder (Platichthys stellatus Pallas) is approximately $25.5 \%$. They diagnosed flounders with Hct levels around $8 \%$ as moderate anaemic and flounders with Hct levels $<5 \%$ as severely anaemic. Anaemia is strictly defined as a decrease in red blood cell mass (Lydyard, Cole, Holton, Irving, Porakishvili, Venkatesan \& Ward 2010) and according to Thrall, Weiser, Allison \& Campbell (2012) fish are anaemic when Hct values are $<20 \%$. Data for Hct and/or $\mathrm{Hb}$ values in common sole are scarce. Yet, sole grown on natural food in outdoor ponds at an experimental farm (Zeeuwse Tong, Colijnsplaat, The Netherlands) show Hct levels of $20 \pm 2 \%$ for males and $22 \pm 1 \%$ for females (Palstra et al. 2015), levels approximately twice the amount found in sole fed CPEL. Lower levels of $\mathrm{Hct}$ and $\mathrm{Hb}$ are associated with anaemia. Could the lower levels found in sole fed CPEL indicate an anaemia in sole? Taking into consideration Thrall et al. (2012), the data of Wood et al. (1979) and Palstra et al. (2015), this seems plausible. Moreover, when we stopped feeding with RW, we found that Hct levels decreased again with 30\% within 21 days (unpublished data). Therefore, we suggest that the levels of Hct $(9.8 \%)$ and $\mathrm{Hb}\left(16.3 \mathrm{~g} \mathrm{l}^{-1}\right)$ in common sole fed CPEL indicate a moderate anaemia.

Both the Hct and Hb levels in sole fed RW follow the Morgan-Mercer-Flodin growth model with a "lag phase", probably reflecting the start of the production of erythrocytes and the synthesis of $\mathrm{Hb}$, followed by an exponential stage of recovery which stops at a maximum asymptotic level. Hct rises earlier than $\mathrm{Hb}$, which is expected as red blood cells continue $\mathrm{Hb}$ synthesis while circulating in the body (Gallaugher \& Farrell 1998). Literature about the kinetics of the recovery from anaemia in fish is limited. In the studies of Lane (1979) and Wood et al. (1979) nothing is mentioned about feeding the fish during a recovery period such as described in this study. More is known about the kinetics of recovery from anaemia in rats. Recovery of rats from iron deficiency, by feeding ferric citrate to supplement iron, took 3 weeks (Feltrin, Batista de Morais, Cássia Freitas de, Beninga de Morais, Fagundes Neto \& Silvério Amancio 2009). The recovery time of anaemia in sole seems comparable. However, this does not necessarily mean that the moderate anaemia in sole is an iron deficiency anaemia and that CPEL was iron deficient, as an anaemia can have many causes (e.g. low folate, zinc, copper etc.). The relation between $\mathrm{Hct}$ and $\mathrm{Hb}$ in this study is comparable to data in literature (Gallaugher \& Farrell 1998).

\section{Conclusions}

This study shows a clear effect of a RW diet on Hct and $\mathrm{Hb}$ levels in sole. Feeding RW increases the Hct and $\mathrm{Hb}$ levels and alleviate the moderate anaemia of common sole. This 
indicates that the increase of $\mathrm{Hct}$ and $\mathrm{Hb}$ in sole is diet related. Yet, the exact mechanism that increases these levels in sole is unknown. We suggest that the increase of Hct and $\mathrm{Hb}$ in sole can be a result of differences in feed intake, or of the dietary composition between CPEL and RW, and/or of a health promoting effect of RW.

\section{Acknowledgements}

The authors thank Y. van Es, A. Hofman and N. Ros for their help during the experiment. This work was financially supported by the "Zeeland Sole" foundation and IMARES. A patent application covering the use of Annelida and Mollusca in fish feed has been filed in 2012. 


\section{References}

Farrell A.P. \& Richards J.G. (2009). Defining hypoxia: An integrative synthesis of the response of fish to hypoxia. In: Fish Physiology, vol. 27. Hypoxia. (Eds. Farrell A.P., Brauner C.J., Hoar W.S. \& Randall D.J.), pp. 478-503. Academic press/Elsevier, Amsterdam.

Feltrin C., Batista de Morais M., Cássia Freitas de K., Beninga de Morais T., Fagundes Neto U., Silvério Amancio O.M. (2009). Effect of Soluble Fiber Pectin on Growth and Intestinal Iron Absorption in Rats During Recovery from Iron Deficiency Anemia. Biological Trace Element Research 129, 221-228.

Gallaugher P. \& Farrell A.P. (1998). Haematocrit and blood oxygen carrying capacity. In: Fish Physiology, vol. 17. Fish respiration. (Eds. Perry S.F. \& Tufts B.), pp. 185-219. Academic Press, New York.

Kampen E.J. \& van, Zijlstra W.G. (1961). Standardization of Haemoglobinometry II. The Haemiglobincyanide Method. Clinica Chimica Acta 6, 538-544.

Lane H.C. (1979). Some haematological responses of normal and splenectomized rainbow trout (Salmo gaidneri) to a $12 \%$ blood loss. Journal of Fish Biology 14, 159-164.

Lydyard P.M., Cole M.F., Holton J., Irving W.L., Porakishvili N., Venkatesan P \& Ward N.K. ( 2010). Case studies in infectious disease. 609 p. Garland Science, Taylor and Francis Group, New York and London.

Mas-Muñoz J. (2013). Variation in behavior and growth of common sole: genetic and environmental influences. $\mathrm{PhD}$ Thesis, Wageningen University, Wageningen, The Netherlands. 165pp.

Palstra A.P., Blok M.C., Kals J., Blom E., Tuinhof-Koelma N., Dirks R.P., Forlenza M. \& Blonk R.J.W. (2015). Inand outdoor reproduction of first generation common sole Solea solea under a natural photothermal regime: temporal progression of sexual maturation assessed by monitoring plasma steroids and gonadotropin mRNA expression. General and Comparative Endocrinology 15, 221:183-92. doi: 10.1016/j.ygcen.2014.12.004.

Thrall M.A., Weiser G., Allison R.W. \& Campbell T.W. (2012). Veterinary Hematology and Clinical Chemistry. $2^{\text {nd }}$ ed. 792 p. Wiley-Blackwell Oxford, UK.

Wood C.M., McMahon B.R. \& McDonald D.G. (1979). Respiratory, ventilatory, and cardiovascular responses to experimental anaemia in the starry flounder, Platichthys stellatus. Journal of Experimental Biology $\mathbf{8 2}$, 139-162. 


\section{Chapter 3}

Mussel (Mytilus edulis L.) and ragworm (Nereis virens, Sars) both alleviate anaemia in common sole (Solea, solea $\mathrm{L}$.)

Jeroen Kals

Robbert J.W. Blonk

Henk van der Mheen

Johan W. Schrama

Johan A.J. Verreth

Published in Aquaculture Research: DOI: 10.1111//are.12871 


\begin{abstract}
The aim of the present study was to provide experimental evidence for the hypothesis that feeding mussel to sole will result in similar haematocrit and haemoglobin values as in sole fed ragworm. Additionally, dietary components of the diets were analysed to gain insight into which components could be of importance to explore the alleviation of nutritional anaemia in sole. As both iron and vitamin $\mathrm{B}_{12}$ are known to play a role in erythropoiesis, the process which produces red blood cells, we focused on those two. Sole were fed three different diets, being commercial pellets, mussel, and ragworm. Feeding strategy was restricted, i.e. feed intake was $0.54 \mathrm{~g} \mathrm{dm} \mathrm{fish}^{-1} \mathrm{~d}^{-1}$ and equal for all diets. Both, the haematocrit and haemoglobin values of the pellet fed sole did not change. The haemoglobin values of sole fed mussel and ragworm rose with $37 \%$ and $75 \%$, respectively within 23 days. The haemoglobin level of sole fed pellets was significantly lower than that of sole fed mussel or ragworm, which were comparable. Haematocrit paralleled the findings of haemoglobin. We suggest that the higher levels of haematocrit and haemoglobin found in both, sole fed mussel and fed ragworm, compared to sole fed pellets can be explained by a combination of heme and the high vitamin $\mathrm{B}_{12}$ levels found in mussel and ragworm.
\end{abstract}

Keywords: Anaemia; Sole, Solea solea; Mussel, Mytilus edulis; ragworm, Nereis virens; hematocrit, hemoglobin; growth; heme; vitamin $\mathrm{B}_{12}$. 


\section{Introduction}

Common sole (Solea, solea L.), is a polychaete-mollusc feeder (De Groot 1971). Based on the feeding ecology of sole we assume that both ragworm (Nereis virens, Sars) and mussel (Mytilus edulis L.) reflect the dietary requirements of common sole.

Common sole grows approximately $70 \%$ faster on ragworm than on commercial pellets (Ende, Kroeckel, Schrama, Schneider \& Verreth 2014), the latter causing them to suffer from nutritional anaemia (Kals, Blonk, Palstra, Sobotta, Mongile, Schneider, Planas, Schrama \& Verreth, submitted). Changing the diet from pellet to ragworm alleviates this nutritional anaemia (Kals, Blonk, Mheen, Schrama \& Verreth $2015^{\mathrm{a}}$ ). This suggests a mismatch between the feeding requirements of sole and the dietary composition of the commercial pellets.

Fonds, Drinkwaard, Resink, Eysink \& Toet (1989) and Ende et al. (2014) showed that growth of sole fed mussel is comparable to growth of sole fed ragworm. We therefore expect that also mussel will alleviate anaemia in sole, consequently showing comparable levels of haematocrit $(\mathrm{Hct})$ and haemoglobin $(\mathrm{Hb})$ for sole fed mussel or ragworm, but higher for sole fed pellet.

Apart from trying to find evidence for the foregoing hypothesis, we wanted to gain insight into which dietary components could be important to alleviate nutritional anaemia in sole.

\section{Material and methods}

This experiment was approved by the Ethical Committee for Animal Experiments and conducted at IMARES, Yerseke, The Netherlands. The experimental set-up contained three diets; raw mussel meat (mussel), fresh ragworm (ragworm) and a commercial pellet (pellet) (crude protein $63 \%$, ether extract 14\%, ash 12\%). The diets were tested in triplicate for a

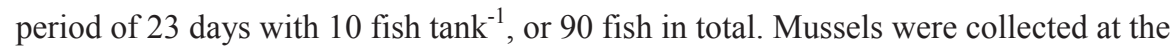
Oosterschelde, The Netherlands. The meat was separated from their shell and stored at $-80^{\circ} \mathrm{C}$. The frozen mussel was thawed in a fridge the day before feeding. Ragworms were delivered by Topsy Baits, Wilhelminadorp, The Netherlands.

Sole, $(220 \pm 44 \mathrm{~g})$ reared on pellet and naïve to ragworm and mussel, were randomly accommodated in 9 tanks $\left(0.4 \mathrm{~m}^{2}, 1301\right)$, in a flow through system using sand filtered seawater. Husbandry conditions were: photoperiod 12L:12D, light intensity 11-15 lux, temperature $16.9 \pm 1.3^{\circ} \mathrm{C}$, oxygen $8.3 \pm 0.5 \mathrm{mg} \mathrm{l}^{-1}, \mathrm{pH} 8.1 \pm 0.1$, TAN $0.3 \pm 0.2 \mathrm{mg} \mathrm{l}^{-1}, \mathrm{NO}_{2}^{-}$, $0.01 \pm 0 \mathrm{mg} \mathrm{l}^{-1}$, salinity $25-30 \mathrm{~g} \mathrm{l}^{-1}$ and flow $4.5 \pm 0.51 \mathrm{~min}^{-1} \mathrm{kept}$ within pre-set limits. 
Temperature and oxygen were measured daily; flow, $\mathrm{pH}, \mathrm{TAN}, \mathrm{NO}_{2}^{-}$weekly. Fish were fed by hand twice a day (8:30 and 16:30). During acclimatisation, all fish were fed the pellet. The dry matter content of the diets was analysed to enable equal feeding levels (restricted to $0.54 \mathrm{~g}$ $\mathrm{dm}$ fish $^{-1} \mathrm{~d}^{-1}$ ) for all diets. One hour after feeding, tanks were checked if all feed was consumed. Both, ragworm and mussel, were cut and sieved for one minute to drain excess fluids prior to weighing. Daily samples, equal to the amount of feed given, were taken and stored at $-20^{\circ} \mathrm{C}$, and at the end of the experiment pooled per treatment and analysed for dry matter content, proximate composition, iron and vitamin $\mathrm{B}_{12}$. The proximate composition and $B_{12}$ were analysed by Nutrilab, Rijswijk, The Netherlands. The iron content was analysed by the Chemical Biological Soil Laboratory, Wageningen, The Netherlands. The experiment consisted of a 7-day acclimatization and a 23-day experimental period. Fish were sacrificed, using an overdose of phenoxyethanol (1:1000) before sampling. Blood was sampled by caudal venous puncture, using a heparinized syringe $(0.6 \mathrm{~mm} / 30 \mathrm{~mm}$ needle) at the start (30 fish) and at the end $\left(10\right.$ fish $\left.\operatorname{tank}^{-1}\right)$ of the experiment. The samples were stored in tubes on ice and processed within 15 minutes. Hct was determined by centrifuging blood samples for five minutes at $5000 \mathrm{~g}$ (SpinCrit, Brown, Indianapolis, US). and $\mathrm{Hb}$ was determined according to van Kampen \& Zijlstra (1961). Data were analysed using one-way ANOVA to test for diet effects. Homogeneity of variance was tested using Levene's test. For all tests a probability $\mathrm{p}<0.05$ is considered significant. When significant, means were compared using the Fisher's LSD test.

\section{Results}

No mortality occurred during the experiment. No feed refusal or spillage was observed. The proximate composition, iron and $\mathrm{B}_{12}$ content of the diets are shown in table 3.1. As both iron and $B_{12}$ are playing a role in erythropoiesis (Koury \& Ponka 2004) we focused on those two. The high levels of $\mathrm{B}_{12}$ and iron in both mussel and ragworm are prominent when compared to the respective levels in pellets.

Table 3.1: The proximate composition, iron and vitamin $B_{12}$ content of the different diets and requirements according to (NRC 2011)*.

\begin{tabular}{lccccc}
\hline Diet & Unit & Ragworm & Mussel & Pellet (CPEL) & NRC (2011) \\
\hline Dry matter & $\mathrm{g} \mathrm{kg}^{-1}$ & 181 & 252 & 894 & NA \\
Crude protein & $\mathrm{g} \mathrm{kg}^{-1} \mathrm{dm}$ & 685 & 575 & 670 & NA \\
Ether extract & $\mathrm{g} \mathrm{kg}^{-1} \mathrm{dm}$ & 138 & 103 & 177 & NA \\
$\mathbf{F e}$ & $\mathrm{mg} \mathrm{kg}^{-1} \mathrm{dm}$ & 352 & 372 & 277 & $30-150^{*}$ \\
$\mathbf{B}_{\mathbf{1 2}}$ & $\mu \mathrm{g} \mathrm{kg}^{-1} \mathrm{dm}$ & 1602 & 1671 & 338 & $20-50^{*}$ \\
\hline
\end{tabular}

*Minimum and maximum values of different species as no values of sole are given. NA is not applicable. 
At the start of the experiment, sole reared on pellet had an average Hct and $\mathrm{Hb}$ level of $12.5 \%$ and $19.6 \mathrm{~g} \mathrm{l}^{-1}$, respectively. At the end both levels were affected by $\operatorname{diet}(\mathrm{p}<0.05$, table 3.2). Hct levels of sole fed mussel or ragworm increased by $39.7 \%$ and $51.8 \%$, respectively, and are not different ( $p>0.05$ ), while Hb levels increased by $36.5 \%$ and $74.5 \%$, respectively. The average $\mathrm{Hb}$ level of sole fed pellet $\left(18.9 \mathrm{~g} \mathrm{l}^{-1}\right)$ is significantly lower compared to the levels of sole fed mussel $(\mathrm{p}<0.05)$ or ragworm $(\mathrm{p}<0.01)$, which are comparable $(\mathrm{p}>0.05)$.

Table 3.2: Haematocrit (Hct) level in percentage and haemoglobin (Hb) level in $g t^{-1}$ with standard deviations of sole fed ragworm, mussel and pellets.

\begin{tabular}{lccc}
\hline Diet & Day & Hct (\%) & Hb $\left.\mathbf{~ ( g ~ l}^{-\mathbf{1}}\right)$ \\
\hline--- & 0 & $12.5 \pm 3.17$ & $19.6 \pm 8.10$ \\
Pellets & 23 & $13.1 \pm 1.16^{\mathrm{a}}$ & $18.9 \pm 3.28^{\mathrm{a}}$ \\
Mussel & 23 & $17.4 \pm 1.95^{\mathrm{b}}$ & $26.7 \pm 4.38^{\mathrm{b}}$ \\
Ragworm & 23 & $19.0 \pm 1.42^{\mathrm{b}}$ & $34.1 \pm 5.13^{\mathrm{b}}$ \\
p-value & -- & $<\mathbf{0 . 0 1}$ & $\mathbf{0 . 0 1}$ \\
\hline
\end{tabular}

${ }^{a b}$ Means within columns with a common superscript are not significantly different using the one or two sided Fisher LSD post hoc test depending on the hypothesis.

\section{Discussion}

The Hct and $\mathrm{Hb}$ values of sole fed mussel or ragworm rose strongly. In contrast, the $\mathrm{Hct}$ and $\mathrm{Hb}$ values of sole fed pellet stayed anaemic. This confirms earlier findings for sole fed ragworm (Kals et al. 2015 ; Kals et al. submitted) showing that mussel and ragworm both alleviate anaemia in common sole.

In anaemic states, the maximum oxygen consumption of fish falls sharply (Gallaugher \& Farrell 1998) and hampers metabolic performance, including growth (Wang, Lefevre, Huong, Cong \& Bayley 2009). Mas-Muñoz (2013) found that the positive effect of ragworm on growth of sole disappeared at lower water temperatures, while Hct values of these sole were up to $98 \%$ higher compared to sole fed pellet (Kals et al. $2015^{\mathrm{a}}$ ). We infer that the slow growth of sole fed pellet, kept at "optimal" culture temperatures, is due to their nutritional anaemia, which hampers oxygen uptake.

We believe that higher levels of Hct and Hb improve the ability to take up oxygen, as maximum oxygen consumption is highly dependent on these levels and suppose that iron and $\mathrm{B}_{12}$ are key elements in alleviating anaemia in common sole . 
The iron concentration, of major importance for the synthesis of $\mathrm{Hb}$, is comparable in mussel and ragworm and higher than in the pellet (table 3.1). However, also in the pellet, the iron level was above the requirement as known for fish in general (table 3.1). Nevertheless, sole fed pellet stayed anaemic. Moreover, in Kals et al. (submitted) we showed that, although the dietary iron intake of sole fed treated pellets versus sole fed boiled ragworm was not significantly different, the Hct level of sole fed boiled ragworm was significantly higher. Therefore, not the intake of iron, but the absorption of iron might explain the anaemia in sole fed pellet. This might be related to the source of iron in the diets. In mussel and ragworm, this source is mostly heme iron in its native form of which the structure is comparable (Vinogradov 1985). The iron in the pellet consists of inorganic iron from the premix and/or damaged heme due to processing. The absorption of heme iron, which is independent of $\mathrm{pH}$, may therefore be essential for sole to achieve normal Hct and $\mathrm{Hb}$ levels. An additional factor that could be responsible for different $\mathrm{Hct}$ and $\mathrm{Hb}$ levels between sole fed pellet, ragworm or mussel, is the difference in the dietary level of $\mathrm{B}_{12}$ between these diets. $\mathrm{B}_{12}$ is essential for erythropoiesis (Koury \& Ponka 2004). The higher levels of $B_{12}$ in ragworm and mussel may explain the higher Hct and $\mathrm{Hb}$ levels of sole fed these diets. In ragworm we found levels of $\mathrm{B}_{12}$ from 1134 to $3033 \mu \mathrm{g} \mathrm{kg}^{-1} \mathrm{dm}$ and in mussel a level of $1671 \mu \mathrm{g} \mathrm{kg}^{-1} \mathrm{dm}$. These high levels of $\mathrm{B}_{12}$ are comparable, yet four times higher than the levels in the pellet, and 20 to 100 times higher than the amount of $\mathrm{B}_{12}$ in a general premix or mentioned as requirement for fish, in NRC (2011). In most fish species, $B_{12}$ requirements are low or not required due to sufficient production by the intestinal flora (NRC 2011). Yet, $\mathrm{B}_{12}$ absorption depends on a low $\mathrm{pH}$ and pepsin like activity in the stomach (Pawlak, James, Raj, Cullum-Dugan \& Lucas 2012; Nielsen, Rasmussen, Andersen, Nexø \& Moestrup 2012). Sole lacks this pre-digestion in the stomach, has a low pepsin like activity and its intestine has an alkaline character (Clark, MacDonald \& Stark 1985; Lagardere, 1987; Yúfera \& Darías 2007). In conclusion, we infer that $\mathrm{B}_{12}$ absorption in sole is limited and suggest that sole depends on the inactive process of $\mathrm{B}_{12}$ diffusion. Since only $1 \%$ of the available $\mathrm{B}_{12}$ is absorbed through diffusion (Pawlak et al. 2012), sole may depend on high dietary levels of $B_{12}$.

\section{Conclusions}

Mussel and ragworm both alleviate anaemia in common sole. We cannot exclude that also other factors could explain a comparable effect of mussel and ragworm on Hct, Hb levels and growth of sole. But looking at the current data we suggest that the ability of mussel and 
ragworm to alleviate anaemia in sole can be explained by a combination of heme and high $\mathrm{B}_{12}$ levels.

\section{Acknowledgements}

The authors thank Y. van Es, A. Hofman and N. Ros for their help . This work was financially supported by IMARES. A patent application covering the use of Annelida and Mollusca in fish feed has been filed in 2012. 


\section{References}

Clark J., MacDonald N. \& Stark J.R. (1985). Metabolism in marine flatfish. II. Protein digestion in Dover sole (Solea solea L.). Comparative Biochemistry and Physiology B. 81, 217-222.

Ende S.S.W., Kroeckel S., Schrama J.W., Schneider O. \& Verreth J.A.J. (2014). Feed intake, growth, and nutrient retention of common sole (Solea, solea L.) fed natural pray and an artificial feed. Aquaculture Research 1-8.

Fonds M., Drinkwaard B., Resink J.W., Eysink G.G.J. \& Toet W. (1989). Measurements of metabolism, food intake, and growth of Solea solea (L.) fed with mussel meat or with dry food. In: De Pauw N., Jaspers E., Ackefors H., Wilkins N., (Eds.). Aquaculture-A biotechnology in progress, vol. 2. European Aquaculture Society, Bredene, Belgium, pp. 851-874.

Gallaugher P. \& Farrell A.P. (1998). Hematocrit and blood oxygen carrying capacity. In: Perry SF., Tufts B., (Eds.), Fish Physiology, vol. 17. Fish respiration. Academic Press, New York, pp 185-219.

Groot S.J de (1971). On the interrelationship between morphology of the alimentary tract, food and feeding behaviour in flatfishes (Pisces : Pleuronectiformes). Netherlands Journal of Sea Research 5, 121-196.

Kals J., Blonk R.J.W., Mheen H.W. van der, Schrama J.W. \& Verreth J.A.J. (2015 a). Feeding ragworm (Nereis virens Sars) increases haematocrit and haemoglobin levels in common sole (Solea solea L.). Aquaculture Research, DOI: 10.1111/are.12767.

Kals J., Blonk R.J.W., Palstra A.P, Sobotta T.K., Mongile, F., Schneider O, Planas J.V, Schrama J.W. \& Verreth J.A.J. (submitted). Feeding ragworm (Nereis virens Sars) to common sole (Solea, solea L.) alleviates nutritional anaemia and stimulates growth. Aquaculture Research doi: 10.1111/are.12919

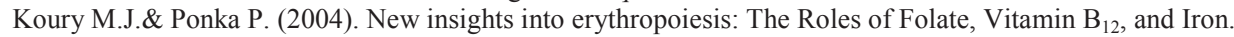
Annual Review of Nutrition, 24,105-131.

Lagardere J.P. (1987). Feeding ecology and daily food consumption of common sole, Solea vulgaris, Quensel, juvenile on the French Atlantic coast. Journal of Fish Biology 30, 91-104.

Mas-Muñoz J. (2013). Variation in behaviour and growth of common sole: genetic and environmental influences. PhD Thesis, Wageningen University, Wageningen, The Netherlands. 165pp.

Nielsen M.J., Rasmussen M.R., Andersen C.B.F., Nexø E. \& Moestrup S.K. ( 2012). Vitamin B12 transport from food to the body's cells - a sophisticated, multistep pathway. Nature Reviews Gastroenterology and Hepatology 9, 345-354

NRC (2011). Nutrient requirements of Fish and Shrimp, Committee on Nutrient requirements of Fish and Shrimp, National Research Council. National Academies Press, Washington, D.C. 2011, 376pp.

Pawlak R., James P.S., Raj S., Cullum-Dugan D. \& Lucus D. (2012). Understanding vitamin B12. American Journal of Lifestyle Medicine 7,60-65.

van Kampen E.J. \& Zijlstra W.G. (1961). Standardization of hemoglobinometry II. The hemiglobincyanide method. Clinica Chimica Acta 6, 538-544.

Vinogradov S.N. (1985) The structure of invertebrate extracellular hemoglobins (Erythrocruorins and chlorocruorins). Comparative Biochemistry and Physiology 1, 1-15

Yúfera M. \& Darías M.J. (2007). Changes in the gastrointestinal pH from larvae to adult in Senegal sole (Solea senegalensis). Aquaculture 267, 94-99.

Wang T., Lefevre S., Huong D.T.T., Cong V.N., Bayley M. (2009). The effects of hypoxia on growth and digestion. In: Farrell, A.P., Brauner, C.J., Hoar, W.S., Randall, D.J. (Eds.), Fish Physiology, vol. 27. Hypoxia. Academic press/Elsevier, Amsterdam, pp 361-398 


\section{Chapter 4}

Feeding ragworm (Nereis virens Sars) to common sole (Solea solea L.) alleviates nutritional anaemia and stimulates growth

Jeroen Kals

Robbert J.W. Blonk

Arjan P. Palstra

Tim K. Sobotta

Fulvio Mongile

Oliver Schneider

Josep V. Planas

Johan W. Schrama

Johan A.J. Verreth

Published in Aquaculture Research: DOI: 10.1111/are.1291 


\begin{abstract}
Common sole fed with commercial pellets develop anaemia and are restricted in their growth performance. The anaemia can be the result of a difference in feed intake, a nutritional deficiency, an inflammatory response to infection, or combinations of these aspects. In this study, it was investigated whether feeding ragworm would alleviate the anaemia and stimulate growth. Sole were fed with one of three diets: a commercial feed, a commercial feed treated with ragworm extract, or chopped ragworm. By comparing groups, three hypotheses were tested: (1) feeding ragworm alleviates the anaemia and positively affect the sole's metabolic performance reflected in feed intake, feed efficiency and growth; (2) anaemia is alleviated by a higher feed intake when feeding ragworm, and (3) anaemia is caused by an inflammatory response to infection.

The sole fed with a commercial diet suffered from anaemia. Feeding sole with ragworm alleviated the anaemia as the average haematocrit level nearly doubled in these fish as compared to fish fed with pellets. Investigation of the expression of genes in the liver indicated that the anaemia in sole fed with pellets is a nutritional anaemia and not an anaemia due to an inflammatory response. Sole fed with ragworm showed improved growth which may be a consequence of the higher haematocrit levels in these fish increasing their oxygen carrying capacity. Addition of ragworm extract to the pellets levelled the feed intake between pellets and ragworm, but did not improve the anaemic state of sole and had only a limited effect on growth.
\end{abstract}

Keywords: Solea solea L.; Nereis virens Sars; growth; anemia; hepcidin; gene expression. 


\section{Introduction}

Common sole (Solea solea L.) fed with commercial pellets exhibit a type of anaemia. When the diet of sole was changed from pellet to ragworm (Nereis virens, Sars), within 21 days this anaemia was alleviated: the average haematocrit (Hct) level rose from $9.8 \%$ to $19.0 \%$, and the average haemoglobin $(\mathrm{Hb})$ level from $16.3 \mathrm{~g}^{-1}$ to $39.7 \mathrm{~g} \mathrm{l}^{-1}$ (Kals, Blonk, Mheen van der, Schrama \& Verreth $2015^{\mathrm{a}}$ ). This indicates that the anaemia in common sole is diet related.

It is expected that the alleviation of the anaemia is positively related to the growth performance of common sole. A negative relation between anaemia and growth performance is shown in sheep, pigs, fish and humans (Bhatia \& Seshadri 1993; El-Zibdeh \& Furuichi 1996; Green, Graham \& Morgan 1997; Jiang, Jiang, Zhu \& Jiang 2009). The mechanism behind this relation is that $\mathrm{Hct}$ and $\mathrm{Hb}$ facilitate oxygen uptake in the cardiovascular system. The amount of oxygen absorbed from the environment and transported in vertebrates is a function of blood flow and blood oxygen carrying capacity (OCC). A higher OCC in fish through elevated Hct levels will support metabolism for digestion, osmoregulation, swimming (Thorarensen, Gallaugher, Kiessling \& Farrell 1993; Gallaugher, Thorarensen \& Farrell 1995), assimilation efficiency and growth (Wang, Lefevre, Huong, Cong \& Bayley 2009). It is therefore expected that an increase of Hct levels will have a significant effect on the metabolic performance (e.g. feed intake, feed efficiency and growth) of sole. Ende, Kroeckel, Schrama, Schneider \& Verreth (2014) found that common sole grew $\pm 70 \%$ faster on ragworm than on a commercial feed.

At this moment it is not clear which factor is causing the anaemia in sole. An increase of Hct and $\mathrm{Hb}$ in sole fed with ragworm versus the sole fed with pellets as reported by Kals et al. $\left(2015^{\mathrm{a}}\right)$ can be a result of a difference in feed intake or a difference in the dietary composition between pellet and ragworm. Because an anaemia can, besides a nutritional deficiency, also be caused by an inflammatory response to infection or a combination of both (Kreamer \& Zimmermann 2007), there may also be a health promoting effect of the ragworm.

To elucidate what factor is alleviating the anaemia in sole, we tested whether feeding ragworm per se alleviates the anaemia and positively affects the growth, or if anaemia is alleviated by a higher feed intake. To be able to determine if the observed anaemia is caused by an inflammatory response or by a nutritional deficiency, we quantified the expression of five liver marker genes being related to iron homeostasis and/or inflammatory response to infection. 


\section{Material and methods}

\section{Ethics}

This experiment was approved by the ethical Committee for Animal Experiments (DEC) and conducted at the IMARES Department of Aquaculture in Yerseke, The Netherlands.

\section{Experimental set-up, diets and preparation}

The experimental set-up contained three diets: $1^{\text {st }}$, a commercial pellet (crude protein $63 \%$, ether extract $14 \%$, ash $12 \%$, iron approximately $250 \mathrm{mg} \mathrm{kg}^{-1}$, copper approximately 13 $\left.\mathrm{mg} \mathrm{kg}{ }^{-1}, 3 \mathrm{~mm}\right)$ treated with a physiological salt solution; $2^{\text {nd }}$, the commercial pellet treated with ragworm extract; and $3^{\text {rd }}$, chopped live ragworm (crude protein $71 \%$, ether extract, $13 \%$, ash $12 \%$, iron approximately $380 \mathrm{mg} \mathrm{kg}^{-1}$, approximately $11 \mathrm{mg} \mathrm{kg}^{-1}$ ). The diet treated with ragworm extract was added to the experimental design to minimize a possible effect of feed intake on Hct. The diets were tested in triplicate, with 15 fish tank ${ }^{-1}$ and 9 tanks, adding up to 135 fish in total. The extract was produced by homogenizing cooled ragworms using a blender. Homogenates were centrifuged (20 min, $4500 \mathrm{rpm}$ ) to remove solids. Obtained supernatants were diluted $\left(8 \mathrm{~g}\right.$ extract $\left.50 \mathrm{ml}^{-1}\right)$ using a physiological salt solution for proper spraying and to ensure an even distribution of extract on pellets. The diets were produced by spraying the commercial sole pellet with a physiological salt solution or a diluted extract using $8 \mathrm{~g}$ extract. $\mathrm{kg}^{-1}$ feed or $1.4 \mathrm{~g} \mathrm{dm} \mathrm{kg}^{-1}$ feed. Assuming the iron content in the extract is equal to the iron content in the ragworm, maximum iron addition to the diet through the extract would be approximately $0.54 \mathrm{mg} \mathrm{kg}^{-1}$ and negligible compared to the dietary iron contents analysed. Moreover, analysed iron contents of all the diets are above the requirements for fish as mentioned in NRC, 2011. The treated pellets were dried for $24 \mathrm{~h}$ at room temperature before storage. Ragworms (Topsy Baits B.V., Wilhelminadorp, The Netherlands) were delivered three times a week and stored in a flow through tank to ensure a daily supply of fresh ragworms. The dry matter content of the diets were $89.1 \%, 89.6 \%$ and $18.0 \%$ for respectively the untreated pellet, treated pellet and ragworm.

\section{Fish housing and husbandry}

The fish were obtained from a commercial sole farm (Solea B.V., IJmuiden, The Netherlands), where they were fed with the same commercial pellet as during the experiment. Moreover, the sole used in the experiment were naïve to ragworm feeding. At the start of the 
experiment the mean average bodyweight of the soles was $73 \pm 13 \mathrm{~g}$ (SD). Fish were randomly allocated to one of the 9 experimental tanks $\left(0.4 \mathrm{~m}^{2}, 1301\right)$, integrated in a flow through system, using sand filtered seawater with a flow of $2.51 \mathrm{~min}^{-1} \operatorname{tank}^{-1}$. Husbandry conditions were: photoperiod $12 \mathrm{~L}: 12 \mathrm{D}$, light intensity $11-15 \mathrm{lux}$, temperature $15.7 \pm 2.3^{\circ} \mathrm{C}$, oxygen $8.9 \pm$ $0.7 \mathrm{mgl}^{-1}, \mathrm{pH} 8.16 \pm 0.2, \mathrm{TAN}$ (total ammonia nitrogen) $0.07 \pm 0.1, \mathrm{mg} \mathrm{l}^{-1}, \mathrm{NO}_{2}^{-} 0.05 \pm 0.05$ $\mathrm{mg}^{-1}, \mathrm{NO}_{3}^{-} 1.14 \pm 0.8 \mathrm{mg} \mathrm{l}^{-1}$, salinity $25-30 \mathrm{ppt}$ and the conditions stayed within pre-set limits. Temperature and oxygen content were measured daily. The $\mathrm{pH}, \mathrm{TAN}, \mathrm{NO}_{2}{ }^{-}$and $\mathrm{NO}_{3}{ }^{-}$ were measured weekly. Mortality, date and weight of dead animals were recorded.

\section{Feeding}

Fish were fed by hand to satiation twice a day (8:30 and 16:30 o'clock). During acclimatization (19 days), the fish were fed with the commercial diet. Ragworms were chopped and sieved for one minute, to drain excess fluids prior to weighing. They were sampled daily and stored at $-20^{\circ} \mathrm{C}$ for analysis of the average proximate composition. The quantities were based on the feed intake per tank from the previous day. Daily samples were pooled per treatment to get the average dry matter content and proximate composition. The samples were analysed by Nutrilab BV. Rijswijk, The Netherlands.

\section{Calculation of feed intake and feed conversion}

Feed intake in $\mathrm{g} \mathrm{d}^{-1}$, as the sum of the feed given in the morning and the afternoon, was estimated by the weight of the pellets given, minus those recovered, times the average pellet weight, or the wet weight of the ragworms given minus the wet weight of those recovered. The feed intake was calculated on dry matter basis. Feed efficiency is expressed in the feed conversion ratio on dry matter $\left(\mathrm{FCR}_{\mathrm{DM}}\right)$ and was calculated using: $\mathrm{FCR}_{\mathrm{DM}}=(\mathrm{Feed}$ intake $\mathrm{x}$ dry matter diet)/growth.

\section{Calculation of growth}

The fish were weighed at the start and at the end of the 57-day growth period and not fed one day prior to weighing. From the individual weight data, average body weight at the start $\left(\mathrm{BW}_{0}\right)$ and at the end $\left(\mathrm{BW}_{\mathrm{t}}\right)$ of the growth period was calculated per tank which was considered as the experimental unit. Growth rates expressed in $\mathrm{g} \mathrm{d}^{-1}$ were calculated per tank using the formula: $\left(\mathrm{BW}_{(\mathrm{t})}-\mathrm{BW}_{(0)}\right) / \mathrm{t}$, with $\mathrm{t}$ the being the duration of the growth period. 


\section{Sampling}

Blood and liver were sampled at the start and at the end of the experiment. Tissue sampling at the end of the experiment, was done one week after having weighted the fish for growth. Due to logistic limitations, the tissue sampling was spread over three consecutive days. Replicates were equally divided over the different sampling days. Fish for sampling were sacrificed using an overdose of phenoxy ethanol (1:1000).

\section{Blood}

Blood was obtained by caudal venous puncture using a heparinized syringe $(0.6 \mathrm{~mm} / 30 \mathrm{~mm}$ needle) as soon as the fish was anaesthetized. After collection, the samples were transferred into Eppendorfs, stored on ice and processed within approximately 15 minutes. The Hct level was determined using heparinized capillaries ( $\varnothing 1.5 \mathrm{~mm}, \mathrm{~L} 75 \mathrm{~mm})$ and a haematocrit centrifuge (Mikro hematocrit, Type 00912 Heraeus-Christ GmbH, Germany) that was applied for 5 minutes.

\section{Primer sequences}

The primers for the target genes were designed, using the Genamics Expression software. Primer sequences and GenBank accession numbers of target genes are given in Table 4.1.

For the genes beta actin and hsp70, primers were designed against Solea solea NCBI partial sequences. For gene hamp1, primers were designed against the Solea senegalensis NCBI complete sequence, and for the genes transferrin and casp 3 against the S. senegalensis NCBI partial sequences (Salas-Leiton, Anguis, Martín-Antonio, Crespo, Planas, Infante, Cañavate \& Manchado 2010). For gene ferritin, primers were designed against a $S$. senegalensis EST sequence that showed a high identity (86\%) as protein sequence with a partial protein sequence (ABJ98672) for ferritin heavy chain of turbot Scophthalmus maximus, as shown through a tBLASTn homology search. Primers that were designed against S. senegalensis sequences were specifically designed against conserved regions that were identified by aligning with the sequences of several other fish species, through a nucleotide BLAST (BLASTn or megaBLAST) homology search versus teleost fishes. 
Table 4.1 Nucleotide sequence and GenBank accession number of primers used for Q-PCR

\begin{tabular}{|c|c|c|c|}
\hline Target gene & Genbank & Forward sequence $\left(5^{\prime}-3^{\prime}\right)$ & Reverse sequence $\left(5^{\prime}-3^{\prime}\right)$ \\
\hline Beta actin & HM246512 & CCCTGAACCCTAAAGCCAACA & CACACCATCACCGGAGTCCA \\
\hline Hamp1 & AB455099 & CTCGTGCTCGCCTTTGTTTG & CAGCAGTAAACCCAGGCGTCA \\
\hline Transferrin & FJ345407 & GGCAGATGGCAAAGGAGAAGTGGC & TAATCTTTCGTCCTTGCGTGTGA \\
\hline Ferritin & FF290484 & CGTCAGGAAGCCAGAGAGAGATG & TGTGGGTCATTGTGGGTGGA \\
\hline Hsp70 & GU474638 & CGTGTGCGCTTTGCTCTTTC & GAAGGACATCAGCGACAACAAGAG \\
\hline Casp3 & HQ115741 & CGGAGGAAGACCATAGTGACAGC & GTCTTGATGGGCATGGCTCC \\
\hline
\end{tabular}

Real-time quantitative Polymerase Chain Reaction (Q-PCR)

Q-PCR was only performed for groups for which feed intake was identical in order to exclude feed intake as an interfering factor in processes of iron homeostasis and/or inflammatory response to infection. Liver tissue of eight fish fed with pellets with ragworm extract and eight fish fed with fresh ragworm had been flash frozen in liquid nitrogen, stored at $-80^{\circ} \mathrm{C}$ and used for RNA isolation. The RNA was isolated with TRIzol (Invitrogen, Baro, Spain), measured by Nanodrop, subsequently DNAse treated with RQ1 DNAse (Promega, Madison, USA), reverse transcribed using Superscript III (Invitrogen, Baro, Spain), according to the manufacturers protocols and cDNA was diluted and used as a template. The reactions (20 $\mu$ l final volume) contained $10 \mu \mathrm{l}$ of SYBR GreenER qPCR SuperMix (Invitrogen), 500 $\mathrm{nM}$ concentration of forward and reverse primers and $5 \mu \mathrm{l}$ of cDNA. Reactions were run in a MyiQ Real-Time PCR Detection System (BioRad) using the following protocol: $2 \mathrm{~min}$ at 50 ${ }^{\circ} \mathrm{C}, 8 \mathrm{~min}$ at $95{ }^{\circ} \mathrm{C}$, followed by 40 cycles of $15 \mathrm{sec}$ denaturation at $95{ }^{\circ} \mathrm{C}$ and $30 \mathrm{sec}$ at the corresponding melting temperatures, and a final melting curve of 81 cycles from $55{ }^{\circ} \mathrm{C}$ to 95 ${ }^{\circ} \mathrm{C}\left(0.5^{\circ} \mathrm{C}\right.$ increments every $\left.10 \mathrm{sec}\right)$. Samples were run in triplicate and fluorescence was measured at the end of every extension step. Fluorescence readings were used to estimate the values for the threshold cycles $(\mathrm{Ct})$. The $\mathrm{Ct}$ values were normalized for each gene against those obtained for the housekeeping gene beta actin. Normalized $\mathrm{Ct}$ values were expressed as fold changes (fc) using the relative quantification method (Livak \& Schmittgen 2001), calculated for fish fed with pellets with ragworm extract relative to fish fed with ragworm.

\section{Statistical analysis}

Data were analysed using one way ANOVA to test for diet effects. Homogeneity of variance was tested using the Levene's test. For all tests, a probability $\mathrm{p}<0.05$ was considered significant. When significant, the means were compared using the one-sided Fishers LSD post-hoc test. For all data, except the gene expression data, the tank was the experimental unit. 
For the expression data, the individual fish was the experimental unit and the normalized $\mathrm{Ct}$ values, expressed as fold changes, were compared between the groups performing the MannWhitney U-tests.

\section{Results}

Feed intake, feed conversion ratio and growth

No problems occurred during the experiment and the mortality was low ( $2 \%$ averaged over all tanks). Feed intake as well as growth were affected by the diet $(\mathrm{P}<0.05$; Table 4.2). On dry matter basis, sole fed with ragworm had an equal feed intake as sole fed with pellets that were treated with the ragworm extract. Despite the equal feed intake, sole fed with ragworms grew $37 \%$ faster. Sole fed with pellets without ragworm-extract had a $20 \%$ lower feed intake and a $71 \%$ slower growth compared to sole fed ragworm. The feed conversion ratio $\left(\mathrm{FCR}_{\mathrm{DM}}\right)$ tended to be different between the treatments $(\mathrm{P}<0.10)$, being the lowest for sole fed with ragworm and the highest for the sole fed with pellets without the ragworm extract (Table 4.2).

Table 4.2 Body weight at start (BWstart) and at end (BWend), Feed intake (FI), growth, hepatosomatic index (HSI) and feed conversion on dry matter (FCRdm) of the fish fed ragworm, treated pellets and untreated pellets

\begin{tabular}{|c|c|c|c|c|}
\hline Diet & Ragworm & Pellet + extract & Pellet & P-value \\
\hline BW $_{\text {start }}(\mathrm{g})$ & $78.95 \pm 3.73$ & $78.04 \pm 2.56$ & $75.22 \pm 2.35$ & 0.34 \\
\hline $\mathrm{BW}_{\text {end }}(\mathrm{g})$ & $118.8 \pm 6.85^{\mathrm{a}}$ & $109.9 \pm 6.25^{b}$ & $98.8 \pm 2.66^{c}$ & 0.01 \\
\hline 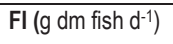 & $0.69 \pm 0.04^{a}$ & $0.68 \pm 0.03^{a}$ & $0.56 \pm 0.06^{b}$ & 0.01 \\
\hline Growth $\left(\mathrm{g} \mathrm{d}^{-1}\right)$ & $0.70 \pm 0.08^{a}$ & $0.56 \pm 0.08^{b}$ & $0.41 \pm 0.09 c$ & 0.02 \\
\hline HSI (\%) & $1.42 \pm 0.12$ & $1.60 \pm 0.20$ & $1.47 \pm 0.11$ & 0.24 \\
\hline FCRDM & $1.02 \pm 0.03$ & $1.25 \pm 0.17$ & $1.34 \pm 0.20$ & 0.09 \\
\hline
\end{tabular}

\section{Haematocrit and hepatosomatic index}

The average Hct level of the sole at the start of the experiment was low (11.4\%) and remained low during the experiment, irrespective whether the fish were fed with treated 
pellets or with untreated pellets. However, the Hct values of sole fed with ragworm increased with $83-87 \%$ up to a Hct level of $21.2 \%$ on average at the end of the experiment (Figure 4.1 ). At the end of the experimental period, the Hct values were affected by the dietary treatment $(\mathrm{P}<0.00$; Figure 4.1). HSI was not affected by the diet (Table 4.2).

Expression of liver marker genes in iron homeostasis and immune response

The primers for all investigated genes worked well, as indicated by the clear specific dissociation peaks in the melting curve analyses and the sufficiently high expression values of the PCR-products. For the expression of the liver marker genes relative to the beta actin housekeeping gene, the sole fed with ragworm were taken as references. Expression of two of the three markers for the iron homeostasis differed between the sole fed with treated pellets versus the sole fed with ragworm. The gene expression of hampl (fc $0.09 \pm 0.03 ; \mathrm{P}<0.05$ ) and transferrin (fc $0.27 \pm 0.04 ; \mathrm{P}<0.05$ ) were down regulated in sole fed with the treated pellets versus sole fed with ragworms, whereas the ferritin expression was not different (fc $1.28 \pm 0.39 ; \mathrm{P}>0.05)$. Also $h s p 70$ (fc $1.53 \pm 0.60 ; \mathrm{P}>0.05)$ and casp3 (fc $0.83 \pm 0.17 ; \mathrm{P}>0.05$ ) were not different between both diets (Figure 4.1).

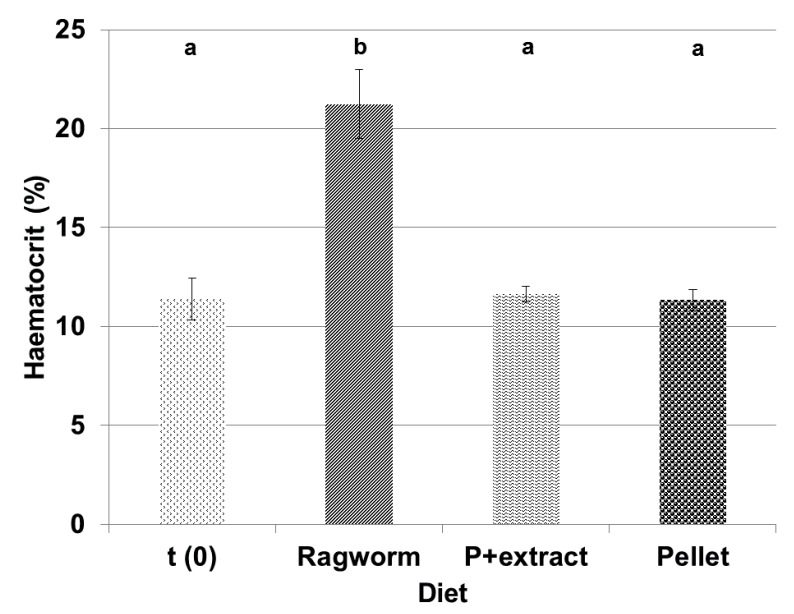

Figure 4.1 The average haematocrit values in \%. With $t(0)$, ragworm, P+extract and Pellet, coding for samples at start, live chopped ragworm, pellet treated with ragworm extract and the untreated pellet, respectively. ${ }^{a b c}$ Means within columns with a common superscript are not significantly different using the one sided Fisher LSD post hoc test $(P<0.05)$ 


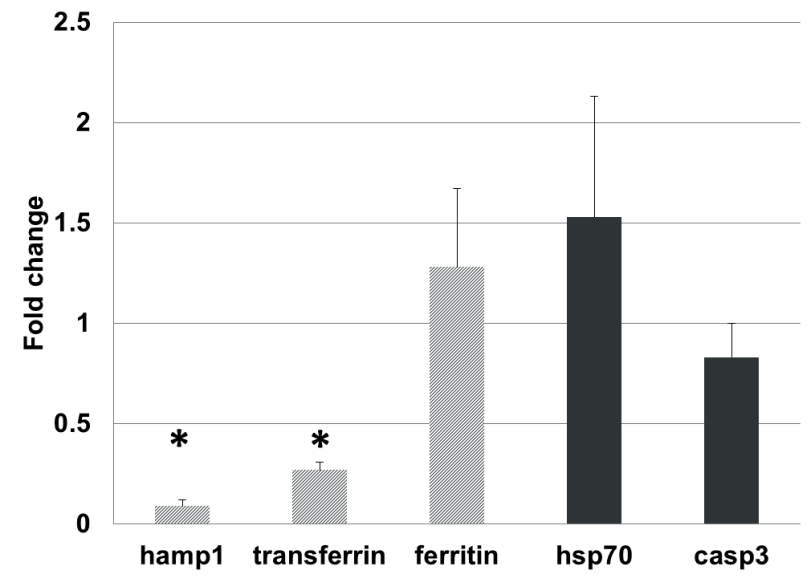

Figure 4.2 Expression of marker genes in iron homeostasis (hepcidin - hamp1, transferrin and ferritin in light grey) and immune response (heat shock protein 70 - hsp 70 and cysteine-aspartic acid peptidase 3 - casp 3 in dark grey) in liver tissue. Expression of genes is normalized for the expression of beta actin in liver tissue and is shown as fold change of sole fed with pellet plus ragworm extract relative to sole fed with ragworm, set to 1 . *Means are significantly different using the Mann-Whitney U-test $(P<0.05)$.

\section{Discussion}

Common sole fed with commercial pellets develop anaemia and are restricted in their growth. This is a major obstacle towards a viable cultivation of sole. In this study we investigated if feeding ragworm instead of commercial pellets could alleviate anaemia and stimulate growth, and could thus present a solution for this problem. To our knowledge this is the first time, insights were provided to elucidate what factor is alleviating the anaemia in sole and gene expression profiles indicated differences in the molecular regulation of iron homeostasis and/or inflammatory response to infection in the liver.

The feed intake of sole fed with ragworm was equal to that of sole fed with treated pellets (Table 4.2), yet the Hct values of sole fed with ragworm almost doubled as compared to values in sole fed with treated pellets. Hence, we can conclude that the feed intake did not affect the Hct level. In another experiment, evaluating the effect of processing (e.g. boiling) on the nutritional value of ragworm as feed for common sole, we determined iron intake and measured Hct. The experiment was run with three tanks per treatment, 15 soles per tank of which 10 were sampled for Hct. Although the iron intake of sole fed with treated pellets versus sole fed with boiled ragworm was comparable $\left(0.160 \pm 0.01\right.$ versus $0.144 \pm 0.03 \mathrm{mg}$ fish ${ }^{-}$ 
${ }^{1} \mathrm{~d}^{-1},(\mathrm{p}>0.05)$, the Hct of sole fed with boiled ragworm was significantly higher $11.6 \% \pm 0.7$ versus $17.0 \% \pm 1.7(\mathrm{p}<0.01)$ (unpublished data). This indicates that the higher Hct value in sole fed with ragworm is caused by another factor than the iron intake (e.g. a difference in iron absorption between diets).

To evaluate the cause of the anaemia, being a nutritional deficiency, an inflammatory response to infection or a combination of both, we assessed the expression profiles of the marker genes involved in iron homeostasis and immune response. The regulation of iron homeostasis is accomplished by the interaction of proteins like the iron transporter transferrin, the iron storage protein ferritin and the iron absorption regulator hepcidin, all three being proteins that are also involved in the response to infection (Rodrigues, Va'zquez-Dorado, Neves \& Wilson 2006; Kreamer \& Zimmermann 2007; Neves, Wilson \& Rodrigues 2009). A significant down-regulated expression was found for hampl and transferrin in sole fed with pellets and ragworm extract versus sole fed with ragworm (Figure 4.2). Hepcidin is the master regulator of iron homeostasis via its ability to block ferroportin, the only known iron export protein (Ganz 2005). Hepcidin expression is induced independently by the accumulation of iron or inflammation and is suppressed when iron stores are depleted, by anaemia, hypoxemia and accelerated erythropoiesis (Kreamer \& Zimmermann 2007; Kemna, Tjalsma, Willems \& Swinkels 2008; Muñoz, Villar \& García-Erce 2009). The down-regulated expression of hampl indicates an iron deficiency in the anaemic sole fed with pellets. The expression of transferrin in our study was also down-regulated, probably driven by the lack of iron to transport. In fish, transferrin can act either as a negative or positive acute phase protein during inflammation (Congleton \& Wagner, 1991; Bayne \& Gerwick, 2001). As the expression of hsp70 is not different between the treatment groups, there is no indication of a difference in cell stress (Tavaria, Gabriele, Kola \& Anderson 1996; Morana 2007). The lack of difference in expression of casp3 between both groups indicates that there are no differences in apoptosis (Porter \& Jänicke 1999). Synthesis of ferritin is induced when much iron is available, especially during oxidative stress (Orino, Lehman, Tsuji, Ayaki, Torti \& Torti 2001) and inflammatory conditions (Torti, Kwak, Miller, Miller, Ringold \& Myambo 1988; Rogers, Bridges, Durmowicz, Glass, Auron \& Munro 1990; Chasteen, 1998; Lieu, Heiskala, Peterson \& Yang 2001; Torti \& Torti 2002), whereas during severe iron deprivation its synthesis is repressed (Neves et al. 2009). In our study, the ferritin expression was not different between the groups which does not support a difference in oxidative stress, high iron availability or iron deprivation between fish fed with pellets or with ragworms. Thus, the combined down-regulation of hepcidin (indicating an anaemia without an immune response), 
the down-regulation of transferrin (indicating an acute phase response, but no iron deficiency), the similar expressions of respectively $h s p 70$ (no indication of cell stress), casp3 (no indication of apoptosis) and ferritin (no indication of oxidative stress, iron overload, iron deficiency, inflammatory conditions and/or major intracellular changes) in sole fed with treated pellets indicates a nutritional anaemia, but not necessarily an iron deficiency anaemia. This supports the finding in Kals et al. $\left(2015^{\mathrm{a}}\right)$, that the anaemia in sole is diet related and that feeding ragworm alleviates this type of anaemia.

The hepatosomatic index (HSI) is often used as an indicator of overall fish health (Busacker, Adelman \& Goolish 1990). In the current study, the HSI values were not affected by the diet and did fall within the normal range of 1-2\% for teleost's (Bruslé \& Gonzalez 1996). This indicates that these sole had normal liver sizes, making pathological liver problems (e.g. related to an inflammatory response to infection) unlikely.

In this study, the average feed intake between fish fed with ragworm and fish fed with treated pellets was equal, but growth was not (Table 4.2). This suggest the appearance of a combination of impaired digestion, lower assimilation efficiency and/or a metabolic problem, as indicated by the higher $\mathrm{FCR}_{\mathrm{DM}}$ value in sole fed with pellets as compared to those fed with ragworm (Table 4.2). The low Hct values found in sole fed with pellets (Figure 4.1) are likely causing a reduction in the oxygen carrying capacity (OCC) of the blood and, as data do implicate, may limit growth. Anaemia is a form of functional hypoxia (Farrell \& Richards 2009). Hypoxia in fish compromises metabolic performance, including growth (Wang et al. 2009). In Nile tilapia (Oreochromis niloticus), the assimilation efficiency ((feed consumedfaecal output)/(feed consumption)) was reduced from $\sim 80 \%$ in normoxia to $54 \%$ under severe hypoxia. In the same study, the FCR, being related to the assimilation efficiency, increased, from 1.52 to 6.75 (Tsadik \& Kutty 1987). As we have reconfirmed in this study, sole fed with commercial pellets have low Hct levels (Figure 4.1) and consequently suffer from an anaemia or functional hypoxia, which in general do affect the feed intake, feed efficiency and growth. In feeding experiments, Hct levels are often not measured, and therefore information about a possible anaemia in experimental fish is scarce. However, as showed in this study, diets can have a significant influence on Hct levels and potentially on the metabolic performance. Not measuring Hct may impair the right interpretation of the results of these experiments.

We suggest that a nutritional anaemia in sole caused the low Hct levels and the poor growth found in the sole fed with pellets. The improved growth in sole fed with ragworm may have been the consequence of the higher Hct levels in these fish increasing their oxygen carrying capacity. 


\section{Conclusion}

Pellet-fed sole are suffering from a nutritional anaemia and not an anaemia due to an inflammatory response to infection. Feeding ragworm to sole, alleviates this nutritional anaemia. Addition of ragworm extract to the pellet levels the long term feed intake with the sole fed with ragworm, but has only a limited effect on growth and does not improve the anaemic state of the sole. The slow growth of pellet-fed sole might be the consequence of low Hct values which hampers the oxygen uptake and lowers therewith the overall metabolic capacity.

\section{Disclosure statement}

A patent application covering the use of Annelida and Mollusca in fish feed has been filed in 2012.

\section{Acknowledgements}

The authors thank Y. van Es, A. Hofman and N. Ros for their help and caretaking of the experimental animals during the execution of the experiment and P. Vereijken from Biometris for his statistical support. The authors also thank D. Crespo for assistance with QPCR. This study was financially supported by the "Zeeland Sole" foundation, IMARES and a grant from the Dutch Ministry of Economic Affairs, Agriculture and Innovation (project "Marine Aquaculture: Customized Nutrition). 


\section{References}

Bayne C.J. \& Gerwick L. (2001). The acute phase response and innate immunity in fish. Developmental and Comparative Immunology. 25, 725-743.

Bhatia D. \& Seshadri S. (1993). Growth performance in anemia and following iron supplementation. Indian paediatrics. 30 (2), 195-200.

Bruslé J. \& Gonzalez G. (1996). The structure and function of fish liver. In: Munshi J.S.D., Dutta H.M., (Eds.), Fish Morphology. Science Publishers Inc. New York.

Busacker G.P., Adelman I.R. \& Goolish E.M. (1990). Growth. In: Schreck C.B., Moyle C.B., (Eds.), Methods for Fish Biology. American Fisheries Society, Bethesda, MA, pp. 363-387.

Chasteen N.D. (1998). Ferritin. Uptake, storage, and release of iron. Metal Ions in Biological Systems. 35, 479514.

Congleton J.L. \& Wagner E.J. (1991). Acute-phase hypoferremic response to lipopolysaccharide in rainbow trout (Oncorhynchus mykiss). Comparative Biochemistry and Physiology A . 98, 195-200.

Ende S.S.W., Kroeckel S., Schrama J.W., Schneider O. \& Verreth J.A.J. (2014). Feed intake, growth, and nutrient retention of common sole (Solea, solea L.) fed natural pray and an artificial feed. Aquaculture Research doi:10.1111/are.12526.

El-Zibdeh M., Ide K. \& Furuichi M. (1996). Effects of the Deletion of Mg or Fe from Semi Purified Diets on Growth and Efficiency of Feed Utilization of Yellow Croaker Nibea albiflora. Journal of the Faculty of Agriculture, Kyushu University. 40 (3-4), pp. 391-397.

Farrell A.P. \& Richards, J.G. (2009). Defining hypoxia: An integrative synthesis of the response of fish to hypoxia. In: Farrell A.P., Brauner C.J., Hoar W.S., Randall D.J. (Eds.), Fish Physiology, vol. 27. Hypoxia. Academic press/Elsevier, Amsterdam, pp. 478-503.

Gallaugher P. \& Farrell A.P. (1998). Hematocrit and blood oxygen carrying capacity. In: Perry S.F., Tufts B., (Eds.), Fish Physiology, vol. 17. Fish respiration. Academic Press, New York, pp 185-219.

Gallaugher P., Thorarensen H.P. \& Farrell A.P. (1995). Hematocrit in oxygen transport and swimming in rainbow trout (Oncorhynchus mykiss) Respiratory Physiology. 102, 279-292.

Ganz T. (2005). Cellular iron: ferroportin is the only way out. Cell Metabolism. 1, 155-157.

Green L.E., Graham M. \& Morgan K.L., (1997). Preliminary study of the effect of iron dextran on a nonregenerative anaemia of housed lambs. Veterinary Record 140, 219-222.

Jiang J.F., Jiang J.B., Zhu H.S. \& Jiang M.I. (2009). Combined treatment with vitamin A and iron to prevent piglet anemia. Journal of Swine Health and Production. 17, 22-27.

Kals J., Blonk R.J.W., Mheen H.W. van der, Schrama J.W. \& Verreth J.A.J. (2015 a). Feeding ragworm (Nereis virens Sars) increases haematocrit and haemoglobin levels in common sole (Solea solea L.). Aquaculture Research, DOI: 10.1111/are.12767.

Kemna E.H.J.M., Tjalsma H., Willems H.L. \& Swinkels D.W. (2008). Hepcidin: from discovery to differential diagnosis. Haematologica. 93, (1) 90-97.

Kraemer K. \& Zimmermann M.B. (2007). Nutritional anemia. SIGHT AND LIFE Press. c/o SIGHT AND LIFE / DSM. Nutritional Products Ltd. Internet: www.sightandlife.org 400pp.

Lieu P.T., Heiskala M., Peterson P.A \& Yang, Y. (2001). The roles of iron in health and disease. Molecular Aspects of Medicine. 22, 1-87.

Livak K.J. \& Schmittgen T.D. (2001). Analysis of relative gene expression data using real-time quantitative PCR and the 2- $\Delta \Delta \mathrm{CT}$ method. Methods 25, 402-408.

Morana K.A. (2007). New tricks for an old dog: the evolving world of Hsp70. New York Academy of Sciences 1113, $1-14$.

Muñoz M., Villar I. \& García-Erce J.A. (2009). An update on iron physiology. Journal of New Gastroenterology 15 (37), 4617-4626

Neves J.V., Wilson J.M. \& Rodrigues, P.N.S. (2009). Transferrin and ferritin response to bacterial infection: The role of the liver and brain in fish. Developmental and Comparative Immunology. 33, 848-857.

Orino K., Lehman L., Tsuji Y., Ayaki H., Torti S.V. \& Torti F.M. (2001). Ferritin and the response to oxidative stress. Journal of Biochemistry. 357, 241-7.

Porter A.G. \& Jänicke, R.U. (1999). Emerging roles of caspase-3 in apoptosis. Cell Death \& Differentiation. 6 (2): 99-104.

Rodrigues P.N.S., Va'zquez-Dorado S., Neves J.V. \& Wilson J.M. (2006). Dual function of fish hepcidin: Response to experimental iron overload and bacterial infection in sea bass (Dicentrarchus labrax) Developmental and Comparative Immunology. 30, 1156-1167.

Rodrigues P.N.S.,\& Pereira, F.A. (2004). A model for acute iron overload in sea bass (Dicentrarchus labrax L.). Lab Animal. 38, 418-424.

Rogers J.T., Bridges K.R., Durmowicz G.P., Glass J., Auron P.E. \& Munro H.N. (1990). Translational control during the acute phase response, Ferritin synthesis in response to interleukin-1. Journal of Biological Chemistry. 265, 14572-14578. 
Salas-Leiton E., Anguis V., Martín-Antonio B., Crespo D., Planas J.V., Infante C., Cañavate J.P. \& Manchado M. (2010). Effects of stocking density and feed ration on growth and gene expression in the Senegalese sole (Solea senegalensis): Potential effects on the immune response. Fish \& Shellfish Immunology $\mathbf{2 8}$ 296-302.

Tavaria M., Gabriele T., Kola I.\& Anderson R.L. (1996). A hitchhiker's guide to the human Hsp70 family. Cell. Stress. Chaperones. 1 (1): 23-28.

Thorarensen H., Gallaugher P.E., Kiessling A.K. \& Farrell A. P. (1993). Intestinal blood flow in swimming chinook salmon Oncorhynchus tshawytscha and the effects of haematocrit on blood flow distribution. Journal of Experimental Biology. 179, 115-129.

Torti F.M. \& Torti S.V. (2002). Regulation of ferritin genes and protein. Blood, 99, 3505-3516.

Torti S.V., Kwak E.L., Miller S.C., Miller L.L., Ringold G.M. \& Myambo K.B. (1988). The molecular cloning and characterization of murine ferritin heavy chain, a tumor necrosis factor-inducible gene. Journal of Biological Chemistry. 26, 12638-12644.

Tsadik G.G.\& Kutty M.N. (1987). Influence of ambient oxygen on feeding and growth of the Tilapia (Oreochromis niloticus) (Linnaeus). FAO document AC168E.

Wang T., Lefevre S., Huong D.T.T., Cong V.N. \& Bayley M. (2009). The effects of hypoxia on growth and digestion. In: Farrell A.P., Brauner C.J., Hoar W.S., Randall D.J. (Eds.), Fish Physiology, vol. 27. Hypoxia. Academic press/Elsevier, Amsterdam, pp 361-398. 


\section{Chapter 5}

The relation between ragworm meal inclusion level, haematocrit level and growth of common sole (Solea solea L.).

Jeroen Kals

Robbert J.W. Blonk

Henk W. v.d. Mheen

Johan W. Schrama

Johan A.J. Verreth

In preparation 


\begin{abstract}
The aim of the present study was to determine the minimum amount of freeze dried ragworm meal in the diet, necessary to keep growth and the haematocrit (Hct) levels of sole comparable to the levels found in common sole fed fresh ragworm and to prevent nutritional anaemia. In addition, the dietary iron and $\mathrm{B}_{12}$ contents were calculated to gain insight in their relation with the Hct levels and growth. Sole were fed one of seven diets, five respectively containing $0 \%, 10 \%, 25 \%, 50 \%$ and $75 \%$ ragworm meal, a commercial pellet and ragworm representing a negative and a positive control diet, respectively. The Hct levels were affected by ragworm meal inclusion level and rose to nearly double the start values with rising ragworm meal inclusion level. This, in contrary to the Hct level of soles fed commercial pellets, which stayed anaemic. Growth increased from 2.33 to $6.96 \mathrm{~g} \mathrm{~kg}^{-0.8} \mathrm{~d}^{-1}$ with the rising ragworm meal levels. Consequently, the inclusion level of ragworm meal to maintain Hct levels and growth rates comparable to sole fed fresh ragworm is $100 \%$. The effect of ragworm on the Hct level and growth could not be explained by the level of crude protein, ether extract, amino acids, calcium or phosphate. We suggest that the higher Hct level and better growth resulting from higher ragworm meal inclusion might relate to the combination of high dietary heme iron and $\mathrm{B}_{12}$.
\end{abstract}

Keywords: Solea solea; ragworm; haematocrit; growth; common sole; heme; vitamin $B_{12}$. 


\section{Introduction}

Common sole (Solea solea L.) fed ragworm (Nereis virens Sars) grows $\pm 70 \%$ faster compared to sole fed commercial pellets (Ende, Kroeckel, Schrama, Schneider \& Verreth 2014). Moreover, sole fed commercial pellets suffers from a nutritional anaemia (Kals, Blonk, Palstra, Sobotta, Mongile, Schneider, Planas, Schrama \& Verreth 2015 ${ }^{\mathrm{a}}$ ). Feeding ragworm alleviates this nutritional anaemia within three weeks (Kals, Blonk, Mheen van der, Schrama \& Verreth $2015^{\mathrm{b}}$ ). This suggests that components, important for the alleviation of the nutritional anaemia in sole, are present in ragworm, yet are lacking in the tested commercial pellets.

Besides the nutritional differences between the commercial pellet and ragworm, processing may also explain part of the differences in haematocrit (Hct) and growth between sole fed fresh ragworm or commercial pellets. Boiling for example, which could be seen as an analogue to cooking extrusion or steam pelleting in the modern feed industry, has a negative impact on the dietary effect of ragworm. Sole fed boiled ragworm showed a lower feed intake, slower growth (unpublished data) and lower Hct level than sole fed fresh ragworm (Kals et al. $2015^{\mathrm{a}}$ ). This suggests that, at least part of the, component(s) important for the alleviation of anaemia and increase in growth of sole are heat sensitive, thereby explaining why it is crucial to feed ragworm or its components in a fresh or non-denatured state. Unfortunately, feeding solely fresh ragworm or a pellet completely made of non-denatured (e.g. freeze dried) ragworm meal, is neither technical nor economical viable. Therefore, the aim of the present study is to determine the minimum amount of freeze dried ragworm meal in the diet, necessary to keep growth and Hct levels comparable to those of sole fed fresh ragworm.

\section{Material and methods}

This experiment was approved by the ethical Committee for Animal Experiments and conducted at IMARES, Yerseke, The Netherlands.

\section{Fish, housing and husbandry}

This experiment assessed the impact of the amount of freeze dried ragworm meal in the diet on the Hct levels and growth of sole using a dose response trial. To maximize the response of the diets the experiment was carried out with anaemic sole. Anaemic sole $(73 \pm 11.9 \mathrm{~g})$ obtained from Solea B.V., IJmuiden, The Netherlands and naive to mussel and ragworm feeding were accommodated in 21 tanks at a density of 15 fish per tank. All tanks $\left(0.4 \mathrm{~m}^{2}, 130 \mathrm{~L}\right)$ received a continuous flow of $7 \mathrm{~L} \mathrm{~min}^{-1} \operatorname{tank}^{-1}$ of fresh filtered seawater. 
Husbandry conditions were: Photoperiod 12L:12D, light intensity 11-15 lux, temperature 19.2 $\pm 0.4^{\circ} \mathrm{C}$, oxygen $7.1 \pm 0.3 \mathrm{mg} \mathrm{L}^{-1}, \mathrm{pH} 7.7 \pm 0.2$, flow $6.6 \pm 0.9 \mathrm{~L} \mathrm{~min}^{-1}$, total ammonium nitrogen (TAN) $0.03 \pm 0.1 \mathrm{mg} \mathrm{L}^{-1}, \mathrm{NO}_{2}^{-} 0.08 \pm 0.08 \mathrm{mg} \mathrm{L}^{-1}, \mathrm{NO}_{3}^{-} 3.0 \pm 2.7 \mathrm{mg} \mathrm{L}^{-1}$ and salinity $30 \mathrm{~g} \mathrm{~L}^{-1}$, which stayed within preset limits. Temperature and oxygen were measured daily. Flow, $\mathrm{pH}$, TAN, $\mathrm{NO}_{2}^{-}$and $\mathrm{NO}_{3}{ }^{-}$were measured weekly.

\section{Experimental design, diets and preparation}

The experiment consisted of a 14-day acclimatisation and a 42-day experimental period. During acclimatization fish were fed the commercial pellet $(3 \mathrm{~mm}$, crude protein \pm $63 \%$, ether extract $\pm 14 \%$, ash $12 \%$, iron $\pm 250 \mathrm{mg} \mathrm{kg}^{-1}, \mathrm{~B}_{12} \pm 338 \mu \mathrm{g} \mathrm{kg}^{-1} \mathrm{dm}$ ). During the experimental period sole were fed one of seven diets in triplicate. Of the seven diets tested, five were diets containing respectively $0 \%(\mathrm{RW} 0), 10 \%(\mathrm{RW} 10), 25 \%(\mathrm{RW} 25), 50 \%(\mathrm{RW} 50)$ and 75\%(RW75) ragworm meal. These five diets (RW0, RW10, RW25, RW50 and RW75) were isonitrogenous, isoenergetic, comparable in amino acid composition as well as in calcium and phosphates levels (table 5.1, 5.2 and 5.3). The commercial pellet (CPEL) and fresh ragworm (RW100) were added to the experimental set up as a negative and positive control diet, respectively. Moreover, fresh ragworm was assumed to mimic a diet containing $100 \%$ ragworm meal. The amino acid composition of the diets, listed in (Table 5.3) was calculated using the amino acid composition of the different dietary ingredients. The analyzed amino acid composition of fresh ragworm was used as a reference for the amino acid requirements of sole, and the experimental diets RW0 to RW75 were formulated accordingly (Table 5.3). The addition of diamol was used to keep ash levels comparable between diets. The diets were prepared through cold extrusion in cooperation with Research Diet Services (RDS, Wijk bij Duurstede, The Netherlands). Cold extrusion was used to keep the heat liable components in its undenatured state. For example heme iron, a major component in ragworm, is sensitive to heat (Lombardi-Boccia, Martinez-Dominguez \& Aguzzi 2002). Ragworms (Topsy Baits B.V., Wilhelminadorp, The Netherlands), were delivered three times a week. The freeze dried ragworm meal was delivered by Seabait Ltd, Shoreline Polycheate Farms LPP, Woodhorn Village, UK. Recipes and their composition are shown in the Tables 5.1, 5.2 and 5.3 . 
Table 5.1: Experimental set-up and recipes

\begin{tabular}{lccccc}
\hline Code & RW0 & RW10 & RW25 & RW50 & RW75 \\
\hline Amount of ragworm meal $^{2}$ (\%) & $\mathbf{0}$ & $\mathbf{1 0}$ & $\mathbf{2 5}$ & $\mathbf{5 0}$ & $\mathbf{7 5}$ \\
Test ingredients in \% $^{\text {Ragworm meal }}{ }^{\mathrm{a}}$ & & & & & \\
Pea protein $^{\mathrm{b}}$ & 0 & 10.00 & 25.00 & 50.00 & 75.00 \\
Casein $^{\mathrm{c}}$ & 24.02 & 21.88 & 18.66 & 13.30 & 7.94 \\
Soy Protein Concentrate $^{\mathrm{d}}$ & 21.85 & 19.42 & 15.78 & 9.72 & 3.66 \\
Fish Oil $^{\mathrm{e}}$ & 17.54 & 15.20 & 11.70 & 5.85 & 0.00 \\
Diamol $^{\dagger}$ & 11.82 & 10.24 & 7.88 & 3.94 & 0.00 \\
Sugar $^{\mathrm{g}}$ & 9.61 & 8.33 & 6.41 & 3.20 & 0.00 \\
Lime $^{\mathrm{h}}$ & 1.52 & 1.32 & 1.02 & 0.51 & 0.00 \\
Basal ingredients $^{\mathrm{T}}$ & 0.23 & 0.20 & 0.15 & 0.08 & 0.00 \\
Check $^{1}$ & 13.41 & 13.41 & 13.41 & 13.41 & 13.41 \\
\hline
\end{tabular}

${ }^{1}$ Fresh ragworms, ${ }^{2}$ Percentage of freeze dried (non-denatured) ragworm meal (N. Virens), "Wheat gluten' $5 \%$, Binder1 ${ }^{j}, 2 \%$, Binder $^{k} 2 \%$, Salt $2 \%$, Binder $3^{m} 1 \%$, Mineral and vitamin premix $1.36 \%$, Betain ${ }^{\mathrm{n}} 0.05 \%$, a Seabait Ltd, Shoreline Polycheate Farms LPP Woodhorn Village, UK, ${ }^{b}$ Roquette Freres, Lestrem, France, ${ }^{\circ}$ Acid casein $30 / 60$ mesh, Lactalis, Bourgbarré, France, ${ }^{\mathrm{d}}$ Soycomil R ADM Eurpoort BV The Netherlands, ${ }^{\mathrm{e}}$ Coppens International The Netherlands, ${ }^{f}$ Damolin A/S, Hamburg, ${ }^{g}$ Melis, van Suikerunie Dinteloord, ${ }^{h}$ Inducal 250 van Sibelco/Ankerpoort, Maastricht, 'Gluvital 21000 Cargill Bergen op Zoom The Netherlands, ${ }^{j}$ Binder1, ${ }^{k}$ Binder2 and ${ }^{m}$ Binder3; Ingredients are not specified because of confidentiality reasons of ongoing research. 'Animalfeed salt van Kloek zout, The Netherlands, " Betafin van Danisco Animal Nutrition Marlborough UK, ${ }^{\dagger}$ (taken from Borges, Oliveira, Casal, Dias, Conceição, \& Valente 2009) Vitamins (mg or IU kg-1 diet): vitamin A (retinyl acetate); $2.4 \mathrm{mg}, 8000$ IU; vitamin D3 (cholecalciferol), $0.04 \mathrm{mg} 1700 \mathrm{IU}$; vitamin K3 ((menadione sodium bisulfite), $10 \mathrm{mg}$; vitamin B1 (thiamine), $8 \mathrm{mg}$; vitamin B2 (riboflavin), $20 \mathrm{mg}$; vitamin B6, ${ }^{2}$ vitamin $B_{12}$ (cyanocobalamin) $0.02 \mathrm{mg}$, (pyridoxine hydrochloride), $10 \mathrm{mg}$; folic acid, $6 \mathrm{mg}$; biotin, $0.7 \mathrm{mg}$; inositol, $300 \mathrm{mg}$; niacin, $70 \mathrm{mg}$; pantothenic acid, $30 \mathrm{mg}$, choline, $1500 \mathrm{mg}$; vitamin C, $500 \mathrm{mg}$; vitamin E, $300 \mathrm{mg}$; Minerals (g or mg kg-1 diet): Mn (manganese oxide), $20 \mathrm{mg}$; I (potassium iodide), $1.5 \mathrm{mg}$; Cu (copper sulphate), $5 \mathrm{mg}$; Co (cobalt sulphate), $0.1 \mathrm{mg} ; \mathrm{Mg}$ (magnesium sulphate), $500 \mathrm{mg} ; \mathrm{Zn}$ (zinc oxide) $30 \mathrm{mg}$; Se (sodium selenite) $0.3 \mathrm{mg} ; \mathrm{Fe}$ (Iron Sulfate) $60 \mathrm{mg}$; Calcium carbonate $2150 \mathrm{mg}$; Dicalcium phosphate $5000 \mathrm{mg}$; Potasium Chloride 1000mg; Antixoidant BHT (E300-321) 100 mg; Anti-fungal Calcium propionate $1000 \mathrm{mg}$.

Table 5.2: Analysed proximate composition of diets

\begin{tabular}{|c|c|c|c|c|c|c|c|c|}
\hline \multicolumn{2}{|l|}{ Code } & CPEL & RW0 & RW10 & RW25 & RW50 & RW75 & RW100 \\
\hline \multicolumn{2}{|c|}{ Amount of ragworm meal ${ }^{2}(\%)$} & 0 & 0 & 10 & 25 & 50 & 75 & $100^{1}$ \\
\hline \multicolumn{9}{|c|}{ Analyzed (macro) nutritional composition } \\
\hline \multicolumn{9}{|c|}{ Unit } \\
\hline DM & $\left(\mathrm{g} \mathrm{kg}^{-1}\right)$ & 923 & 645 & 671 & 672 & 718 & 770 & 164 \\
\hline Ash & $\left(\mathrm{g} \mathrm{kg}^{-1} \mathrm{dm}\right)$ & 120 & 158 & 159 & 161 & 192 & 178 & 128 \\
\hline $\mathrm{CP}$ & $\left(\mathrm{g} \mathrm{kg}^{-1} \mathrm{dm}\right)$ & 673 & 583 & 572 & 564 & 587 & 539 & 659 \\
\hline EE & $\left(\mathrm{g} \mathrm{kg}^{-1} \mathrm{dm}\right)$ & 93 & 133 & 122 & 118 & 100 & 99 & 79 \\
\hline CF & $\left(\mathrm{g} \mathrm{kg}^{-1} \mathrm{dm}\right)$ & $<3.0$ & 17 & 19 & 16 & 22 & 17 & 18 \\
\hline NFE & $\left(\mathrm{g} \mathrm{kg}^{-1} \mathrm{dm}\right)$ & 37 & 109 & 127 & 141 & 98 & 168 & 116 \\
\hline$P$ & $\left(\mathrm{~g} \mathrm{~kg}^{-1} \mathrm{dm}\right)$ & 18.4 & 10.7 & 10.4 & 10.4 & 11.5 & 10.5 & 8.5 \\
\hline $\mathrm{Ca}$ & $\left(\mathrm{g} \mathrm{kg}^{-1} \mathrm{dm}\right)$ & 22.8 & 5.3 & 5.1 & 5.1 & 6.3 & 5.2 & 1.7 \\
\hline GE & $\left(\mathrm{MJ} \mathrm{kg}^{-1}\right)$ & 20.3 & 21.3 & 21.0 & 20.8 & 20.0 & 19.9 & 21.1 \\
\hline CP/GE & 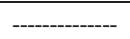 & 33.1 & 27.4 & 27.3 & 27.1 & 29.4 & 27.1 & 31.2 \\
\hline
\end{tabular}

${ }^{1}$ Fresh ragworms, ${ }^{2}$ percentage of freeze dried (non-denatured) ragworm meal (N. Virens). With $D M=d r y$ matter, $C P=C r u d e$ protein, $E E=E$ ther extract, $C F=$ Crude fiber, NFE=Nitrogen Free Extract, $P=$ Phosphorus, $C a=C a l c i u m$ and GE=Gross Energy. 
Dose response ragworm meal, Hct and growth

Table 5.3: Calculated or analyzed amino acid composition of diets.

\begin{tabular}{|c|c|c|c|c|c|c|c|c|}
\hline Code & & $\mathrm{CPEL}^{2}$ & $\mathrm{RWO}^{1}$ & RW10 ${ }^{1}$ & RW25 $^{1}$ & RW50 ${ }^{1}$ & $\mathrm{RW}^{1} 5^{1}$ & RW100 ${ }^{2}$ \\
\hline Lysine $^{a}$ & $\mathrm{~g} \mathrm{~kg}^{-1}$ & 46.4 & 37.6 & 37.1 & 36.4 & 35.2 & 34.1 & 34.0 \\
\hline Methionine $^{a}$ & "” & 16.7 & 10.3 & 10.3 & 10.3 & 10.3 & 10.3 & 10.3 \\
\hline Cysteine $^{b}$ & "” & 5.1 & 5.6 & 5.6 & 5.6 & 5.7 & 5.7 & 5.3 \\
\hline Threonine $^{a}$ & "" & 24.1 & 21.4 & 21.2 & 20.8 & 20.3 & 19.7 & 19.5 \\
\hline Tryptophan $^{\text {a }}$ & "" & 6.3 & 6.3 & 6.3 & 6.2 & 6.1 & 6.1 & 6.0 \\
\hline Isoleucine $^{a}$ & ""s" & 24.5 & 26.6 & 26.0 & 25.0 & 23.4 & 21.8 & 20.2 \\
\hline Arginine $^{a}$ & "" & 33.4 & 32.9 & 32.9 & 32.9 & 32.9 & 32.8 & 32.9 \\
\hline Phenylalanine $^{a}$ & "“" & 22.9 & 28.4 & 27.6 & 26.3 & 24.2 & 22.0 & 19.3 \\
\hline Histidine $^{a}$ & "” & 14.8 & 14.7 & 14.5 & 14.2 & 13.8 & 13.4 & 13.0 \\
\hline Leucine $^{\mathrm{a}}$ & "" & 42.1 & 46.5 & 45.2 & 43.3 & 40.2 & 37.0 & 33.5 \\
\hline Tyrosine $^{b}$ & "" & 17.4 & 22.0 & 21.6 & 21.0 & 20.0 & 19.1 & 18.1 \\
\hline Valine $^{a}$ & "“" & 28.7 & 30.4 & 29.7 & 28.7 & 27.1 & 25.5 & 24.0 \\
\hline Alanine & ""s & 34.9 & 20.4 & 22.2 & 24.9 & 29.5 & 34.1 & 38.9 \\
\hline Asparagine & "" & 52.5 & 51.8 & 50.8 & 49.3 & 46.8 & 44.2 & 43.3 \\
\hline Glutamate & "" & 80.0 & 110.2 & 106.0 & 99.7 & 89.1 & 78.7 & 61.0 \\
\hline Glycine & "" & 33.8 & 17.8 & 18.9 & 20.6 & 23.5 & 26.3 & 29.0 \\
\hline Proline & "“" & 23.0 & 40.4 & 40.1 & 39.7 & 38.9 & 38.3 & 35.1 \\
\hline Serine & "" & 22.7 & 27.9 & 27.0 & 25.6 & 23.3 & 21.0 & 18.5 \\
\hline
\end{tabular}

Calculated ${ }^{l}$ or analyzed ${ }^{2}$ nutrients, ${ }^{a}$ Essential, ${ }^{b}$ conditionally essential.

Table 5.4: Calculated or analyzed iron and vitamin $B_{12}$ content of diets.

\begin{tabular}{llcrrrrrr}
\hline Code & & CPEL & RW0 & RW10 & RW25 & RW50 & RW75 & RW100 \\
\hline Iron (calculated) & $\mathrm{mg} \mathrm{kg}^{-1} \mathrm{dm}$ & -- & 131 & 312 & 583 & 1035 & 1486 & -- \\
\hline Iron (analysed) & $\mathrm{mg} \mathrm{kg}^{-1} \mathrm{dm}$ & 223 & 3946 & 3348 & 2825 & 2426 & 1406 & 505.0 \\
\hline $\mathrm{B}_{12}$ (calculated) & $\mu \mathrm{g} \mathrm{kg}^{-1} \mathrm{dm}$ & -- & 20 & 133 & 304 & 587 & 871 & -- \\
\hline $\mathrm{B}_{12}$ (analysed) & $\mu \mathrm{m} \mathrm{kg}^{-1} \mathrm{dm}$ & 338 & 40 & -- & -- & -- & 571 & 1598 \\
\hline
\end{tabular}

\section{Feeding}

Fish were fed to satiation twice a day (8:30 and 16:30). Satiation feeding was checked by looking if pellets or pieces of ragworms were still present in the tank one hour after the start of feeding. Uneaten feed was removed from the tanks. The feed load was equal for all tanks, adapted daily and based on the tank with the highest feed load. Ragworms were chopped and sieved for 1 minute to drain excess fluids prior to weighing. Ragworms were sampled daily and stored at $-20^{\circ} \mathrm{C}$ for analysis of the average proximate composition. The quantities were based on the feed intake per tank from the previous day. Daily samples were pooled to get the average dry matter, proximate composition, calcium, phosphate levels and vitamin $\mathrm{B}_{12}$ levels. The samples were analysed by Nutrilab BV. Rijswijk, The Netherlands except for iron. Iron was analysed by the Chemical Biological Soil Laboratory (CBLB), Wageningen also in The Netherlands, using the ICP-EAS. 


\section{Calculation of growth}

The fish were weighed at the start and at the end of the 42-day growth period and not fed one day prior to weighing. From the individual weight data, average body weight at the start $\left(\mathrm{BW}_{0}\right)$ and at the end $\left(\mathrm{BW}_{\mathrm{t}}\right)$ were calculated per tank, which was considered the experimental unit. Growth rates expressed in $\mathrm{g} \mathrm{d}^{-1}, \% \mathrm{BW} \mathrm{d}{ }^{-1}$ and $\mathrm{g} \mathrm{kg}^{-0.8} \mathrm{~d}^{-1}$ were calculated using the formulas: $\left(\mathrm{BW}_{(\mathrm{t})-} \mathrm{BW}_{(0)}\right) / \mathrm{t},\left(\mathrm{LN}\left(\mathrm{BW}_{(\mathrm{t})}\right)-\mathrm{LN}\left(\mathrm{BW}_{(0)}\right)\right) /(\mathrm{t}) * 100$ and $\left(\left(\mathrm{BW}_{(\mathrm{t})-}\right.\right.$ $\left.\left.\left.\mathrm{BW}_{(0)}\right) /\left(\left(\mathrm{BW}_{(\mathrm{t})} * \mathrm{BW}_{(0)}\right)^{0.5} / 1000^{0.8}\right)\right)\right) / \mathrm{t}$, respectively with $\mathrm{t}$ representing the duration of the growth period and LN the natural logarithm.

\section{Sampling}

Blood was sampled by caudal venous puncture, using a heparinized syringe $\left(0.6 \mathrm{~mm} / 30 \mathrm{~mm}\right.$ needle) at the start (10 fish) and at the end of the experiment (10 fish $\left.\operatorname{tank}^{-1}\right)$. After collection, blood was transferred into tubes, stored on ice and processed within 15 minutes. The Hct level was determined by using capillaries (Ø 1,5mm, L 75mm) and a haematocrit centrifuge (Mikro hematocrit, Type 00912 Heraeus-Christ GmbH, Germany) to centrifuge for 5 minutes at $11,000 \mathrm{rpm}$ or $5000 \mathrm{~g}$. Due to logistic limitations, blood sampling was spread over three consecutive days. Replicates were equally divided over the different sampling days. Weighing of fish was done on the same day as blood sampling. Fish for sampling were sacrificed using an overdose of phenoxy ethanol (1:1000).

\section{Statistical analysis}

Data were analysed for diet effects using One-Way ANOVA. Homogeneity of variance was tested using the Levene's test. Tank was used as the experimental unit. For all tests a probability $\mathrm{p}<0.05$ was considered significant. When significant, means were compared using the Fishers LSD post hoc test. Curves were fitted by regression analysis using curve estimation (SPSS Statistics, IBM).

\section{Results}

No problems occurred during the experiment, except that the diet without ragworm meal (RW0) was hardly accepted by the fish and consequently resulted in negative growth ($\left.1.11 \pm 0.24 \mathrm{~g} \mathrm{~kg}^{-0.8} \mathrm{~d}^{-1}\right)$. Therefore, treatment RW0 was excluded from the study for further analysis. Mortality during the experiment was limited to four fish (1.3\%) and not related to treatment.

Sole, which were raised on CPEL and naive to ragworm and mussel had an average 
Hct level at start of $9.8 \pm 0.7 \%$. At the end of the experiment, the average Hct level of sole fed CPEL, the negative control, was $11.2 \pm 0.9 \%$ and not different from the value at start $(\mathrm{p}>0.05)$. In contrast, the average Hct level of sole fed fresh ragworm(RW100), the positive control, more than doubled (table 5.5, p=0). The Hct levels of sole fed the diets RW10-RW75 (table 5.5) were laying within the range from the negative (CPEL) towards the positive control (RW100). The Hct levels of the sole fed the diets RW10-RW75 gradually rose from $12.6 \pm 1.3$ to $17.7 \pm 0.1 \%$ with the stepwise increasing ragworm meal inclusion level (table 5.5, $\mathrm{p}=0$ ). Assuming fresh ragworm mimics a diet of 100\% ragworm meal (RW100), the relation between ragworm meal inclusion level and the Hct level of sole fed diet RW10 to RW100, the negative control not included, is linear (Fig. 5.1A, $\mathrm{Y}=0.1012 \mathrm{X}+11.69, \mathrm{R}^{2}=0.91, \mathrm{p}<0.05$, with $\mathrm{Y}$ representing heamatocrite in \% and $\mathrm{X}$ the inclusion level of ragworm meal in \%).

At the end of the experiment, the growth of sole fed CPEL, the negative control, was $4.58 \mathrm{~g} \mathrm{~kg}^{-0.8} \mathrm{~d}^{-1}$ and comparable with the growth of the fish fed diet RW50 (table 5.5; $\mathrm{p}>0.05$ ). The growth of sole fed fresh ragworm(RW100), the positive control, expressed in $\mathrm{g} \mathrm{kg}^{-0.8} \mathrm{~d}^{-1}$ was $52 \%$ higher. The growth of the sole fed the diets RW10-RW75 gradually increased from $2.33 \pm 0.39$ to $5.82 \pm 0.27 \mathrm{~g} \mathrm{~kg}^{-0.8} \mathrm{~d}^{-1}$ with the stepwise rising ragworm meal inclusion level (table 5.5, $\mathrm{p}=0$ ). Again, assuming fresh ragworm mimics a diet of $100 \%$ ragworm meal (RW100), the relation between ragworm meal inclusion level and growth of sole fed diet RW10 to RW100, the negative control not included, is linear (Fig. 5.1B, Y $=0.0501 \mathrm{X}+$ 2.0796, $\mathrm{R}^{2}=0.96, \mathrm{p}<0.05$, with $\mathrm{Y}$ representing growth in $\mathrm{g} \mathrm{kg}^{-0.8} \mathrm{~d}^{-1}$ and $\mathrm{X}$ the inclusion level of ragworm meal in \%). Since both Hct and growth were linearly affected by the inclusion level of ragwormmeal, also Hct and growth were strongly correlated ( $\mathrm{Y}=0.4602 \mathrm{X}-3.1144$, $\left.\mathrm{R}^{2}=0.90, \mathrm{p}<0.05\right)$, with $\mathrm{Y}$ respresenting growth in $\mathrm{g} \mathrm{kg}^{-0.8} \mathrm{~d}^{-1}$ and $\mathrm{X}$ the heamatocrite in $\%$.

Table 5.5: Bodyweight at start (BWstart), at end (BWend), growth, metabolic growth rate (GMBW) specific growth rate (SGR) and haematocrit (Htc) of the fish fed diets with $0 \%(R W 0), 10 \%(R W 10), 25 \%(R W 25), 50 \%$ (RW50), 75\% (RW75) of ragworm meal respectively, fresh ragworm ( $R$ W100) and commercial pellets (CPEL).

\begin{tabular}{lcccccccc}
\hline \multicolumn{1}{c}{ Diet } & RW0 & RW10 & RW25 & RW50 & RW75 & RW100 & CPEL & P-value \\
\hline BW $_{\text {start }}(\mathrm{g})$ & $75.8 \pm 1.1$ & $71.1 \pm 4.5$ & $78.0 \pm 1.4$ & $70.5 \pm 4.9$ & $73.0 \pm 2.7$ & $73.8 \pm 4.7$ & $72.8 \pm 0.8$ & 0.16 \\
\hline BW $_{\text {end }}(\mathrm{g})$ & $70.1 \pm 1.5$ & $83.8 \pm 7.4$ & $98.7 \pm 4.2$ & $98.3 \pm 4.7$ & $108.3 \pm 5.1$ & $117.6 \pm 6.5$ & $99.6 \pm 2.9$ & 0 \\
\hline Growth $\left(\mathrm{g} \mathrm{d}^{-1}\right)$ & $\mathrm{NA}$ & $0.3 \pm 0.07^{\mathrm{a}}$ & $0.5 \pm 0.08^{\mathrm{b}}$ & $0.66 \pm 0.04^{\mathrm{c}}$ & $0.84 \pm 0.06^{\mathrm{d}}$ & $1.04 \pm 0.09^{\mathrm{e}}$ & $0.64 \pm 0.06^{\mathrm{c}}$ & 0 \\
\hline GMBW $\left(\mathrm{g} \mathrm{kg}^{-0.8} \mathrm{~d}^{-1}\right)$ & $\mathrm{NA}$ & $2.33 \pm 0.39^{\mathrm{a}}$ & $3.46 \pm 0.47^{\mathrm{b}}$ & $4.85 \pm 0.36^{\mathrm{c}}$ & $5.82 \pm 0.27^{\mathrm{d}}$ & $6.96 \pm 0.53^{\mathrm{e}}$ & $4.58 \pm 0.34^{\mathrm{c}}$ & 0 \\
\hline SGR $\left(\% \mathrm{BW}\right.$ gain $\left.\mathrm{d}^{-1}\right)$ & $\mathrm{NA}$ & $0.39 \pm 0.06^{\mathrm{a}}$ & $0.56 \pm 0.07^{\mathrm{b}}$ & $0.79 \pm 0.06^{\mathrm{c}}$ & $0.94 \pm 0.04^{\mathrm{d}}$ & $1.11 \pm 0.09^{\mathrm{e}}$ & $0.75 \pm 0.05^{\mathrm{c}}$ & 0 \\
\hline Htc$(\%)$ & $\mathrm{NA}$ & $12.6 \pm 1.3^{\mathrm{a}}$ & $14.3 \pm 0.4^{\mathrm{b}}$ & $17.6 \pm 0.2^{\mathrm{c}}$ & $17.7 \pm 0.1^{\mathrm{c}}$ & $22.5 \pm 1.0^{\mathrm{d}}$ & $11.2 \pm 0.9^{\mathrm{e}}$ & 0 \\
\hline${ }_{\text {abc } \text { Means with a common superscript are not significantly different } \text { using the Fisher LSD post hoc test }(P<0.05) .}$
\end{tabular}


$5.1 \mathrm{~A}$

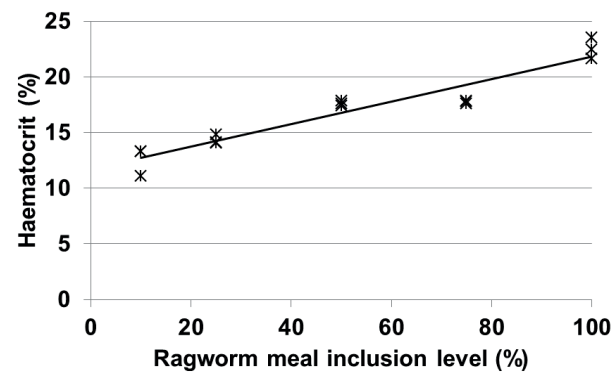

$5.1 \mathrm{~B}$

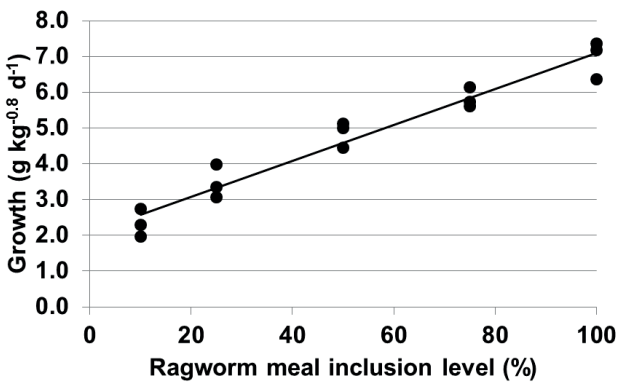

Figure 5.1A (left): The relation between ragworm meal inclusion level (\%) and Hct (\%): $y=0.1012 x+11.69$, $R^{2}=0.91$ and figure $5.1 B$ (right): The relation between ragworm meal inclusion level(\%) and growth in metabolic body weight $\left(\mathrm{g} \mathrm{kg}^{0.8} \mathrm{~d}^{-1}\right): y=0.0501 x+2.0796, R^{2}=0.96$. Fresh ragworm (RW100) is depicted as a diet with $100 \%$ ragworm meal, the negative control (CPEL) is not included.

\section{Discussion}

Fish were moderately anaemic at start. In Kals et al. $\left(2015^{\mathrm{a}}\right)$ we concluded this anaemia in sole fed commercial pellets is a nutritional anaemia. Both Hct, an indicator for the state of anaemia, and growth show a positive linear relationship with the ragworm meal inclusion level. Consequently, the minimum inclusion level of ragworm meal without negatively affecting Hct and growth in sole is $100 \%$.

Both, the Hct level and growth of sole fed fresh ragworm (RW100) accord the linear regression lines representing Hct and growth as a function of the ragworm meal inclusion level, i.e. the measured Hct and growth values of sole fed fresh ragworm (RW100) do not differ from the estimated values for $\operatorname{Hct}(p=0.33)$ and growth in $g \cdot \mathrm{kg}^{0.8} \cdot \mathrm{d}^{-1}(\mathrm{p}=0.72)$. This infers that feeding fresh ragworm has no added value over feeding a pellet containing $100 \%$ of freeze dried ragworm meal.

The question is which compound, present in ragworm meal, caused this linear response of Hct and growth? As the diets RW10 tot RW75 were isonitrogenous, isoenergetic and largely comparable in amino acid as well as in calcium and phosphates levels (table 5.1, 5.2 and 5.3), the level of crude protein, ether extract, amino acids, calcium or phosphate of the diets in the current experiment cannot explain the difference in Hct and growth between the diets RW10-RW75 (Table 5.2 and 5.3). A difference in digestibility between the diets could possibly explain the results, yet, this seems no plausible argument as the apparent digestibility coefficients of the non-marine derived ingredients used in the experimental recipes (e.g. 
casein, soy protein concentrate, pea protein concentrate and wheat gluten) are high and fluctuate for fish in general between 85-100\% (Tibbetts, Milley \& Lall 2006; NRC 2011). Moreover, the feeding level was ad libitum.

Iron is most commonly deficient in a nutritional anaemia (Latham 1997; Kraemer \& Zimmermann 2007). However, in all experimental diets the calculated iron level was above the requirements as mentioned for fish in general (NRC 2011). We did analyze the iron contents of the diets (table 5.4), yet the results are not usable due to the unexpected iron content of the diamol (39 g. $\left.\mathrm{kg}^{-1}\right)$, which was added to keep ash levels comparable between the experimental diets RW0-RW75. The iron within the inert siliceous composition of the diamol got freed though due to the $\mathrm{HNO}_{3}-\mathrm{HCl}$ destruction used for the ICP-AES analysis of minerals. Diamol (acid insoluble ash) is often used as an indigestible marker in digestibility studies. Hence, we assume the iron from the diamol was not available for absorption by the fish and therefore, we used the calculated iron values (table 5.4) for insights instead. As diet RW75 did not contain diamol (table 5.1) we used the analyzed iron levels in this diet as a reference. In this study, both growth and Hct rose with the increasing calculated dietary iron levels, mainly related to the increasing levels of ragworm meal of which the iron content was 2062 mg. $\mathrm{kg}^{-1} \cdot \mathrm{dm}$. This level seems high but, falls within the range of the iron content found for Nereis species by Vinogradov, Sharma \& Walz (1991). However, it seems that the amount of dietary iron on itself is not conclusive. Feeding fresh ragworm (RW100) with a lower total iron content compared to diet RW25, RW50 and RW75, still results in higher Hct levels and growth. Therefore, not the intake of iron, but the absorption or bioavailability of iron might explain the differences in Hct between the experimental diets. The bioavailability of iron depends on the form in which it is present in the diet (e.g. heme vs. non-heme) as discussed in Kals et al. $2015^{\mathrm{b}}$ and Kals, Blonk, Mheen van der, Schrama \& Verreth $2015^{\mathrm{c}}$. Ragworm, a polychaete, contains mainly heme iron. According to Vinogradov et al. (1991), $2.36 \%$ of the weight of the Nereis species consists of heme iron. The bioavailability of heme iron is superior to that of non-heme (Anderson et al. 1997; Maage \& Sveir 1998; Bury, Walker \& Glover 2003; Miret, Simpson, \& McKie 2003; Kraemer \& Zimmermann 2007), which could explain the difference in Hct between the different RW diets. However, one would expect the iron from the freeze dried ragworm meal also to be fully heme iron. But, it could have been possible that during the process of freeze drying, which is a relatively long time process, part of the heme from the ragworm was decomposed to biliverdin and inorganic iron by the enzyme heme oxygenase (Abele-Oeschger, Oeschger \& Theede 1994). The inorganic iron can easily oxidize to $\mathrm{Fe}^{3+}$, which cannot be absorbed. The greenish colour (of the blood vessels) in 
ragworm is due to biliverdin (Abele-Oeschger et al. 1994) and not what is sometimes thought, the pigment hemocyanin. Polychaetes do not have the copper containing hemocyanin (Scott \& Major, 1972; Vinogradov 1985; Magnum, Miller, Scot, Hole \& Morse 1987).

An additional factor that could explain the difference in the Hct level between sole fed commercial pellets and sole fed diets with increasing percentages of ragworm meal, is the increase in the calculated dietary level of vitamin $\mathrm{B}_{12}$. As discussed in Kals et al. $2015^{\mathrm{b}}$ and Kals, Blonk, Mheen van der, Schrama \& Verreth submitted) we believe that $\mathrm{B}_{12}$ absorption in sole is limited and suggest sole may depend on high dietary levels of $\mathrm{B}_{12}$.

Like the Hct level, growth improved with rising levels of ragworm meal (Fig. 5.1B). We suggest that the rising Hct levels improve the sole's ability to take up oxygen from the environment, as maximum oxygen consumption is highly dependent on the Hct levels, as discussed in Kals et al. 2015 . However, the growth of sole fed the commercial pellet is comparable to the growth of sole fed diet RW50 even though the average Hct level of these sole was $57 \%$ higher (11.2\% vs. $17.6 \%$ ). This difference, we cannot explain based on the current observations. The mechanism causing the observed strong correlation between the Hct level and growth in sole fed a ragworm diet or fresh ragworm requires further assessment to enable proper diet formulation for common sole.

\section{Conclusions}

The inclusion level of ragworm meal to maintain Hct levels and growth rates comparable to sole fed fresh ragworm is $100 \%$. There seems to be no added value of feeding fresh ragworm compared to freeze dried ragworm meal. The positive effect of ragworm on Hct and growth cannot be explained by the levels of crude protein, ether extract, amino acids, calcium or phosphate. We suggest that the ability of ragworm (meal) to alleviate anaemia and stimulate growth in sole can be explained by a combination of heme iron and high $\mathrm{B}_{12}$ levels, even though the levels of heme iron and $\mathrm{B}_{12}$ are related to the increase of ragworm meal. We therefore, cannot exclude that also other factors could explain a comparable effect of ragworm (meal) on Hct levels and growth.

\section{Disclosure statement}

A patent application covering the use of Annelida and Mollusca in fish feed has been filed in 2012. 


\section{Acknowledgements}

The authors thank Y. van Es, A. Hofman and N. Ros for their help and caretaking of the experimental animals during the experiment. This work was financially supported by the "Zeeland Sole" foundation and IMARES. 


\section{References}

Abele-Oeschger D., Oeschger R. \& Theede H. (1994). Biochemcial adaptations of Nereis diversicolor (Polychaeta) to temporarily increased hydrogen perioxide levels in intertidal sandflats. Marine Ecology Progress Series 106,101-110.

Andersen F., Lorentzen M.,Waagbø R. \& Maage A. (1997). Bioavailability of different forms of iron in Atlantic salmon (Salmo salar) smolt. Aquaculture Nutrition 3, 239-246.

Borges P., Oliveira B., Casal S., Dias J., Conceição L. \& Valente L.M.P. (2009). Dietary lipid level affects growth performance and nutrient utilisation of Senegalese sole (Solea senegalensis) juveniles. British Journal of Nutrition 102 (7):1007-14. doi: 10.1017/S0007114509345262.

Bury N.R., Walker P.A. \& Glover C.N. (2003). Nutritive metal uptake in teleost fish. The Journal of Experimental Biology 206, 11-23.

Ende S.S.W., Kroeckel S., Schrama J.W., Schneider O. \& Verreth J.A.J. (2014). Feed intake, growth, and nutrient retention of common sole (Solea, solea L.) fed natural pray and an artificial feed. Aquaculture Research 1-8.

Kals J., Blonk R.J.W., Mheen H.W. van der, Schrama J.W. \& Verreth J.A.J. (2015). Feeding ragworm (Nereis virens Sars) increases haematocrit and haemoglobin levels in common sole (Solea solea L.). Aquaculture. Research. DOI: 10.1111/are.12767.

Kals J., Blonk R.J.W., Mheen H.W. van der Schrama J.W. \& Verreth J.A.J. (2015 ${ }^{\mathrm{b}}$ ). Mussel (Mytilus edulis L.) and ragworm (Nereis virens, Sars) both alleviate anaemia in common sole (Solea solea L.). Aquaculture Research. doi: 10.1111/are.12871

Kals J., Blonk R.J.W., Mheen H.W. van der, Schrama J.W. \& Verreth J.A.J. $\left(2015^{\mathrm{c}}\right)$. Effect of different iron sources on the alleviation of nutritional anaemia in common sole (Solea, solea). Aquaculture. 451: 266270. http://dx.doi.org/10.1016/j.aquaculture.2015.08.036

Kraemer K. \& Zimmermann, M.B. (2007). Nutritional anemia. SIGHT AND LIFE Press. c/o SIGHT AND LIFE / DSM. Nutritional Products Ltd. Internet: www.sightandlife.org 400pp.

Latham M.C. (1997). Human Nutrition in the Developing World 1997. Food and Agriculture Organization of the United Nations Rome, Italy.

Lombardi-Boccia G., Martinez-Dominguez B. \& Aguzzi A. (2002). Total Heme and Non-heme Iron in Raw and Cooked Meats. Journal of Food Science, 67,1738-1741.

Maage A. \& Sveier H. (1998). Addition of dietary iron(III) oxide does not increase iron status of growing Atlantic salmon. Aquaculture international 6, 249-252.

Magnum C.P., Miller K.I., Scot J.L., Hole van K.E. \& Morse M.P. (1987). Bivalve Hemocyanin: structural, functional, and phylogenetic relationships. The Biological. Bulletin 173, 205-221.

Miret S., Simpson R.J.\& McKie A.T. (2003). Physiology and molecular biology of dietary iron absorption. Annual Review of Nutrition 23,283-301.

NRC (2011). Nutrient requirements of Fish and Shrimp, Committee on Nutrient requirements of Fish and Shrimp, National Research Council. National Academies Press, Washington, D.C. 2011, 376pp.

Scot, D.M. \& Major, C.W. (1972). The effect of copper (II) on survival, respiration, and hearth rate in the common blue mussel, Mytilus Edulis. Biological Bulletin 143,679-688.

Tibbetts S.M., Milley J.E. \& Lall S.P. (2006). Apparent protein and energy digestibility of common and alternative feed ingredients by Atlantic cod, Gadus morhua (Linnaeus, 1758). Aquaculture, 4, 13141327.

Vinogradov, S.N. (1985). The structure of invertebrate extracellular hemoglobins (Erythrocruorins and chlorocruorins). Comparative Biochemistry and Physiology 1, 1-15

Vinogradov S.N., Sharma P.K. \& Walz, D.A. (1991). Iron and heme contents of the extracellular hemoglobins and chlorocruorins of annalids. Comparative Biochemistry and Physiology B 98,187-194. 


\section{Chapter 6}

Effect of different iron sources on the alleviation of nutritional anaemia in common sole (Solea solea).

Jeroen Kals

Robbert .J.W. Blonk

Henk W. van der Mheen

Johan W. Schrama

Johan .A.J. Verreth

Published in Aquaculture: http://dx.doi.org/10.1016/j.aquaculture.2015.08.036 


\begin{abstract}
Sole fed commercial pellets suffers from a nutritional anaemia. The hypotheses tested are: (1) the nutritional anaemia in sole fed commercial pellets is caused by an iron deficiency; (2) the assumed iron deficiency is due to inadequate absorption of iron; (3) an increase in absorption due to a higher bioavailability of heme or iron chelates will alleviate anaemia in sole and (4) haematocrit (Hct) and haemoglobin ( $\mathrm{Hb}$ ) are expected to follow the iron absorption patterns. In addition, we estimated the absorption of copper, cobalt, chromium, manganese, molybdenum and zinc in order to evaluate possible interaction between available iron sources and the absorption of other divalent minerals.

Sole were fed four diets, each with a different iron source: iron sulphate, iron methionate, iron proteinate or heme. Feeding was restricted and equal for all diets. At the start of the experiment, sole reared on commercial pellets had average values of $\mathrm{Hct}, \mathrm{Hb}$ and the hepatosomatic index of $12.5 \%, 19.6 \mathrm{~g} .1^{-1}$ and $1.13 \%$, respectively. The values at the end of the experiment did not differ from the values at the start and were not affected by the source of iron. The apparent absorption coefficients (AAC) of iron, manganese, zinc, cobalt, chromium and molybdenum, except for copper, were unaffected by the iron sources. Yet, the iron absorption was high for all sources tested. The AAC of copper was $15-22 \%$ higher in sole fed the diet with heme. The use of the different iron sources, including heme, did not affect Hct and $\mathrm{Hb}$ in anaemic sole. The high absorption of iron and copper in sole fed heme did not affect $\mathrm{Hct}$ and $\mathrm{Hb}$, which suggests that the nutritional anaemia in sole is not an iron nor a copper deficiency anaemia.
\end{abstract}

Keywords: Sole, (Solea, sole); anemia; mineral absorption; copper; iron sulphate; iron methionate; iron proteinate; heme iron. 


\section{Introduction}

Common sole (Solea, solea) grows approximately 70\% faster on ragworm (Nereis virens ) or mussel (Mytilus edulis) than on commercial pellets (Ende, Kroeckel, Schrama, Schneider \& Verreth 2014). Moreover, sole fed commercial pellets suffers from a nutritional anaemia (Kals, Blonk, Palstra, Sobotta, Mongile, Schneider, Planas, Schrama \& Verreth submitted). Feeding ragworm or mussel alleviates this anaemia within three weeks (Kals, Blonk, Mheen van der, Schrama \& Verreth 2015' Kals, Blonk, Mheen van der, Schrama \& Verreth $2015^{\mathrm{b}}$ ). This suggests that components important for the recovery of anaemia are present in ragworm and mussel, yet are missing in current commercial feeds.

Anaemia is strictly defined as a decrease in red blood cell mass (Lydyard, Cole, Holton, Irving, Porakishvili, Venkatesan \& Ward 2010) and according to Thrall, Weiser, Allison \& Campbell (2012) fish are anaemic when Hct values are $<20 \%$. According to Wood, McMahon \& McDonald, 1979), the normal Hct level of healthy flounder (Platichthys stellatus) is $\pm 25 \%$. They diagnosed flounders with Hct levels around $8 \%$ as moderate anaemic and flounders with Hct levels $<5 \%$ as severely anaemic. Data for Hct and/or $\mathrm{Hb}$ values in common sole are scarce. Yet, sole grown on natural food in outdoor ponds at an experimental farm (Zeeuwse Tong, Colijnsplaat, The Netherlands) show Hct levels of $20 \pm 2 \%$ for males and $22 \pm 1 \%$ for females (Palstra, Blok, Kals, Blom, Tuinhof-Koelma, Dirks, Forlenza \& Blonk 2015), levels approximately twice the amount found in sole fed commercial pellets (Kals et al. 2015 ${ }^{\mathrm{a}}$, Kals et al. 2015 ). Lower levels of Hct and Hb are associated with anaemia. Taking into consideration Thrall et al. (2012), the data of Wood et al. (1979), Palstra et al. (2015) and the fact that within a fish species the range of Hct levels for normocythemia tend to be relatively narrow (Gallaugher \& Farrell 1998) Hct and Hb levels in common sole fed commercial pellets indicate a moderate (nutritional) anaemia.

Many nutritional factors can play a role in a nutritional anaemia (Kraemer \& Zimmermann 2007), but for sole several can be ruled out. Feed intake and iron intake can be eliminated (Kals et al. submitted). Impaired iron absorption due to intake of dietary milk or soy proteins, phytates or plant polyphenols, can be excluded as the commercial pellet tested in Kals et al. submitted hardly contains these components. Likewise, the (macro) nutritional composition of the feed, the amino acid composition, as well as the phosphorus and calcium levels, cannot explain the difference in haematocrit (Hct) between sole fed ragworm or commercial pellets. Hct levels gradually increased when using diets with a stepwise rising share of ragworm meal, while the diets were comparable with respect to the nutritional parameters mentioned (Kals et al. unpublished data). 
In most cases, iron is deficient in a nutritional anaemia (Kraemer \& Zimmermann 2007; Latham 1997). We compared the intake of iron, copper, cobalt, chrome, manganese, selenium and zinc between sole fed commercial pellets or boiled ragworm. Despite the fact that the iron intake in sole fed boiled ragworm was not different from that in sole fed commercial pellets, sole fed boiled ragworm recovered from their anaemia while sole fed commercial pellets stayed anaemic (Kals et al. submitted). Likewise, the intake of copper, cobalt, chrome, manganese, selenium and zinc was comparable or significantly higher in sole fed commercial pellets when compared to sole fed boiled ragworm (Kals et al. unpublished data). This suggests that the higher Hct level in sole fed boiled ragworm is not due to a higher intake of dietary iron or the other minerals mentioned.

Yet, a factor which in relation with these observations cannot be excluded from being involved in anaemia, is the bioavailability of iron and/or the other minerals present in the diet. For example, the bioavailability of iron depends on the form in which iron is presented to the fish (heme versus. non heme iron). The absorption of heme differs from that of non heme, as the absorption of heme has its own pathway, independent of the intestinal $\mathrm{pH}$ (Kraemer \& Zimmermann 2007) and mostly immune for antagonists (e.g. other divalent minerals as for example copper, cobalt, zinc etc.) that interfere with the iron absorption (Andersen, Lorentzen, Waagbø \& Maage 1997). Moreover, the absorption of non heme iron requires the reduction of $\mathrm{Fe}^{3+}$ to $\mathrm{Fe}^{2+}$, and hence, an acidic environment. Kwong \& Niyogi (2008) showed that a rise in intestinal $\mathrm{pH}$ reduced iron absorption. Therefore, the alkaline character of the sole's intestine (Clark, MacDonald \& Stark 1985; Yúfera \& Darías 2007) might negatively affect the sole's ability to absorb non heme iron, consequently leading to low Hct and $\mathrm{Hb}$ levels. Among the non heme iron sources, chelates (e.g. iron methionate, iron proteinate) are better absorbed than mineral salts (Park \& Harmston 1994). Nevertheless, the bioavailability of heme in general is superior to that of non heme iron (Andersen et al. 1997; Bury, Walker \& Glover 2003; Kraemer \& Zimmermann 2007; Maage \& Sveier 1998; Miret, Simpson \& McKie 2003). Iron in mussel and ragworm is mostly heme iron in its undenatured state (Vinogradov, Sharma \& Walz 1991). Iron in the commercial pellet is mostly of non heme origin, coming with the premix or damaged forms of heme from feed ingredients like fishmeal. Sugiura, Dong \& Rathbone (1998) showed that the absorption of iron from fish meals is low. Inadequate absorption of iron due to a low bioavailability of a specific iron source, can cause an iron deficiency and as a consequence anaemia. In the current study we have tested four hypotheses: (1) the nutritional anaemia in sole fed commercial pellets is caused by an iron deficiency, (2) the assumed iron deficiency is due to an inadequate 
absorption of iron, (3) an increase in iron absorption due to a higher bioavailability of heme and/or iron chelates, will alleviate anaemia in sole and (4) Hct and Hb levels, as sensitive indicators of recovery from iron depletion (Maage \& Sveier 1998), are expected to follow iron absorption patterns. In addition, we estimated the absorption of copper, cobalt, chromium, manganese, molybdenum and zinc, since it is known that there might be interaction (antagonism) between the iron sources and the absorption of other divalent minerals.

\section{Material and methods}

This experiment was approved by the ethical Committee for Animal Experiments and conducted at IMARES, Department of Aquaculture, Yerseke, The Netherlands.

\section{Experimental design, diets and preparation}

The experiment consisted of a 7-day acclimatisation and a 23-day experimental period. The experimental set-up contained four different diets with each diet having an equal iron content, yet a different source of iron. The iron sources tested were: iron sulphate heptahydrate $\left(\mathrm{Fe}\left(\mathrm{SO}_{4}\right) \cdot 7 \mathrm{H}_{2} \mathrm{O}\right)$, iron methionate, iron proteinate and haemoglobin. In all diets $64 \%$ of the dietary iron is supplied by the added test sources, the remaining $36 \%$ of the dietary iron was provided by the ingredients of the basal diet. The total dietary iron content was formulated to be equal to the iron content in ragworm (352 mg. $\mathrm{kg}^{-1} \cdot \mathrm{dm}$, Kals et al. $2015^{\mathrm{b}}$ ). This iron level is far above the iron requirements for fish (NRC, 2011) (table 3). Vitamin $\mathrm{B}_{12}$ is directly involved in erythropoiesis, the process which produces red blood cells (Koury \& Ponka 2004). Taurine can also affect the haematological parameters (Anand, Rajakumar, Felix \& Balasubramanian 2010; Sirdah, El-Agouza \& Abu Shahla 2002) as it is indirectly involved through the methylation pathway (Scott \& Weir 1981). Therefore, the diets were formulated to have an equal vitamin $B_{12}$ and taurine content at the level of $1.9 \mathrm{mg} . \mathrm{kg} \mathrm{dm}^{-1}$ and 7.6 g.kg.dm ${ }^{-1}$, respectively, which are the levels measured in ragworm (unpublished data). The diets were tested in triplicate, giving 12 experimental units with ten fish per tank, adding up to 120 fish in total. All diets were isonitrogenous, isoenergetic and equal in amino acid composition, total iron, calcium, phosphate, taurine and vitamin $\mathrm{B}_{12}$ content. Individual amino acids were added to compensate for the amino acid content of the iron sources, especially of the heme iron. The diets were prepared through cold extrusion in cooperation with Research Diet Services (RDS, Wijk bij Duurstede, The Netherlands). Cold extrusion was used to keep 
the iron sources, especially haemoglobin, in their undenatured state. Heme iron is sensitive to heat (Lombardi-Boccia, Martinez-Dominguez \& Aguzzi 2002).

Yttrium oxide was used as an inert marker for the determination of mineral absorption. All diets were treated with a ragworm extract $\left(8 \mathrm{~g} \mathrm{WW} \cdot \mathrm{kg}^{-1}\right.$ or $1.4 \mathrm{~g} \mathrm{dm} \mathrm{kg}^{-1}$ of feed) to guarantee sufficient feed intake. Extracts were produced by homogenizing cooled ragworms (Topsy Baits B.V., Wilhelminadorp, The Netherlands), using a blender. Homogenates were centrifuged (20min, 4500rpm) to remove solids. The extracts (the supernatant) obtained were diluted (8g extract WW. $\left.50 \mathrm{ml}^{-1}\right)$, using a physiological salt solution for proper spraying and ensuring an even distribution of extracts on the pellets. Treated pellets were dried for $24 \mathrm{~h}$ at room temperature before storage. Recipes and there composition are shown in table 6.1, 6.2 and 6.3.

\section{Fish housing and husbandry}

Common sole, (individual weight $220 \pm 45 \mathrm{~g}$ ) reared on commercial pellets within our own facilities and naïve to mussel and ragworm feeding, were accommodated in 12 tanks $(0.4$ $\left.\mathrm{m}^{2}, 1301\right)$ receiving a continuous flow of $41 \cdot \mathrm{min}^{-1} \cdot \operatorname{tank}^{-1}$ of fresh filtered seawater. Husbandry conditions were: photoperiod 12L:12D, light intensity $11-15$ lux, temperature $16.9 \pm 1.3^{\circ} \mathrm{C}$, oxygen $8.3 \pm 0.5$ mg. $1^{-1}, \mathrm{pH} 8.1 \pm 0.1$, total ammonia nitrogen (TAN) $0.3 \pm 0.2 \mathrm{mg} .1^{-1}, \mathrm{NO}_{2}{ }^{-}$ $0.01 \pm 0 \mathrm{mg} .1^{-1}$, salinity $25-30 \mathrm{ppt}$ and flow $4.5 \pm 0.51 . \mathrm{min}^{-1}$, which stayed within pre-set limits. Temperature and oxygen content were measured daily. Flow, $\mathrm{pH}$, TAN and $\mathrm{NO}_{2}{ }^{-}$, were measured weekly.

\section{Feeding}

Fish were fed by hand twice a day (8:30 and 16:30). Dry matter (dm) content of diets were analysed at the start of the experiment, in order to apply equal feeding levels on $\mathrm{dm}$ basis for all diets. Feeding level was restricted and set at $0.54 \mathrm{~g} . \mathrm{dm}$.fish.d ${ }^{-1}$, which is approximately $85 \%$ of the maximum feeding level of a $200 \mathrm{~g}$ sole (unpublished data). One hour after feeding, tanks were checked for uneaten feed. During acclimatization fish were fed commercial pellets ( $3 \mathrm{~mm}$, crude protein $63 \%$, ether extract $14 \%$, ash $12 \%$ ). 
Table 6.1: Diet formulations and inclusion level of different iron sources.

\begin{tabular}{|c|c|c|c|c|}
\hline Diet Code & $\mathbf{A}$ & B & $\mathrm{C}$ & D \\
\hline Iron source & Iron sulphate & Heme & Iron proteinate & Iron methionate \\
\hline Basal ingredients ${ }^{\ddagger \ddagger}(\%)$ & 57.2 & 57.2 & 57.2 & 57.2 \\
\hline \multicolumn{5}{|l|}{ Test ingredients (\%): } \\
\hline Caseine $^{\mathrm{a}}$ & 16.38 & 9.00 & 16.35 & 16.35 \\
\hline Pea protein conc. ${ }^{b}$ & 13.00 & 12.70 & 13.00 & 13.00 \\
\hline Corn gluten $^{\mathrm{d}}$ & 12.50 & 13.00 & 12.50 & 12.50 \\
\hline L-threonine ${ }^{e}$ & 0.35 & 0.40 & 0.35 & 0.35 \\
\hline DL-methionin ${ }^{\mathrm{f}}$ & 0.16 & 0.30 & 0.16 & 0.12 \\
\hline L-iso leucin ${ }^{\mathrm{g}}$ & 0.00 & 0.30 & 0.00 & 0.00 \\
\hline Corn $\operatorname{Starch}^{\mathrm{h}}$ & 0.27 & 0.86 & 0.28 & 0.34 \\
\hline Yttrium oxide $^{\mathrm{w}}$ & 0.02 & 0.02 & 0.02 & 0.02 \\
\hline \multicolumn{5}{|l|}{ Iron sources } \\
\hline Bovine Hemoglobin $^{1}$ & -- & 6.200 & -- & -- \\
\hline Iron sulfate hydrate $(20 \%)^{2}$ & 0.101 & -- & -- & -- \\
\hline Iron proteinate $^{3}$ & -- & -- & 0.127 & -- \\
\hline Iron methionate ${ }^{4}$ & -- & -- & -- & 0.106 \\
\hline Check & 100.00 & 100.00 & 100.00 & 100.00 \\
\hline
\end{tabular}

${ }^{*}$ Soy protein concentrate $12.5 \%$, Fish meal $11 \%$, Fish Oil $6 \%$, CPSP special Gk $5 \%$, Squid meal $4 \%$, Wheat gluten ${ }^{m} 5 \%$, Soyalecithin ${ }^{n}$ $0.6 \%$, Cholesterol $0.3 \%$, Premix (Iron \& $B_{12}$ free) $\uparrow 2 \%$, Binder $1^{p} 2 \%$, Binder $2^{q} 2 \%$, Salt, $2 \%$, MCP $1.5 \%$, Binder $3^{t} 1 \%, T M G^{u}, 1 \%$, Lucantin Pink ${ }^{v}, 0.5 \%$, Taurin ${ }^{x}, 0.626 \%$, Vitamin $B_{12}{ }^{y} 0.19 \%$. ${ }^{a}$ Acid casein 30/60 mesh, Lactalis, Bourgbarré, France, ${ }^{b}$ Roquette Freres, Lestrem, France, ${ }^{c}$ Soycomil R ADM Eurpoort BV, ${ }^{d}$ Cargill, The Netherlands, ${ }^{e}$ Ajinomoto Parijs France, ${ }^{,}$Sumitomo Tokyo Japan, ${ }^{g}$ Evonik, Hanau, Germany, ${ }^{h}$ Cgel C3401 Cargill, The Netherlands, ${ }^{i}$ Danish LT fishmeal. Type LT (Triple Nine Fish Protein Esbjerg, DK), ${ }^{j}$ Coppens International The Netherlands, ${ }^{k}$ Sopropeche Boulogne sur Mer, France, 'Sopropeche Boulogne sur Mer, France, ${ }^{m}$ Gluvital 21000 Cargill, The Netherlands, ${ }^{n}$ Nutripur G Cargill, Hamburg, Germany, ${ }^{\circ}$ Cholesterol SF van Dishman Netherlands BV, Veenendaal, ${ }^{p}$ Binder $1,{ }^{q}$ Binder 2 and 'Binder3; Ingredients are not specified because of confidentiality reasons of on-going research. ${ }^{r}$ Animalfeed salt van Kloek zout The

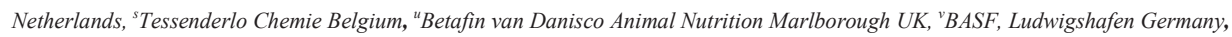
${ }^{{ }^{W}}$ Sigma Aldrich, USA, ${ }^{x}$ Taurin, ${ }^{y}$ vitamin $B_{12}$ (cyanocobalamin) Rosun, Krimpen a/d Ijssel The Netherlands, ${ }^{1}$ Bovine Hemoglobin (CAS $9008-$ 02-0) with batchnummer $081 M 7002 \mathrm{~V}$ (iron 0.31\% \& dm 97\%), Sigma-Aldrich, USA, ${ }^{2}$ Ferromel 30: Melspring International, Velp, NL, ${ }^{3}$ Buffermin $®$ Iron proteinate (IFN 6-26-150) JH Biotech, Inc. Ventura, CA, USA, ${ }^{4}$ Buffermin $\mathbb{B}$ Methionate, JH Biotech, Inc. Ventura, CA, USA.. 'Vitamins (mg or IU kg-1 diet): vitamin A (retinyl acetate); $2.7 \mathrm{mg}$, $9000 \mathrm{IU}$; vitamin D3 (cholecalciferol), $0.04 \mathrm{mg} 1700 \mathrm{IU}$; vitamin K3 (menadione sodium bisulfite), $10 \mathrm{mg}$; vitamin $B 1$ (thiamine), $10 \mathrm{mg}$; vitamin B2 (riboflavin), $20 \mathrm{mg}$; vitamin B6 (pyridoxine hydrochloride), $12 \mathrm{mg}$; folic acid, $10 \mathrm{mg}$; biotin, $0.7 \mathrm{mg}$; inositol, $800 \mathrm{mg}$; niacin, $70 \mathrm{mg}$; pantothenic acid, $30 \mathrm{mg}$, choline chloride, 1500 $\mathrm{mg}$; vitamin C, $500 \mathrm{mg}$; vitamin E, $300 \mathrm{mg}$; Minerals (g or mg $\mathrm{kg}^{-1}$ diet): Mn (manganese sulphate), $20 \mathrm{mg}$; I (potassium iodide), $1.5 \mathrm{mg} ; \mathrm{Cu}$ (copper sulphate), $5 \mathrm{mg}$; Co (cobalt sulphate), $2 \mathrm{mg}$; Cr (chromium sulphate), $2.6 \mathrm{mg} ; \mathrm{Mg}$ (magnesium sulphate), 500mg; $\mathrm{Zn}$ (zinc sulphate) $60 \mathrm{mg}$; Se (sodium selenite) $0.3 \mathrm{mg}$; BHT (E300-321) $100 \mathrm{mg}$; Calcium propionate $1000 \mathrm{mg}$. 
Effect of iron source on anaemia in sole

Table 6.2: Analysed proximate composition of diet formulations.

\begin{tabular}{lccccc}
\hline Iron source & & Iron sulphate & Heme & Iron proteinate & Iron methionate \\
\hline Analysed composition ${ }^{1}$ & Unit & & & & \\
\hline $\mathrm{DM}$ & $\left({\left.\mathrm{g} \cdot \mathrm{kg}^{-1}\right)}^{-1}\right.$ & 909 & 913 & 920 & 917 \\
\hline $\mathrm{ASH}$ & $\left(\mathrm{g} \cdot \mathrm{kg}^{-1} \cdot \mathrm{dm}\right)$ & 94 & 92 & 94 & 94 \\
\hline $\mathrm{CP}$ & $\left(\mathrm{g} \cdot \mathrm{kg}^{-1} \cdot \mathrm{dm}\right)$ & 661 & 655 & 669 & 661 \\
\hline $\mathrm{EE}$ & $\left(\mathrm{g} \cdot \mathrm{kg}^{-1} \cdot \mathrm{dm}\right)$ & 130 & 122 & 130 & 127 \\
\hline $\mathrm{CF}$ & $\left(\mathrm{g} \cdot \mathrm{kg}^{-1} \cdot \mathrm{dm}\right)$ & 6.6 & 6.6 & 5.4 & 5.5 \\
\hline $\mathrm{NFE}$ & $\left(\mathrm{g} \cdot \mathrm{kg}^{-1} \cdot \mathrm{dm}\right)$ & 17.9 & 37.9 & 22.2 & 30.4 \\
\hline $\mathrm{Check}$ & ---- & 909 & 913 & 920 & 917 \\
\hline $\mathrm{GE}$ & $\left(\mathrm{MJ} \cdot \mathrm{kg}^{-1}\right)$ & 21.2 & 21.1 & 21.5 & 21.3 \\
\hline $\mathrm{CP} / \mathrm{GE}$ & ----- & 31.1 & 31.0 & 31.1 & 31.0 \\
\hline${ }^{1} \mathrm{DM}=$ Dry matter, ASH=Ash, $\mathrm{CP}=\mathrm{Crude}$ Protein, EE=Ether extract, CF=Crude Fibre, NFE=Nitrogen Free Extract, GE=Gross Energy.
\end{tabular}

Table 6 3: Analysed minerals and vitamin $B_{12}$ of diet formulations.

\begin{tabular}{lccccc}
\hline Iron source & & Iron sulphate & Heme & Iron proteinate & Iron methionate \\
\hline Analysed composition & & & & & \\
\hline Vitamin $\mathrm{B}_{12}$ & $\left(\mathrm{ug} \cdot \mathrm{kg}^{-1} \cdot \mathrm{dm}\right)$ & 1254 & 1150 & 959 & 1075 \\
\hline Iron & $\left(\mathrm{mg} \cdot \mathrm{kg}^{-1} \cdot \mathrm{dm}\right)$ & 355 & 323 & 299 & 349 \\
\hline Calcium & $\left(\mathrm{g} \cdot \mathrm{kg}^{-1} \cdot \mathrm{dm}\right)$ & 8 & 8 & 8 & 8 \\
\hline Sodium & $\left(\mathrm{g}^{-1} \mathrm{~kg}^{-1} \cdot \mathrm{dm}\right)$ & 19 & 19 & 19 & 19 \\
\hline Potassium & $\left(\mathrm{g} \cdot \mathrm{kg}^{-1} \cdot \mathrm{dm}\right)$ & 6 & 6 & 6 & 6 \\
\hline Magnesium & $\left(\mathrm{g} \cdot \mathrm{kg}^{-1} \cdot \mathrm{dm}\right)$ & 2 & 2 & 2 & 2 \\
\hline Copper & $\left(\mathrm{mg} \cdot \mathrm{kg}^{-1} \cdot \mathrm{dm}\right)$ & 12 & 12 & 12 & 12 \\
\hline Cobalt & $\left(\mathrm{mg} \cdot \mathrm{kg}^{-1} \cdot \mathrm{dm}\right)$ & 2 & 2 & 2 & 2 \\
\hline Chromium & $\left(\mathrm{mg} \cdot \mathrm{kg}^{-1} \cdot \mathrm{dm}\right)$ & 5 & 5 & 4 & 5 \\
\hline Manganese & $\left(\mathrm{mg} \cdot \mathrm{kg}^{-1} \cdot \mathrm{dm}\right)$ & 36 & 35 & 38 & 38 \\
\hline Molybdenum & $\left(\mathrm{mg} \cdot \mathrm{kg}^{-1} \cdot \mathrm{dm}\right)$ & 1 & 1 & 1 & 1 \\
\hline Zinc & $\left(\mathrm{mg} \cdot \mathrm{kg}^{-1} \cdot \mathrm{dm}\right)$ & 119 & 115 & 121 & 120 \\
\hline
\end{tabular}

Sampling, analysis and calculations

At the end of the experiment, all ten fish of each tank were sacrificed using an overdose of phenoxy ethanol (1:1000). In addition, 30 fish were sacrificed at the start of the experiment. After weighing, fish were sampled for faeces $(n=7)$, liver $(n=5)$ and blood $(n=10)$. Faeces was collected six hours after the last feeding period of each tank. Therefore, the tanks were sequentially fed during the last feeding period. All tanks were sampled in one day in the same sequence as their fish had been fed during the last feeding period.

Blood was obtained by caudal venous puncture, using a heparinized syringe $(0.6 \mathrm{~mm} / 30 \mathrm{~mm}$ needle). Blood samples were transferred into tubes and stored on ice and 
processed within approximately 15 minutes. The Hct levels were determined by using capillaries and a Hct centrifuge (SpinCrit microhematocrit centrifuge, Brown, Indianapolis, US) to centrifuge for 5 minutes at 11,000 rpm or $5000 \mathrm{~g}$. The $\mathrm{Hb}$ levels were determined using the haemiglobincyanide method described by van Kampen \& Zijlstra (1961). Faeces samples were frozen at $-80^{\circ} \mathrm{C}$ for further analysis. Apparent absorption coefficients (AAC's) of the minerals copper $(\mathrm{Cu})$, iron $(\mathrm{Fe})$, manganese $(\mathrm{Mn})$, zinc $(\mathrm{Zn})$, cobalt $(\mathrm{Co})$, chromium $(\mathrm{Cr})$ and molybdenum (Mo) were calculated using the following formula:

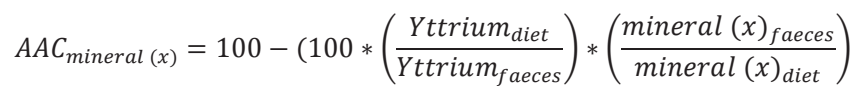

With:

AAC $=$ Apparent absorption coefficient

Yttrium diet $=$ Yttrium concentration in the diet

Yttrium faeces $=$ Yttrium concentration in the faeces

Mineral $(\mathrm{x})$ faeces $=$ concentration of mineral $(\mathrm{x})$ in faeces

Mineral $(\mathrm{x})$ diet $\quad=$ concentration of mineral $(\mathrm{x})$ in $\operatorname{diet}$

The diets were analysed for proximate composition by Nutrilab BV, Rijswijk, The

Netherlands. Yttrium and minerals of both faeces and diet samples were analysed by the Chemical Biological Soil Laboratory (CBLB), Wageningen, The Netherlands, using ICP-EAS for $\mathrm{Cu}, \mathrm{Fe}, \mathrm{Mn}, \mathrm{Zn}$ (Varian Vista pro radial, Agilent Technologies Inc., Santa Clara, CA USA) according to guidelines NPR-6425 and NEN-6966 and using ICP-MS for Co and Mo (Element2, Thermo Fisher Scientific, Inc., Waltham, MA USA) according to guidelines NENEN-ISO 17294-1 and 17294-2).

\section{Statistical analysis}

Data were analysed for the effect of iron source using one way ANOVA.

Homogeneity was tested using the Levene's test. If necessary, data were transformed or tested using the Kruskal Wallis test. The tank was used as the experimental unit. For all tests a probability $\mathrm{p}<0.05$ has been considered significant. When significant, means were compared using the Fishers LSD post hoc test. 


\section{Results}

\section{General aspects of the experiment}

No mortality occurred and no feed refusal and spillage was observed during the experimental period. Therefore, the feed intake $\left(0.54\right.$ g.dm.fish $\left.{ }^{-1} \cdot \mathrm{d}^{-1}\right)$ was identical for all diets. At the end of the experiment a mistake was found, as one tank was stocked with 11 fish. Since the feed intake (i.e. Fe intake) was restricted and equal for all tanks, we decided to exclude this tank from the analyses of $\mathrm{Hct}, \mathrm{Hb}$ and the hepatosomatic index (HSI), all three being long term effect parameters. A data analysis carried out including all tanks, however, revealed that the final results would not lead to major differences. We did include the tank for the analysis of the apparent absorption coefficients (AAC's), as the AAC is relative and represents only a momentarily estimation.

\section{Source of iron}

Sole, which had been reared on commercial pellets had an average Hct level, Hb level and HSI of $12.5 \%, 19.6$ g. $1^{-1}$ and $1.13 \%$ respectively, at the start of the experiment (table 6.4 ). The respective values at the end of the experiment did not differ from the starting values $(p>0.05)$. Moreover, none of the parameters were affected by the source of iron $(p>0.05$; table 6.4).

Table 6.4. Effect of iron source on haematocrit (Hct), haemoglobin (Hb), the hepatosomatic index (HSI) and their standard deviation.

\begin{tabular}{|c|c|c|c|c|}
\hline Diet & Iron Source & Het (\%) & $\mathrm{Hb}\left(\mathrm{g} . \mathrm{l}^{-1}\right)$ & HSI (\%) \\
\hline Start t $(0)$ & -- -- & $12.5 \pm 3.2$ & $19.6 \pm 8.1$ & $1.13 \pm 0.27$ \\
\hline $\mathbf{A}$ & Mineral iron ${ }^{1}$ & $13.1 \pm 0.1$ & $20.6 \pm 0.4$ & $1.18 \pm 0.03$ \\
\hline B & Heme iron $^{2}$ & $13.5 \pm 0.6$ & $21.3 \pm 1.6$ & $1.29 \pm 0.36$ \\
\hline $\mathrm{C}$ & Iron proteinate $^{3}$ & $13.2 \pm 0.3$ & $21.3 \pm 1.3$ & $1.28 \pm 0.06$ \\
\hline D & Iron methionate 4 & $13.8 \pm 1.9$ & $21.1 \pm 4.2$ & $1.23 \pm 0.11$ \\
\hline$P$ value & -- & 0.93 & 0.99 & 0.89 \\
\hline
\end{tabular}




\section{Mineral absorption}

The AAC's of iron, manganese, zinc, cobalt, chromium and molybdenum in sole were not affected by the iron source (table 6.5). However, the AAC of copper was affected by the diet and was $15-22 \%$ higher in sole fed the diet with heme as iron source (table 6.5, $\mathrm{p}<0.05$ ).

Table 6.5: The apparent absorption coefficients ( $A A C$ 's) of $\mathrm{Cu}, \mathrm{Fe}, \mathrm{Mn}, \mathrm{Zn}, \mathrm{Co}, \mathrm{Cr}$ and Mo in sole fed diets with different iron sources.

\begin{tabular}{|c|c|c|c|c|c|c|c|c|}
\hline \multicolumn{9}{|c|}{ Apparent absorption coefficient (\%) } \\
\hline Diet & Source & $\mathrm{Cu}$ & $\mathrm{Fe}$ & Mn & Zn & Co & $\mathrm{Cr}$ & Mo \\
\hline $\mathbf{A}$ & $\mathrm{Fe}\left(\mathrm{SO}_{4}\right)$ & $1.4 \pm 3.8^{\mathrm{a}}$ & $17.8 \pm 1.2$ & $24.1 \pm 5.0$ & $14.8 \pm 2.7$ & $14.9 \pm 8.9$ & $18.4 \pm 7.2$ & $-7.1 \pm 8.2$ \\
\hline B & Heme & $22.3 \pm 3.2^{b}$ & $13.9 \pm 5.9$ & $14.0 \pm 11.5$ & $8.0 \pm 2.4$ & $10.8 \pm 2.7$ & $17.3 \pm 6.6$ & $-1.7 \pm 8.7$ \\
\hline $\mathrm{C}$ & Iron proteinate & $6.8 \pm 2.0^{\mathrm{a}}$ & $15.2 \pm 11.0$ & $23.2 \pm 4.1$ & $13.5 \pm 3.0$ & $17.6 \pm 10.8$ & $11.7 \pm 4.4$ & $-7.4 \pm 6.5$ \\
\hline D & Iron methionate & $-0.0 \pm 5.3^{\mathrm{a}}$ & $13.8 \pm 1.0$ & $25.9 \pm 4.7$ & $11.4 \pm 5.9$ & $23.4 \pm 12.0$ & $17.2 \pm 8.0$ & $-4.2 \pm 2.2$ \\
\hline p-value & -- & 0.00 & 0.56 & 0.24 & 0.22 & 0.43 & 0.63 & 0.74 \\
\hline
\end{tabular}

abc: Means with different superscripts are significantly different $(P<0.05)$.

\section{Discussion}

In this experiment the iron absorption, varied from 13.8-17.8\% (table 6.5). As far as we know, hitherto no other studies have determined the absorption of dietary iron in sole. Hence, we have no literature data to compare with. In general, the absorption efficiency of iron in fish is relatively low (Bury \& Grosell 2003). Storebakken, Shearer, Baeverfjord, Nielsen, Asgard, Scott \& De Laporte (2000) found AAC's of iron in Salmon (Salmo Salar) living in salt water ranging from 10.6 to $14.2 \%$. In African catfish (Clarias gariepinus), iron absorption varied from $-35.8 \%$ to $13.6 \%$ (Leenhouwers, ter Veld, Verreth \& Schrama 2007). In trout (Oncorhynchus mykiss) the AAC of iron, while using diets high in soybean meal, was extremely negative, even with phytase supplementation (Wang, Yang, Han, Dong, Yang \& Zou 2009).

Normally, intestinal $\mathrm{Fe}^{2+}$ uptake is higher in fish with a low iron status (i.e. anaemic condition). Bury et al. (2003) found a strong negative correlation between Hct and iron absorption in Flounder (Platichthys flesus). Standal, Dehli, Rorvik \& Andersen (1999) determined iron absorption levels of $10 \%, 5 \%$ and $1 \%$ for Atlantic salmon with a low iron status, normal iron status and iron overloaded status, respectively. Yet, in this study, despite the high absorption of iron in sole, the fish stayed anaemic independent of the iron source (table 6.4). Moreover, the Hct and $\mathrm{Hb}$ values are far lower than the values achieved with ragworm (Kals et al. 2015 ) or mussel (Kals et al. 2015 b). Apparently the sole could not utilize the absorbed iron for stimulating erythropoiesis. Normally, in iron depleted fish, $\mathrm{Hb}$ is 
a good indicator for the difference in bioavailability, respectively the absorption of iron between the iron sources (Andersen et al. 1997; Maage \& Sveier 1998). Yet, in this experiment we found no difference in iron absorption as well as in the Hct and Hb values between the sources (table 6.5). This implies that sole, which suffer from a nutritional anemia, do not suffer from an iron deficiency anaemia. This supports the conclusion of our previous study (Kals et al. submitted). We expected that the alkaline character of the sole's intestine (Clark et al. 1985; Yúfera \& Darías 2007) would negatively affect the sole's ability to absorb non heme iron. Yet, iron absorption on itself in relation to the iron source seems not a limiting factor.

In contrast to the absorption of non heme iron, the absorption of heme iron is hardly influenced by the iron status of the animal (Andersen et al. 1997; Bothwell 1995; Forbes \& Erdman 1983; Standal et al. 1999). During a low iron status (i.e. anaemia), hepcidin, the major regulator of iron homeostasis, is down regulated (Kals et al. submitted; Kemna, Tjalsma, Willems \& Swinkels 2008; Kreamer and Zimmermann 2007; Muñoz, Villar \& García-Erce 2009), which stimulates the absorption of non heme iron (Ganz 2005), but not the absorption of heme iron. Therefore, the down regulation of hepcidin in common sole (Kals et al. submitted) with low Hct levels might explain why the absorption of heme iron in this experiment is comparable to the absorption of the non heme iron sources tested. Normally, absorption of heme iron is higher than that of non heme iron and ranges from 15 to $20 \%$ (Standal et al. 1999). In this experiment the iron absorption was high for all sources tested. Therefore, our first two hypotheses that the nutritional anaemia in sole fed commercial pellets is due to an iron deficiency anaemia, caused by an inadequate absorption of dietary iron, have to be rejected. Moreover, our third hypothesis, that an increase in iron absorption due to a higher bioavailability of heme and/or iron chelates will alleviate anaemia in sole, has to also be rejected as no significant differences in absorption of iron between sources were observed and the fish stayed anaemic, independent of the iron source. Consequently, our fourth hypothesis that the Hct and Hb levels, as sensitive indicators of a recovery from iron depletion, follow iron absorption patterns could not be tested.

In this study, none of the AAC's of the other minerals analysed, except those of copper, were affected by the source of iron (table 6.5). Interesting is that both, none heme iron and copper, need the divalent metal transporter protein 1 (DMT1) to be absorbed from the lumen into the enterocyte (Arredondo \& Núñez 2005; Kramer \& Zimmerman 2007; Kwong \& Niyogi 2009). When dietary iron is mainly available as heme, copper has no, or less, competition from non heme iron using DMT1 to get absorbed. Heme is absorbed directly via 
the specific heme carrier protein 1 (HCP1), not claiming DMT 1 capacity. Hence, the positive effect of heme iron on copper absorption can be explained by a reduced competitive binding of copper and non heme iron, both claiming DMT1 to get absorbed.

Copper has a crucial function in the transport of iron from the enterocyte to the blood. Hephaestin, a transmembrane copper-dependent ferroxidase, represents a link between copper and iron metabolism and explains an iron deficiency anaemia associated with a copper deficiency (Vulpe, Kuo, Murphy, Cowley, Askwith, Libina, Gitschier \& Anderson 1999). Without copper, iron transport from the enterocyte towards the blood is blocked. In the current experiment the absorption of copper is higher in sole fed heme, yet Hct and $\mathrm{Hb}$ did not respond (table 6.4 and 6.5). This probably indicates that the nutritional anaemia in sole is not a copper deficiency anaemia either.

Peculiar are the negative ADC's of Molybdenum, yet not different between treatments $(\mathrm{p}>0.10)$ and not different from zero $(\mathrm{p}>0.10)$. Trace elements like Molybdenum often provide negative ADC's (Ward, Carter \& Townsend 2005), which is most likely a result from the relatively high presence of Molybdenum in seawater $( \pm 100 \mathrm{nM}$ in seawater versus $\pm 5 \mathrm{nM}$ in continental water (Schwarz \& Belaidi 2013) and the fact that marine fish must drink to keep their water balance in order.

\section{Conclusions}

Iron absorption in sole is high and independent of the iron source. The use of different iron sources, including heme, does not affect the iron absorption neither the Hct and $\mathrm{Hb}$ values in anaemic sole. However, heme does increase the absorption of copper. The high absorption of iron and copper in sole fed heme does not affect the Hct and $\mathrm{Hb}$ values, which indicates that the nutritional anaemia in sole is not an iron or a copper deficiency anaemia. Thus, one or more other dietary components than iron or copper, which are present in mussel and ragworm but not in the formulated diets, are involved in the alleviation of anaemia in sole.

\section{Disclosure statement}

A patent application covering the use of Annelida and Mollusca in fish feed has been filed in 2012. 


\section{Acknowledgements}

The authors thank Y. van Es, A. Hofman and N. Ros for their help and caretaking of the experimental animals during the experiment. This work was financially supported by IMARES. 


\section{References}

Anand P., Rajakumar D., Felix A.J. \& Balasubramanian, T. (2010). Effects of oral administration of antioxidant taurine on haematological parameters in Wistar rats. Pak. Journal of Biological Sciences. 13, 785-793.

Andersen F., Lorentzen M., Waagbø R. \& Maage, A. (1997). Bioavailability of different forms of iron in Atlantic salmon (Salmo salar) smolt. Aquaculture Nutrition. 3, 239-246.

Arredondo M. \& Núñez M.T. (2005). Iron and copper metabolism. Molecular Aspects of Medicine 26, 313-327. Bothwell T.H., (1995). Overview and Mechanisms of Iron Regulation. Nutrition Research. 53, $237-245$.

Bury N.R., Walker P.A. \& Glover C.N. (2003). Nutritive metal uptake in teleost fish. The Journal of Experimental Biology. 206, 11-23.

Bury N.R. \& Grosell M. (2003). Iron acquisition by teleost fish. Comparative Biochemistry and Physiology C 135, 197-105.

Clark J., MacDonald N.L., Stark \& J.R. (1985). Metabolism in marine flatfish. II. Protein digestion in Dover sole (Solea solea L.). Comparative Biochemistry and Physiology. 81B, 217-222.

Ende S.S.W., Kroeckel S., Schrama J.W., Schneider O. \& Verreth, J.A.J. (2014). Feed intake, growth, and nutrient retention of common sole (Solea, solea L.) fed natural pray and an artificial feed. Aquaculture Research. doi: 10.1111/are.12526.

Forbes R.M. \& Erdman J.W. (1983). Bioavailability of Trace Mineral Elements. Annual Review of Nutrition 3, 213-231

Gallaugher P. \& Farrell A.P. (1998). Haematocrit and blood oxygen carrying capacity. In: Fish Physiology, vol. 17. Fish respiration. (Eds. Perry, S.F. \& Tufts, B.), pp. 185-219. Academic Press, New York.

Ganz T. (2005). Cellular iron: ferroportin is the only way out. Cell Metabolism. 1, 155-157

Kals J., Blonk R.J.W., Mheen H.W. van der, Schrama J.W. \& Verreth J.A.J. (2015 ${ }^{\mathrm{a}}$ ). Feeding ragworm (Nereis virens Sars) increases haematocrit and haemoglobin levels in common sole (Solea solea L.). Aquaculture Research DOI: 10.1111/are.12767.

Kals J., Blonk R.J.W., Mheen H.W. van der, Schrama J.W. \& Verreth J.A.J. (2015 b). Mussel (Mytilus edulis L.) and ragworm (Nereis virens, Sars) both alleviate anaemia in common sole (Solea solea L.). Aquaculture Research doi: 10.1111/are.12871

Kemna E.H.J.M., Tjalsma H., Willems H.L. \& Swinkels D.W. (2008). Hepcidin: from discovery to differential diagnosis. Haematologica. 93, 90-97.

Koury M.J. \& Ponka P. (2004). New insights into erythropoiesis: The Roles of Folate, Vitamin B12, and Iron. Annual Review of Nutrition 24, 105-131.

Kraemer K. \& Zimmermann M.B. (2007). Nutritional anemia. SIGHT AND LIFE Press. c/o SIGHT AND LIFE / DSM. Nutritional Products Ltd. Internet: www.sightandlife.org 400pp.

Kwong R.W.M. \& Niyogi, S. (2008). An in vitro examination of intestinal iron absorption in a freshwater teleost, rainbow trout (Oncorhynchus mykiss). Journal of Comparative Physiology B. 178, 963-975.

Kwong R.W.M. \& Niyogi S. (2009). The interactions of iron with other divalent metals in the intestinal tract of a fresh water teleost, rainbow trout (Oncorhynchus mykiss). Comparative Biochemistry and Physiology C. 150, 442-449.

Lydyard P.M., Cole M.F., Holton J., Irving W.L., Porakishvili N., Venkatesan P. \& Ward N.K. (2010). Case studies in infectious disease. 609 pp. Garland Science, Taylor and Francis Group, New York and London.

Latham M.C. (1997). Human Nutrition in the Developing World 1997. Food and Agriculture Organization of the United Nations Rome, Italy.

Leenhouwers J.I., ter Veld M., Verreth J.A.J. \& Schrama J.W. (2007). Digesta characteristics and performance of African catfish (Clarias gariepinus) fed cereal grains that differ in viscosity. Aquaculture. 264, 330341 .

Lombardi-Boccia G., Martinez-Dominguez B. \& Aguzzi A. (2002). Total Heme and Non-heme Iron in Raw and Cooked Meats. Journal of Food Science. 67, 1738-1741.

Maage A. \& Sveier H. (1998). Addition of dietary iron(III) oxide does not increase iron status of growing Atlantic salmon. Aquaculture. International. 6, 249-252.

Miret S., Simpson R.J. \& McKie A.T. (2003). Physiology and molecular biology of dietary iron absorption. Annual Review of Nutrition 23,283-301.

Muñoz M., Villar I. \& García-Erce J.A. (2009). An update on iron physiology. World Journal of Gastroenterology. 15, 4617-4626.

NRC (2011). Nutrient requirements of Fish and Shrimp, Committee on Nutrient requirements of Fish and Shrimp, National Research Council. National Academies Press, Washington, D.C. 2011, 376pp. 
Palstra A.P., Blok M.C., Kals J., Blom E., Tuinhof-Koelma N., Dirks R.P., Forlenza M. \& Blonk R.J.W. (2015). In- and outdoor reproduction of first generation common sole Solea solea under a natural photothermal regime: temporal progression of sexual maturation assessed by monitoring plasma steroids and gonadotropin mRNA expression. General and Comparative Endocrinology doi:10.1016/j.ygcen.2014.12.004

Park F.P. \& Harmston K.J. (1994). Judging organic trace minerals, Feed Management. 45, 35-38

Scott J.M. \& Wier D.G. (1981). The methyl folate trap. The Lancet. 337-340.

Sirdah M.M., El-Agouza I.M.A. \& Abu Shahla, A.N.K. (2002). Possible ameliorative effect of taurine in the treatment of iron-deficiency anaemia in female university students of Gaza, Palestine. European Journal of Haematology 69. 236-242

Standal H., Dehli A., Rorvik K.A. \& Andersen Ø. (1999). Iron status and dietary levels of iron affect the bioavailability of haem and nonhaem iron in Atlantic Salmon Salmo salar. Aquaculture Nutrition 5, 193-198.

Storebakken T., Shearer K.D., Baeverfjord G., Nielsen B.G., Asgard T., Scott T. \& De Laporte A. (2000). Digestibility of macronutrients, energy, and amino acids, absorption, of elements, and absence of intestinal enteritis in Atlantic Salmon, Salmo salar, fed diets with wheat gluten. Aquaculture. 184, 115 132.

Sugiura S.H., Dong F.M. \& Rathbone C.K. (1998). Apparent protein digestibility and mineral availabilities in various feed ingredients for salmonid feeds. Aquaculture 159, 177-202.

Schwarz G. \& Belaidi A.A. (2013). Molybdenum in Human Health and Disease. In Sigel, A., Sigel, H., Sigel, R.K.O. (eds.), Interrelations between Essential Metal Ions and Human Diseases. doi 10.1007/978-94007-7500-8 Springer Dordrecht Heidelberg New York London, pp 415-450.

Thrall M.A.,Weiser G., Allison R.W. \& Campbell T.W. (2012). Veterinary Hematology and Clinical Chemistry. 2nd ed. 792 pp. Wiley-Blackwell Oxford, UK.

Yúfera M. \& Darías M.J. (2007). Changes in the gastrointestinal pH from larvae to adult in Senegal sole (Solea senegalensis). Aquaculture 267, 94-99.

van Kampen E.J. \& Zijlstra W.G., (1961) Standardization of hemoglobinometry II. The hemiglobincyanide method. Clinica Chimica Acta 6, 538-544.

Vinogradov S.N., Sharma P.K. \& Walz D.A. (1991). Iron and heme contents of the extracellular hemoglobins and chlorocruorins of Annelids. Comparative Biochemistry and Physiology B 98,187-194.

Vulpe C.D., Kuo Y.M, Murphy T.L., Cowley L., Askwith C., Libina N., Gitschier J. \& Anderson G.J. (1999). Hephaestin, a ceruplasmin homologue implicated in intestional iron transport, is defective in the sla mouse. Nature Genetics. 21, 195-199.

Wang F., Yang Y.H., Han Z.Z., Dong H.W., Yang C.H. \& Zou Z.Y. (2009). Effects of phytase pre-treatment soybean meal and phytase-sprayed in diets on growth, apparent, digestibility coefficient and nutrient excretion of rainbow trout (Oncorhynchus mykiss, Walbaum). Aquaculture International. 17, 143-157.

Ward A.D., Carter C.G. \& Townsend, A.T. (2005). The use of yttrium oxide and the effect of faecal collection timing for determining the apparent digestibility of minerals and trace elements in Atlantic salmon (Salmo salar, L.) feeds. Aquaculture Nutrition 11; 49-59.

Wood C.M., McMahon B.R. \& McDonald D.G. (1979). Respiratory, ventilatory, and cardiovascular responses to experimental anaemia in the starry flounder, Platichthys stellatus. Journal of Experimental. Biology $\mathbf{8 2}$, 139-162. 


\section{Chapter 7}

Effect of vitamin $B_{12}$ and taurine on the alleviation of nutritional anaemia in common sole, (Solea, solea L.)

Jeroen Kals

Robbert J.W. Blonk

Henk W. van der Mheen

Johan W. Schrama

Johan A.J. Verreth 


\begin{abstract}
Sole fed commercial pellets develop a nutritional anaemia. This study assessed the impact of dietary $\mathrm{B}_{12}$ and taurine supplementation on the haematocrit (Hct) and haemoglobin $(\mathrm{Hb})$ level and mineral absorption in anaemic sole.

During a 23-day experimental period, anaemic sole were fed one of four diets. Diets were equal regarding mineral, amino acid, and macronutrient composition and were formulated, according to a two by two factorial design: two $\mathrm{B}_{12}$ and two taurine levels. The feeding level was restricted and the amount fed per fish was equal for all diets.

$\mathrm{Hct}$ and $\mathrm{Hb}$ levels in anaemic sole are influenced by dietary $\mathrm{B}_{12}$. A "high" dietary level of $\mathrm{B}_{12}$ increases the Hct and $\mathrm{Hb}$ level with $\pm 20 \%$. An increasing level of dietary taurine suppresses the stimulating effect of the "high" dietary level of $\mathrm{B}_{12}$. The applied $\mathrm{B}_{12}$, as well as taurine levels, were unable to completely alleviate the nutritional anaemia in sole.

Nevertheless, the first hypothesis that sole needs high dietary levels of $\mathrm{B}_{12}$ to alleviate anaemia cannot be rejected and the second hypothesis that there is interaction between dietary taurine and $\mathrm{B}_{12}$, which affect Hct and $\mathrm{Hb}$ levels is confirmed for haemoglobin. The impact of $\mathrm{B}_{12}$ and taurine on $\mathrm{Hb}$ and $\mathrm{Hct}$ were not related to a change in the apparent absorption coefficient of iron. $\mathrm{B}_{12}$ and taurine affected the absorption of some covalent minerals in sole. Possibly, these changes are related to the changes in $\mathrm{Hct}$ and $\mathrm{Hb}$, yet the mechanism is not clear.
\end{abstract}

Keywords: Sole, (Solea, solea L.); anemia; hematocrit; hemoglobin; $B_{12}$; taurine. 


\section{Introduction}

Common sole (Solea, solea L.) fed commercial pellets develop a nutritional anaemia (Kals, Blonk, Palstra, Sobotta, Mongile, Schneider, Planas, Schrama \& Verreth $2015^{\mathrm{d}}$ ). Feeding ragworm (Nereis virens Sars) or mussel (Mytilus edulis L.) alleviates this anaemia within 23 days (Kals, Blonk, Mheen van der, Schrama \& Verreth 2015 a; Kals, Blonk, Mheen van der, Schrama \& Verreth $2015^{\mathrm{b}}$ ). This suggests that components important for the recovery of anaemia are present in ragworm and mussel, yet are missing in current commercial pellets.

Anaemia is strictly defined as a decrease in red blood cell mass (Lydyard, Cole, Holton, Irving, Porakishvili, Venkatesan \& Ward 2010) and, according to Thrall, Weiser, Allison and Campbell (2012), fish are anaemic when Hct levels are $<20 \%$. According to Wood, McMahon and McDonald (1979), the normal Hct level of flounder (Platichthys stellatus Pallas) is $\pm 25 \%$. They diagnosed flounders with Het levels around $8 \%$ as moderate anaemic and flounders with Hct levels $<5 \%$ as severely anaemic. Data for Hct and/or $\mathrm{Hb}$ levels in common sole are scarce. Yet, sole grown on natural food in outdoor ponds (Zeeuwse Tong, Colijnsplaat, The Netherlands) showed Hct levels of $20 \pm 2 \%$ for males and $22 \pm 1 \%$ for females (Palstra, Blok, Kals, Blom, Tuinhof-Koelma, Dirks, Forlenza \& Blonk 2015), being approximately twice as high as in sole fed commercial pellets (Kals et al. 2015 ; Kals et al. $2015^{\mathrm{b}}$ ). Following the criteria of Thrall et al. (2012), the data of Wood et al. (1979), Palstra et al. (2015) and the fact that within a fish species the range of Hct levels for normocythemia tend to be relatively narrow (Gallaugher \& Farrell 1998), Hct and Hb levels in common sole fed commercial pellets indicate a moderate (nutritional) anaemia.

Many nutritional factors can induce a nutritional anaemia (Kraemer \& Zimmermann 2007). Yet, a vitamin $B_{12}$ deficiency could be an obvious factor responsible for the nutritional anaemia observed in sole fed commercial pellets. $B_{12}$ is essential for erythropoiesis (Koury \& Ponka 2004), the process which produces red blood cells. The high levels of $B_{12}$ in ragworm (1134 to $3033 \mu \mathrm{g} \mathrm{kg}^{-1} \mathrm{dm}$ ) and in mussel (1671 $\mu \mathrm{g} \mathrm{kg}^{-1} \mathrm{dm}$ ) (Kals et al. 2015 ${ }^{\mathrm{b}}$ ) may explain the ability of these diets to alleviate anaemia in sole. Consequently, mussel and ragworm are comparable in having high levels of $\mathrm{B}_{12}$, which are four times higher than the levels in the commercial pellet, and 20 to 100 times higher than the amount of $\mathrm{B}_{12}$ present in a general premix and the values mentioned as requirements for fish (NRC 2011).

Uptake of $\mathrm{B}_{12}$ occurs via an active and/or passive process i.e. absorption or diffusion, respectively. In Kals et al. $2015^{\mathrm{b}}$ we discussed that $\mathrm{B}_{12}$ absorption depends on a low $\mathrm{pH}$ and pepsin like activity in the stomach (Pawlak, James, Raj, Cullum-Dugan \& Lucus 2012; 
Nielsen, Rasmussen, Andersen, Nexø \& Moestrup 2012). Sole lacks this pre-digestion in the stomach, has a low pepsin like activity and its intestine has an alkaline character (Clark, MacDonald \& Stark 1985; Lagardere 1987; Yúfera \& Darías 2007). We therefore infer that $\mathrm{B}_{12}$ absorption in sole is limited and do suggest that sole depends on the passive process of $\mathrm{B}_{12}$ diffusion. Since only $1 \%$ of the available $\mathrm{B}_{12}$ is absorbed through this process (Pawlak et al. 2012), sole may need high dietary levels of $\mathrm{B}_{12}$. In nature, common sole is a polychaetemollusc feeder (De Groot, 1971) with a limited variety of prey and high feeding specialization (Sa, Bexiga, Vieira, Veiga \& Erzini 2003). Polychaeta (e.g. ragworm) and mollusca (e.g. mussel) is their main natural food. From an evolutionary perspective it seems reasonable to assume that the dietary requirements of sole match the nutrients provided by their natural food organisms (e.g. ragworm and mussel). As both ragworm and mussel contain high levels of $\mathrm{B}_{12}$ (Kals et al. $2015^{\mathrm{b}}$ ), we hypothesized that sole needs high dietary levels of $\mathrm{B}_{12}$ to alleviate or prevent anaemia, which is the first hypothesis of this study.

Taurine is required for many fish species, especially marine teleost's, including flatfish species like Japanese flounder Paralichthys olivaceous L., and Senegalese sole, Solea senegalensis (Kaup, 1858) (Salze \& Davis 2015). The requirement of taurine for sole is, as far as we know, hitherto unknown. A deficiency of taurine can affect Hct and Hb levels (Salze \& Davis 2015; Anand, Rajakumar, Felix \& Balasubramanian 2010; Takagi, Murata, Goto, Hayashi, Hatate, Endo, Yamashita \& Ukawa 2006; Sirdah, El-Agouza \& Abu Shahla 2002). Ragworm contains $\pm 7 \mathrm{~g} \mathrm{~kg}^{-1} \mathrm{dm}$ (own analysis), mussel contains $\pm 25 \mathrm{~g} \mathrm{~kg}^{-1} \mathrm{dm}$ (Spitze, Wong, Rogers \& Fascetti 2003) and the commercial pellet $\pm 3.5 \mathrm{~g} \mathrm{~kg}^{-1} \mathrm{dm}$ (own analysis), of taurine. Humans suffering from pernicious anaemia, a type of $\mathrm{B}_{12}$ deficiency anaemia, often have taurinuria as a result of methionine being catabolised to taurine. Concomitant with this, the activity of the enzyme methionine synthetase, which is essential for the recycling of homocystein into methionine, is also reduced (Scott \& Weir 1981). Treatment with $B_{12}$ stimulates the recycling of methionine (Scott \& Weir 1981). The link between taurine and $B_{12}$ and the fact that taurine can affect Hct and Hb levels makes taurine a co-factor. The second hypothesis of this study is therefore that there is interaction between taurine and $\mathrm{B}_{12}$ regarding the occurrence of anaemia in sole. In addition, taurine is an organic acid that could improve the bioavailability of minerals. Tauson \& Neil (1993) found that oral supplementation of $B_{12}$ in mink resulted in improved intestinal absorption of dietary iron. Moreover, Salze \& Davis (2015) discuss the possibility that taurine acts as a signalling molecule. In the digestive tract of rats dietary taurine induces gastric acid secretion by binding to the $\gamma$-aminobutyric acid receptors (Huang, Chang, Ho, Lu \& Tsai 2011). As the absorption of non heme dietary iron 
requires the reduction of $\mathrm{Fe}^{3+}$ to $\mathrm{Fe}^{2+}$ and hence needs an acid environment, taurine could next to $\mathrm{B}_{12}$ - affect iron absorption.

Many divalent minerals have a function in erythropoiesis. As interaction mechanisms for the absorption of divalent minerals (e.g. $\mathrm{Cu}$ and $\mathrm{Zn}$ ) are well known and also present in fish (Kwong \& Niyogi 2009), we estimated the absorption of copper, cobalt, chromium, iron, manganese, molybdenum and zinc in order to evaluate the effect of both oral vitamin $\mathrm{B}_{12}$ and taurine supplementation on the mineral absorption in common sole.

To summarize, in this study we tested two hypotheses; 1) sole needs high dietary levels of $\mathrm{B}_{12}$ to alleviate or prevent anaemia; 2 ) there is interaction between dietary taurine and $\mathrm{B}_{12}$, which affect $\mathrm{Hct}$ and $\mathrm{Hb}$ levels. In addition it was assessed if $\mathrm{B}_{12}$ and taurine affect mineral absorption in sole.

\section{Material and methods}

This experiment was approved by the ethical Committee for Animal Experiments and conducted at IMARES, The Netherlands.

\section{Fish housing and husbandry}

This experiment assessed the impact of dietary vitamin $\mathrm{B}_{12}$ and taurine supplementation on the alleviation of nutritional anaemia in common sole. Therefore, this experiment was carried out with anaemic sole. Anaemic common sole, (individual weight 220 $\pm 43 \mathrm{~g}$ ) reared on commercial pellets within our own facilities, and naïve to mussel and ragworm feeding were accommodated in 12 tanks integrated in a flow through system at a density of 10 fish per tank. Every tank $\left(0.4 \mathrm{~m}^{2}, 130 \mathrm{~L}\right)$ received a continuous flow of $4 \mathrm{~L}$ min ${ }^{1} \operatorname{tank}^{-1}$ of fresh filtered seawater. Husbandry conditions were: photoperiod 12L:12D, light intensity $11-15 \mathrm{~lx}$, temperature $16.9 \pm 1.3^{\circ} \mathrm{C}$, oxygen $8.3 \pm 0.5 \mathrm{mg} \mathrm{L}^{-1}, \mathrm{pH} 8.1 \pm 0.1$, total ammonia nitrogen (TAN) $0.3 \pm 0.2 \mathrm{mg} \mathrm{L}^{-1}, \mathrm{NO}_{2}^{-} 0.01 \pm 0 \mathrm{mg} \mathrm{L}^{-1}$, salinity $25-30 \mathrm{ppt}$ and flow $4.5 \pm 0.5 \mathrm{~L} \mathrm{~min}^{-1}$, which stayed within pre-set limits. Temperature and oxygen were measured daily. Flow, $\mathrm{pH}$, TAN and $\mathrm{NO}_{2}^{-}$, were measured weekly.

\section{Experimental design, diets and preparation}

The experiment consisted of a 7-day acclimatisation and a 23-day experimental period as sole fed ragworm does recover from a nutritional anaemia within 23 days (Kals et al. $2015^{\mathrm{a}}$ ). During acclimatization fish were fed the commercial pellet $(3 \mathrm{~mm}$, crude protein $63 \%$, 
ether extract $14 \%$, ash $12 \%$, iron $\pm 250 \mathrm{mg} \mathrm{kg}^{-1}$, copper $\pm 13 \mathrm{mg} \mathrm{kg}^{-1}, \mathrm{~B}_{12} \pm 338 \mathrm{ug} \mathrm{kg}^{-1}$, taurine $3.5 \mathrm{~g} \mathrm{~kg} \mathrm{dm}^{-1}$ ). During the experimental period sole were fed one of four diets, according to a 2 by 2 factorial design: 2 vitamin $B_{12}$ levels and 2 taurine levels. Diets were tested in triplicate, giving 12 experimental units, with 10 fish per tank adding up to 120 fish in total.

"High" vitamin $\mathrm{B}_{12}$ and taurine levels were $1.9 \mathrm{mg} \mathrm{kg} \mathrm{dm}^{-1}$ and $7.6 \mathrm{~g} \mathrm{~kg} \mathrm{dm}^{-1}$, respectively, which are the levels analysed in ragworm (unpublished data). "Low" vitamin $\mathrm{B}_{12}$ and taurine levels were $0.34 \mathrm{mg} \mathrm{kg} \mathrm{dm}^{-1}$ and $3.5 \mathrm{~g} \mathrm{~kg} \mathrm{dm}^{-1}$, respectively, these being equal to levels analysed in the commercial pellet (unpublished data). Accordingly, the high and low levels of $\mathrm{B}_{12}$ and taurine are the levels analysed in ragworm vs. the levels analysed in the commercial pellet. The total dietary iron content was formulated to be equal to the iron content analysed in ragworm (352 $\mathrm{mg} \mathrm{kg}^{-1} \mathrm{dm}$; Kals et al. $2015^{\mathrm{b}}$ ), being above the iron requirements of fish (NRC 2011). Moreover, to be able to properly test the effect of $\mathrm{B}_{12}$ and taurine levels on Hct and $\mathrm{Hb}$ it is important to use an iron source securing the availability of dietary iron is not limited. The bioavailability of heme iron in general is superior to that of non heme iron (Andersen, Lorentzen, Waagbø \& Maage 1997; Bury, Walker \& Glover 2003; Kraemer \& Zimmermann 2007; Maage \& Sveier 1998; Miret, Simpson \& McKie 2003). Therefore, we chose for heme iron as the dietary iron source in the experimental diets. In addition, iron in mussel and ragworm is mostly heme iron in its undenatured state (Vinogradov, Sharma \& Walz 1991). Hence, the diets were prepared through cold extrusion in cooperation with Research Diet Services (RDS, Wijk bij Duurstede, The Netherlands). Cold extrusion was used to keep heme iron in its undenatured state as heme iron is sensitive to heat (Lombardi-Boccia, Martinez-Dominguez \& Aguzzi 2002). For the rest the experimental diets were identical and therefore isonitrogenous, isoenergetic and equal in amino acids, calcium and phosphate. Yttrium oxide was used as an inert marker for the determination of mineral absorption.

All diets were treated with a ragworm extract $\left(8 \mathrm{~g} \mathrm{WW} \mathrm{kg}^{-1}\right.$ or $1.4 \mathrm{~g} \mathrm{dm} \mathrm{kg}^{-1}$ of feed) to guarantee sufficient feed intake. Extracts were produced by homogenizing cooled ragworms (Topsy Baits B.V, Wilhelminadorp, The Netherlands) using a blender. Homogenates were centrifuged $(20 \mathrm{~min}, 5000 \mathrm{~g})$ to remove solids. The extracts (the supernatant) obtained were diluted ( 8 g extract WW $\left.50 \mathrm{ml}^{-1}\right)$ using a physiological salt solution for proper spraying to ensure an even distribution of extracts on the pellets. Treated pellets were dried for $24 \mathrm{~h}$ at room temperature before storage. The addition of a ragworm 
extract does not affect Hct values in sole (Kals et al. 2015 ). Diets were stored in a cool and dry place. Recipes and their analysed composition are shown in table 7.1, 7.2 and 7.3.

Table 7.1 Diet formulations, inclusion level of different factors and composition.

\begin{tabular}{|c|c|c|c|c|}
\hline \multirow[b]{2}{*}{ Diet Code ${ }^{\text {* }}$} & \multicolumn{4}{|c|}{ Diets } \\
\hline & $\left(\mathrm{HB}_{12}\right.$-HTau $)$ & (LB LB $_{12}$-HTau) & $\left(\right.$ HB $_{12}$-LTau $)$ & (LB ${ }_{12}$-LTau) \\
\hline Iron source & \multicolumn{4}{|c|}{ Heme } \\
\hline Vitamin $\mathrm{B}_{12}$ & $\mathrm{H}$ & $\mathrm{L}$ & $\mathrm{H}$ & $\mathrm{L}$ \\
\hline Taurine (Tau) & $\mathrm{H}$ & $\mathrm{H}$ & $\mathrm{L}$ & $\mathrm{L}$ \\
\hline Basal ingredients $^{+4}(\%)$ & 85.6 & 85.6 & 85.6 & 85.6 \\
\hline \multicolumn{5}{|l|}{ Test ingredients (\%): } \\
\hline Pea protein conc. ${ }^{b}$ & 12.70 & 12.70 & 13.00 & 13.00 \\
\hline Corn Starch $^{\mathrm{h}}$ & 0.86 & 1.03 & 0.98 & 1.14 \\
\hline Yttrium oxide $^{w}$ & 0.02 & 0.02 & 0.02 & 0.02 \\
\hline Taurine $^{1}$ & 0.626 & 0.626 & 0.210 & 0.210 \\
\hline Vitamin $\mathrm{B}_{12}{ }^{2}$ & 0.190 & 0.028 & 0.190 & 0.028 \\
\hline Check & 100.00 & 100.00 & 100.00 & 100.00 \\
\hline
\end{tabular}

${ }^{*} H B_{12}-H T a u=h i g h B_{12}$, high taurine, $L B_{12}-H T a u=$ low $B_{12}$, high taurine, $H B_{12}-L T a u=h i g h B_{12}$, low taurine, $L B_{12} L T a u=l o w B_{12}$, low taurine. $H=$ high, $L=$ low. ${ }^{* t}$ Basal ingredients: Caseine ${ }^{\mathrm{a}}, 9 \%$, Soy protein conc, $12.5 \%$, Corn gluten ${ }^{\mathrm{d}} 13.5 \%$, L-threonine $\mathrm{e}^{\mathrm{e}} 0.4 \%$, DLmethionin ${ }^{\mathrm{f}} 0.3 \%$ L-iso leucin ${ }^{\mathrm{g}} 0.3 \%$, Fish meal $11 \%$, Fish Oil $6 \%$, CPSP special G ${ }^{\mathrm{k}} 5 \%$, Squid meal $4 \%$, Wheat gluten ${ }^{\mathrm{m}} 5 \%$, Soyalecithin ${ }^{\mathrm{n}}$ $0.6 \%$, Cholesterol ${ }^{\circ} 0.3 \%$, Premix (Iron \& $\mathrm{B}_{12}$ free) $\dagger 2 \%$, Binder $1^{\mathrm{p}} 2 \%$, Binder $2^{\mathrm{q}} 2 \%$, Salt $2 \%$, MCP $1.5 \%$, Binder $3^{\mathrm{t}} 1 \%$, TMG $1 \%$, Lucantin Pink ${ }^{v}$ 0.5\%. Bovine Hemoglobin ${ }^{3}$ a Acid casein 30/60 mesh, Lactalis, Bourgbarré, France, ${ }^{b}$ Roquette Freres, Lestrem, France, ${ }^{\mathrm{c}}$ Soycomil R ADM Eurpoort BV, ${ }^{\mathrm{d}}$ Cargill, Bergen op Zoom, The Netherlands, ${ }^{e}$ Ajinomoto Parijs France, ${ }^{f}$ Sumitomo Tokyo Japan, ${ }^{g}$ Evonik, Hanau, Germany, ${ }^{h}$ Cgel C3401 Cargill Bergen op Zoom The Netherlands, ${ }^{i}$ Danish LT fishmeal. Type LT (Triple Nine Fish Protein Esbjerg,

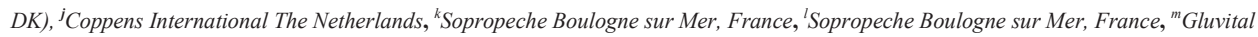
21000 Cargill Bergen op Zoom The Netherlands, ${ }^{n}$ Nutripur G Cargill, Hamburg, Germany, ${ }^{\circ}$ Cholesterol SF van Dishman Netherlands BV, Veenendaal, ${ }^{p}$ Binder $1,{ }^{q}$ Binder 2 and ${ }^{t}$ Binder 3 ; Ingredients are not specified because of confidentiality reasons of on-going research.

${ }^{r}$ Animalfeed salt van Kloek zout The Netherlands, ${ }^{s}$ Tessenderlo Chemie Belgium, "Betafin van Danisco Animal Nutrition Marlborough UK, ${ }^{v}$ BASF, Ludwigshafen Germany, "'Sigma Aldrich, USA, ${ }^{1}$ Taurine, ${ }^{2}$ vitamin $B_{12}$ (cyanocobalamin) Rosun, Krimpen a/d Ijssel The Netherlands, ${ }^{3}$ Bovine Hemoglobin (CAS 9008-02-0) with batchnummer 081M7002V (iron 0.31\% \& dm 97\%), Sigma-Aldrich, USA. ${ }^{\dagger}$ Vitamins (mg or IU kg-1 diet): vitamin A (retinyl acetate); $2.7 \mathrm{mg}, 9000 \mathrm{IU}$; vitamin D3 (cholecalciferol), $0.04 \mathrm{mg} 1700 \mathrm{IU}$; vitamin K3 ((menadione sodium bisulfite), $10 \mathrm{mg}$; vitamin $\mathrm{B1}$ (thiamine), $10 \mathrm{mg}$; vitamin B2 (riboflavin), $20 \mathrm{mg}$; vitamin B6 (pyridoxine hydrochloride), $12 \mathrm{mg}$; folic acid, 10 mg; biotin, $0.7 \mathrm{mg}$; inositol, $800 \mathrm{mg}$; niacin, $70 \mathrm{mg}$; pantothenic acid, $30 \mathrm{mg}$, choline chloride, $1500 \mathrm{mg}$; vitamin C, $500 \mathrm{mg}$; vitamin E, 300 mg; Minerals (g or mg kg-1 diet): Mn (manganese sulphate), $20 \mathrm{mg}$; I (potassium iodide), $1.5 \mathrm{mg}$; Cu (copper sulphate), $5 \mathrm{mg}$; Co (cobalt sulphate), $2 \mathrm{mg}$; $\mathrm{Cr}$ (chromium sulphate), $2.6 \mathrm{mg} ; \mathrm{Mg}$ (magnesium sulphate), 500mg; Zn (zinc sulphate) $60 \mathrm{mg}$; Se (sodium selenite) 0.3 mg; BHT (E300-321) $100 \mathrm{mg}$; Calcium propionate $1000 \mathrm{mg}$. 
High $\mathrm{B}_{12}$ rises Hct and $\mathrm{Hb}$ levels in anaemic sole

Table 7.2 Analysed proximate composition of diet formulations.

\begin{tabular}{|c|c|c|c|c|c|}
\hline Diet Code $^{\varkappa c}$ & & $\left(\right.$ HB $_{12}$-HTau $)$ & $\left(\mathrm{LB}_{12}-\mathrm{HTau}\right)$ & $\left(\mathrm{HB}_{12}\right.$-LTau) & $\left(\right.$ LB $_{12}$-LTau) \\
\hline Analysed composition ${ }^{a}$ & Unit & & & & \\
\hline DM & $\left(\mathrm{g} \mathrm{kg}^{-1}\right)$ & 913 & 916 & 917 & 913 \\
\hline ASH & $\left(\mathrm{g} \mathrm{kg}^{-1} \mathrm{dm}\right)$ & 92.0 & 91.7 & 90.5 & 93.1 \\
\hline $\mathbf{C P}$ & $\left(\mathrm{g} \mathrm{kg}^{-1} \mathrm{dm}\right)$ & 655 & 658 & 655 & 658 \\
\hline $\mathbf{E E}$ & $\left(\mathrm{g} \mathrm{kg}^{-1} \mathrm{dm}\right)$ & 122 & 125 & 123 & 125 \\
\hline $\mathbf{C F}$ & $\left(\mathrm{g} \mathrm{kg}^{-1} \mathrm{dm}\right)$ & 6.6 & 5.5 & 5.5 & 7.7 \\
\hline NFE & $\left(\mathrm{g} \mathrm{kg}^{-1} \mathrm{dm}\right)$ & 37.9 & 36.1 & 42.4 & 22.6 \\
\hline GE & $\left(\mathrm{MJ} \mathrm{Kg}^{-1}\right)$ & 21.1 & 21.2 & 21.2 & 21.2 \\
\hline CP/GE & & 31.0 & 31.0 & 30.9 & 31.1 \\
\hline
\end{tabular}

${ }^{a} D M=$ dry matter, $A S H=$ ash, $C P=$ crude protein, $E E=$ ether extract, $C F=$ crude fibre, $N F E=$ nitrogen free extract, $G E=$ gross energy. ${ }^{*} H B_{12}-H T a u=h i g h B_{12}$, high taurine, $L B_{12}-H T a u=$ low $B_{12}$, high taurine, $H B_{12}-L T a u=h i g h B_{12}$, low taurine, $L B_{12} L T a u=l o w B_{12}$, low taurine. $H=$ high, $L=$ low.

Table 7.3 Analysed minerals and vitamin $B_{12}$ of diet formulations.

\begin{tabular}{|c|c|c|c|c|c|}
\hline Diet $^{* e}$ & & $\left(\mathrm{HB}_{12}-\mathrm{HTau}\right)$ & (LB 12-HTau) & (HB ${ }_{12}-$ LTau) & $\left(\right.$ LB $_{12}$-LTau $)$ \\
\hline Analysed composition & Unit & & & & \\
\hline Vitamin $B_{12}$ & $\left(u g \mathrm{~kg}^{-1} \mathrm{dm}\right)$ & 1150 & 175 & 1330 & 177 \\
\hline Iron & $\left(\mathrm{mg} \mathrm{kg}^{-1} \mathrm{dm}\right)$ & 323 & 316 & 320 & 340 \\
\hline Calcium & $\left(\mathrm{g} \mathrm{kg}^{-1} \mathrm{dm}\right)$ & 8.0 & 7.5 & 7.9 & 7.6 \\
\hline Sodium & $\left(\mathrm{g} \mathrm{kg}^{-1} \mathrm{dm}\right)$ & 18.8 & 18.8 & 17.3 & 18.5 \\
\hline Potassium & $\left(\mathrm{g} \mathrm{kg}^{-1} \mathrm{dm}\right)$ & 6.1 & 6.1 & 6.3 & 6.1 \\
\hline Magnesium & $\left(\mathrm{g} \mathrm{kg}^{-1} \mathrm{dm}\right)$ & 1.6 & 1.6 & 1.7 & 1.6 \\
\hline Copper & $\left(\mathrm{mg} \mathrm{kg}^{-1} \mathrm{dm}\right)$ & 11.8 & 11.5 & 11.9 & 11.5 \\
\hline Cobalt & $\left(\mathrm{mg} \mathrm{kg}^{-1} \mathrm{dm}\right)$ & 2.2 & 2.1 & 2.4 & 2.3 \\
\hline Chromium & $\left(\mathrm{mg} \mathrm{kg}^{-1} \mathrm{dm}\right)$ & 5.5 & 4.7 & 5.1 & 5.1 \\
\hline Manganese & $\left(\mathrm{mg} \mathrm{kg}^{-1} \mathrm{dm}\right)$ & 35 & 36 & 37 & 38 \\
\hline Molybdenum & $\left(\mathrm{mg} \mathrm{kg}^{-1} \mathrm{dm}\right)$ & 0.9 & 0.8 & 0.9 & 0.8 \\
\hline Zinc & $\left(\mathrm{mg} \mathrm{kg}^{-1} \mathrm{dm}\right)$ & 115 & 112 & 119 & 115 \\
\hline
\end{tabular}

${ }^{*} H B_{12}-H T a u=h i g h B_{12}$, high taurine, $L B_{12}-H T a u=$ low $B_{12}$, high taurine, $H B_{12}-L T a u=h i g h B_{12}$, low taurine, $L B_{12}-L T a u=l o w B_{12}$, low taurine $H=$ high, $L=$ low.

\section{Feeding}

Fish were fed by hand twice a day (8:30 and 16:30). Dry matter (dm) content of diets were analysed at the start of the experiment, in order to apply equal feeding levels on $\mathrm{dm}$ basis for all diets. Feeding level was restricted and set at $0.54 \mathrm{~g} \mathrm{dm}$ per fish $\mathrm{d}^{-1}$, which is approximately $85 \%$ of the maximum feeding level of a $200 \mathrm{~g}$ sole (unpublished data). $1 \mathrm{~h}$ after feeding, tanks were checked for uneaten feed. 


\section{Sampling, analysis, measurements and calculations}

After acclimatisation, the start of the experimental period, 30 fish were sacrificed to provide start values for $\mathrm{Hb}$, Hct and HSI. At the end of the experiment, all ten fish of each tank were sacrificed using an overdose of phenoxy ethanol (1:1000). After weighing, all fish were sampled for blood. For each tank, after blood sampling, faeces were collected from seven fish and livers to calculate the HSI from five fish. Faeces were collected from the hindgut by dissection 6 hours after the last feeding period of each tank. Therefore, the tanks were sequentially fed during the last feeding period. All tanks were sampled in one day in the same sequence as their fish had been fed during the last feeding period.

Blood was obtained by caudal venous puncture using a heparinized syringe $(0.6 \mathrm{~mm} / 30 \mathrm{~mm}$ needle). Blood samples were transferred into tubes and stored on ice and processed within approximately 15 minutes. The Hct levels were determined by using capillaries and a Hct centrifuge (SpinCrit microhematocrit centrifuge, Brown, Indianapolis, US) to centrifuge for 5 minutes at $5000 \mathrm{~g}$. The $\mathrm{Hb}$ levels were determined using the method described by van Kampen \& Zijlstra (1961). Faeces samples were frozen at $-80^{\circ} \mathrm{C}$ for further analysis. Apparent absorption coefficients (AAC's) of copper ( $\mathrm{Cu}$ ), iron (Fe), manganese (Mn), zinc $(\mathrm{Zn})$, cobalt (Co), chromium ( $\mathrm{Cr}$ ) and molybdenum (Mo) were calculated using the following formula:

$A A C_{\text {mineral }(x)}=100-\left(100 *\left(\frac{\text { Yttrium }_{\text {diet }}}{\text { Ytrium }_{\text {faeces }}}\right) *\left(\frac{\text { mineral }}{(x)_{\text {faeces }}}\right)\right.$

With:

AAC $=$ Apparent absorption coefficient

Yttrium diet $=$ Yttrium concentration in the diet

Yttrium faeces $=$ Yttrium concentration in the faeces

Mineral $(\mathrm{x})$ faeces $=$ concentration of mineral $(\mathrm{x})$ in faeces

Mineral $(\mathrm{x}) \operatorname{diet}=$ concentration of mineral $(\mathrm{x})$ in $\operatorname{diet}$

The diets were analysed for proximate composition by Nutrilab BV, Rijswijk, The Netherlands. Yttrium and minerals of both faeces and diet samples were analysed by the Chemical Biological Soil Laboratory (CBLB), Wageningen, The Netherlands, using ICP-EAS 
for $\mathrm{Cu}, \mathrm{Fe}, \mathrm{Mn}, \mathrm{Zn}$ (Varian Vista pro radial, Agilent Technologies Inc., Santa Clara, CA USA) according to guidelines NPR-6425 and NEN-6966 and using ICP-MS for Co and Mo (Element2, Thermo Fisher Scientific, Inc., Waltham, MA USA) according to guidelines NENEN-ISO 17294-1 and 17,294-2.

\section{Statistical analysis}

Data were analysed by 2-way ANOVA for the effect of vitamin $\mathrm{B}_{12}$ level, taurine level and their interaction. Homogeneity was tested using the Levene's test. If necessary, data was transformed. The tank was used as the experimental unit. For all tests a probability $\mathrm{p}<0.05$ has been considered significant.

\section{Results}

\section{General aspects of the experiment}

No mortality occurred and no feed refusal or spillage was observed during the

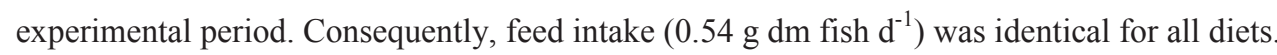
At the end of the experiment a mistake was found, as one tank was stocked with 9 fish. Since the feed intake was restricted and equal for all tanks, we decided to exclude this tank from the analyses of $\mathrm{Hct}, \mathrm{Hb}$ and the hepatosomatic index (HSI), all three being long term effect parameters. However, data analysis carried out including the tank with 9 fish, revealed that the results regarding the Hct, $\mathrm{Hb}$ and the HSI would not lead to major differences. We did include the tank with 9 fish for the analysis of the apparent absorption coefficients (AAC's), as the $\mathrm{AAC}$ is relative and represents only a momentarily estimation.

\section{Vitamin $B_{12}$ and taurine}

This experiment was carried out with anaemic sole. At the start of the experimental period, sole had on average a haematocrit (Hct) level of $12.5 \%$, a haemoglobin $(\mathrm{Hb})$ level $19.6 \mathrm{~g} \mathrm{l}^{-1}$ and a hepatosomatic index (HSI) $1.13 \%$ (table 7.4).

At the end of the experimental period, $\mathrm{Hb}$ was affected by $\mathrm{B}_{12}(\mathrm{p}<0.05$, table 7.4). However, this $\mathrm{B}_{12}$ effect was dependent on the dietary taurine level, indicated by a significant interaction effect $(\mathrm{P}<0.05)$. At the "high" dietary taurine level, there was no difference in $\mathrm{Hb}$ level in sole fed the diets with different $\mathrm{B}_{12}$ levels, whereas at the "low" level taurine diets, increasing the dietary $\mathrm{B}_{12}$ level resulted in a higher $\mathrm{Hb}$ level. Hct levels were also higher in sole fed diets with a "high" level of $\mathrm{B}_{12}(\mathrm{p}<0.05$, table 7.4$)$. Hct tended $(\mathrm{P}<0.10)$ to be affected 
by the interaction effect of $\mathrm{B}_{12}$ and taurine supplementation. Numerically, the pattern in Hct between the four experimental diets was identical to the pattern in $\mathrm{Hb}$ (table 7.4). Final $\mathrm{Hb}$ as well as Hct levels were highest in sole fed the diet with the "high" $\mathrm{B}_{12}$ level and the "low" taurine level (Table 7.4). The HSI was unaffected by any of the dietary treatments $(p>0.05$; table 7.4).

Table 7.4 Effect of the different diets on haematocrit (Hct), haemoglobin (Hb) and hepatosomatic index (HSI).

\begin{tabular}{|c|c|c|c|}
\hline Diet & Het (\%) & Hb $\left(\right.$ g. $\left.I^{-1}\right)$ & HSI \\
\hline Start t(0) & $12.5 \pm 3.2$ & $19.6 \pm 8.1$ & $1.13 \pm 0.27$ \\
\hline$\left(\mathrm{HB}_{12}-\mathrm{HTau}\right)$ & $13.5 \pm 0.6$ & $21.3 \pm 1.6$ & $1.29 \pm 0.36$ \\
\hline$\left(\mathrm{LB}_{12}-\mathrm{HTau}\right)$ & $13.1 \pm 1.1$ & $21.1 \pm 2.2$ & $1.34 \pm 0.04$ \\
\hline$\left(\mathrm{HB}_{12}\right.$-LTau) & $15.0 \pm 1.8$ & $23.0 \pm 1.4$ & $1.18 \pm 0.13$ \\
\hline$\left(\mathrm{LB}_{12}-\mathrm{LTau}\right)$ & $11.9 \pm 0.6$ & $17.6 \pm 1.3$ & $1.30 \pm 0.28$ \\
\hline \multicolumn{4}{|l|}{$P$ value's } \\
\hline Vitamin $B_{12}$ & 0.038 & 0.025 & 0.543 \\
\hline Taurine & 0.899 & 0.378 & 0.590 \\
\hline Vitamin $\mathrm{B}_{12}$ *taurine & 0.086 & 0.031 & 0.829 \\
\hline
\end{tabular}

${ }^{*} H B_{12}-H T a u=h i g h B_{12}$, high taurine, $L B_{12}-H T a u=$ low $B_{12}$, high taurine, $H B_{12}-L T a u=h i g h B_{12}$, low taurine, $L B_{12}-L T a u=$ low $B_{12}$, low taurine. $H=$ high, $L=$ low. \#NA is not applicable.

\section{Mineral absorption}

Dietary taurine as well as $\mathrm{B}_{12}$ levels did not influence the apparent absorption coefficients (AAC's) of Fe. Similarly also the AAC of $\mathrm{Cu}, \mathrm{Mn}$ and Mo were not different between the dietary treatments. The AAC of chromium in sole was affected by dietary $\mathrm{B}_{12}$ level ( $\mathrm{p}<0.05$; table 7.5). At the "high" dietary $\mathrm{B}_{12}$ level the AAC of chromium was higher. Dietary taurine level negatively affected the AAC of cobalt $(\mathrm{p}<0.05$; table 7.5$)$. The AAC of zinc was affected by the interaction effect between taurine and $\mathrm{B}_{12}(\mathrm{P}<0.01)$. In sole fed the diet with a "low" taurine and a "high" $\mathrm{B}_{12}$ level, the AAC of $\mathrm{Zn}$ was the highest, while the AAC of $\mathrm{Zn}$ was similar at the other dietary treatments (Table 7.5). 
High $\mathrm{B}_{12}$ rises Hct and $\mathrm{Hb}$ levels in anaemic sole

Table 7.5 The apparent absorption coefficients of $\mathrm{Cu}, \mathrm{Fe}, \mathrm{Mn}, \mathrm{Zn}, \mathrm{Co}, \mathrm{Cr}$ and $\mathrm{Mo}$ in sole fed diets with heme, varying in high or low dietary $B_{12}$ and taurine.

\begin{tabular}{|c|c|c|c|c|c|c|c|}
\hline \multicolumn{8}{|c|}{ Apparent absorption coefficient (\%) } \\
\hline Diet & $\mathrm{Cu}$ & $\mathbf{F e}$ & Mn & Zn & Co & $\mathrm{Cr}$ & Mo \\
\hline (HB ${ }_{12}$-HTau) & $22.3 \pm 3.2$ & $13.9 \pm 5.9$ & $14.0 \pm 11.5$ & $8.0 \pm 2.4$ & $10.8 \pm 2.7$ & $17.3 \pm 6.6$ & $-1.7 \pm 8.7$ \\
\hline (LB $\left.\mathrm{LB}_{12}-\mathrm{HTau}\right)$ & $17.1 \pm 6.7$ & $9.3 \pm 1.4$ & $18.9 \pm 8.8$ & $12.6 \pm 4.0$ & $15.5 \pm 4.4$ & $7.4 \pm 5.4$ & $-4.8 \pm 13.9$ \\
\hline$\left(\mathrm{HB}_{12}\right.$-LTau) & $15.2 \pm 17.2$ & $13.8 \pm 1.4$ & $14.9 \pm 2.0$ & $19.0 \pm 0.9$ & $25.6 \pm 5.5$ & $19.9 \pm 6.2$ & $-2.1 \pm 3.7$ \\
\hline$\left(\mathrm{LB}_{12}-\mathrm{LTau}\right)$ & $12.8 \pm 2.0$ & $14.9 \pm 3.9$ & $17.5 \pm 5.7$ & $10.7 \pm 4.2$ & $30.1 \pm 2.5$ & $6.6 \pm 9.0$ & $-0.7 \pm 13.1$ \\
\hline \multicolumn{8}{|l|}{ p-values } \\
\hline Vitamin $\mathrm{B}_{12}$ & 0.72 & 0.38 & 0.43 & 0.34 & 0.08 & 0.01 & 0.90 \\
\hline Taurine & 0.69 & 0.17 & 0.96 & 0.04 & $\mathbf{0}$ & 0.82 & 0.77 \\
\hline Vitamin $B_{12} *$ Taurine & 0.10 & 0.21 & 0.80 & 0.01 & 0.95 & 0.65 & 0.73 \\
\hline
\end{tabular}

\section{Discussion}

A "high" dietary level of $\mathrm{B}_{12}$ caused a rise in Hct and $\mathrm{Hb}$ levels in sole (table 7.4). $\mathrm{B}_{12}$ absorption takes place via an active and/or the passive process of diffusion. In relation with the first hypothesis, we assumed that sole depends on the passive process of diffusion and that the active process of $\mathrm{B}_{12}$ absorption became rudimentary over time due to the high $\mathrm{B}_{12}$ levels of their natural diet. When, only $\pm 1 \%$ of the free $\mathrm{B}_{12}$ is absorbed through diffusion (Pawlak et al. 2012), sole may need high dietary levels of $\mathrm{B}_{12}$ to reach their requirements. When commercial feeds with dietary $B_{12}$ levels far below those of ragworm (1134 to $3033 \mu \mathrm{g} \mathrm{kg}^{-1}$ $\mathrm{dm})$ or mussel $\left(1671 \mu \mathrm{g} \mathrm{kg}^{-1} \mathrm{dm}\right)\left(\right.$ Kals et al. $\left.2015^{\mathrm{b}}\right)$ are fed to sole, their $\mathrm{B}_{12}$ uptake might remain below their requirements to prevent anaemia.

The suppressing effect of the "high" dietary taurine level on the stimulating effect of the "high" dietary level of $\mathrm{B}_{12}$ on Hct and $\mathrm{Hb}$ levels was not expected as the "high" taurine level is equal to the levels analysed in ragworm. Moreover, taurine levels in mussel are even three times higher, while mussel and ragworm are equally capable to alleviate anaemia in sole (Kals et al. 2015 b). According to Salze \& Davis, 2015; Anand et al. 2010; Takagi et al. 2006; Sirdah et al. 2002, fish being deficient of taurine are associated with decreasing Hct levels (haemolytic anaemia). Looking at the taurine levels analysed in mussel, it is unlikely that the "high" taurine level chosen in the current study is too high for sole. Therefore, at this moment we cannot explain the suppressing effect of the "high" dietary level of taurine on the stimulating effect of the "high" dietary level of $\mathrm{B}_{12}$ on Hct and $\mathrm{Hb}$ in sole.

Previous studies show the nutritional anaemia in sole fed commercial pellets could be alleviated by feeding ragworm (Kals et al. 2015 $5^{\mathrm{a}}$ ) or mussel (Kals et al. 2015 ). Yet, using 
comparable levels of $\mathrm{B}_{12}$, even though the effect of dietary $\mathrm{B}_{12}$ on the Hct and Hb level in anaemic sole is present, the increase was limited (only $\pm 20 \%$ ). Consequently, sole fed the experimental diet with a "high" dietary level of $\mathrm{B}_{12}$ and a "low" level of taurine could still be considered (moderately) anaemic. Therefore, one can question if $\mathrm{B}_{12}$ and taurine are the compounds from ragworm and mussel that play a role in the alleviation of the nutritional anaemia in sole. Accordingly, it is likely that one or more other dietary components which are present in mussel and ragworm, but not in the formulated diets, are involved in the alleviation of nutritional anaemia in sole. Nevertheless, the first hypothesis cannot be rejected and the second hypothesis is confirmed for haemoglobin.

Absorption of zinc ( $\mathrm{Zn})$ is positively affected by a "low" dietary level of taurine. This effect is stimulated in combination with a "high" dietary $\mathrm{B}_{12}$ level (table 7.5). Zn has an important role in erythrocyte or red blood cell development (Kukita, Kukita, Ouchida, Maeda, Yatsuki \& Kohashi 1999). Therefore, assuming Zn was not abundantly present in the sole's tissue, it is expected that the absorption will rise when erythrocyte production is stimulated. In addition, we believe that an increase in $\mathrm{Hct}$ and $\mathrm{Hb}$ will stimulate the production of super oxide dismutase (SOD), a major antioxidant in red blood cells, containing $\mathrm{Zn}$ and copper $(\mathrm{Cu})$ (Salo, Lin, Pacifici \& Davies 1988). The increased Hct and Hb levels will thus lead to an increase in demand for $\mathrm{Cu}$ and $\mathrm{Zn}$. The absorption of $\mathrm{Cu}$ was high due to heme as the dietary iron source (Kals, Blonk, Mheen van der, Schrama \& Verreth $2015^{\mathrm{c}}$ ). In Kals et al. $2015^{\mathrm{c}}$ we described that the high absorption of both iron and copper in sole fed heme iron did not affect the Hct and $\mathrm{Hb}$ levels and subsequently concluded that the nutritional anaemia in sole is not an iron or a copper deficiency anaemia. In this study the impact of $\mathrm{B}_{12}$ and taurine on the $\mathrm{Hb}$ and Hct level in anaemic sole were not related to a change in the apparent absorption coefficient of iron and or copper.

Cobalt (Co) is part of vitamin $\mathrm{B}_{12}$ (4\% on weight basis) and as such an essential mineral for all animals. In most fish species, $B_{12}$ requirements are low $\left(<0.05 \mathrm{mg} \mathrm{kg}^{-1}\right)$ or not required due to sufficient production by the intestinal flora (NRC 2011), but this only valid when sufficient dietary Co is present. Moreover, Co plays a role in an enzyme involved in endothelial cell proliferation (Griffith, Su, Turk, Chen Chang, Wu, Biemann \& Liu 1997). This enzyme also interacts with eukaryotic initiation factor 2, a protein necessary for protein synthesis in general (Wu, Rehemtulla, Gupta \& Kaufman 1996). The absorption of Co is higher in diets with "low" dietary taurine levels. This seems logical as "high" dietary taurine suppresses Hct and $\mathrm{Hb}$. Yet, Co absorption is also high in sole fed the diet with low $\mathrm{B}_{12}$, which we cannot explain. 
Chromium (Cr) participates in gene expression by binding to chromatin, causing an increase in RNA synthesis (Pechova \& Pavlata 2007). Hence, when red blood cell production is stimulated by a "high" dietary level of $\mathrm{B}_{12}$ and assuming $\mathrm{Cr}$ was not abundant present in the sole's tissue, a rise in absorption of chromium, seems logical.

Peculiar are the negative AAC's of Molybdenum being not different between treatments $(\mathrm{p}>0.10)$ and not different from zero $(\mathrm{p}>0.10)$ and comparable to data found in Kals et al. $2015^{\mathrm{c}}$. Trace elements like Molybdenum often provide negative AAC's (Ward, Carter \& Townsend 2005), which most likely results from the relatively high presence of Molybdenum in seawater $( \pm 100 \mathrm{nM}$ in seawater versus $\pm 5 \mathrm{nM}$ in continental water (Schwarz \& Belaidi 2013) and from the fact that marine fish must drink to keep their water balance in order.

\section{Conclusions}

$\mathrm{Hct}$ and $\mathrm{Hb}$ levels in anaemic sole are influenced by dietary $\mathrm{B}_{12}$. A "high" dietary level of $\mathrm{B}_{12}$ increases the Hct and $\mathrm{Hb}$ level with $\pm 20 \%$. This impact of dietary $\mathrm{B}_{12}$ is however influenced by the dietary taurine level. An increasing level of dietary taurine suppresses the stimulating effect of the "high" dietary level of $\mathrm{B}_{12}$ on Hct and $\mathrm{Hb}$ in anaemic sole. The applied $\mathrm{B}_{12}$ levels as well as taurine levels were unable to completely alleviate the nutritional anaemia in sole induced by feeding commercial pellets. Nevertheless, the first hypothesis cannot be rejected and the second hypothesis is confirmed for haemoglobin. The impact of $\mathrm{B}_{12}$ and taurine on $\mathrm{Hb}$ and Hct were not related to a change in the $\mathrm{AAC}$ of $\mathrm{Fe} . \mathrm{B}_{12}$ and taurine affected the absorption of some covalent minerals in sole. Possibly, these changes are related to the changes in $\mathrm{Hct}$ and $\mathrm{Hb}$, yet when related cause and effect are not clear.

\section{Disclosure statement}

A patent application covering the use of Annelida and Mollusca in fish feed has been filed in 2012.

\section{Acknowledgements}

The authors thank Y. van Es, A. Hofman and N. Ros for their help and caretaking of the experimental animals during the trial. This work was financially supported by IMARES. 


\section{References}

Anand P., Rajakumar D., Felix A.J. \& Balasubramanian T. (2010). Effects of oral administration of antioxidant taurin on haematological parameters in Wistar rats. Pak. Journal of Biological Sciences. 13, 785-93.

Andersen F., Lorentzen M., Waagbø R. \& Maage A. (1997). Bioavailability of different forms of iron in Atlantic salmon (Salmo salar) smolt. Aquaculture Nutrition. 3, 239-246.

Bury N.R., Walker P.A. \& Glover C.N. (2003). Nutritive metal uptake in teleost fish. The Journal of Experimental Biology. 206, 11-23.

Clark J., MacDonald N.L. \& Stark J.R. (1985). Metabolism in marine flatfish. II. Protein digestion in Dover sole (Solea solea L.). Comparative Biochemistry Physiology. 81B, 217-222.

Gallaugher P. \& Farrell A.P. (1998). Haematocrit and blood oxygen carrying capacity. In: Perry S.F., Tufts B. (Eds.), Fish Physiology, vol. 17. Fish Respiration. Academic Press, New York, pp. 185-219.

Griffith E.C., Su Z., Turk B.E., Chen S., Chang Y.H., Wu Z., Biemann K. \& Liu J.O. (1997). Methionine aminopeptidase (type 2) is the common target for angiogenesis inhibitors AGM-1470 and ovalicin. Chemical Biology. 4 (6): 461-71.

Groot S.J. de. (1971). On the interrelationship between morphology of the alimentary tract, food and feeding behaviour in flatfishes (Pisces : Pleuronectiformes). Netherlands Journal of Sea Research. 5, 121-196.

Huang K.H., Chang C.C., Ho J.D., Lu R.H. \& Tsai, L.H. (2011). Role of taurine on acid secretion in the rat stomach. Journal of Biomedical Sciences. 18:11 doi:10.1186/1423-0127-18-11.

Kals J., Blonk R.J.W., Mheen H.W. van der, Schrama J.W. \& Verreth J.A.J. (2015 $\left.{ }^{\mathrm{a}}\right)$. Feeding ragworm (Nereis virens Sars) increases haematocrit and haemoglobin levels in common sole (Solea solea L.). Aquaculture Research. http://dx.doi.org/10.1111/are.12767.

Kals J., Blonk R.J.W., Mheen H.W. van der, Schrama J.W. \& Verreth J.A.J. (2015 ${ }^{\mathrm{b}}$ ). Mussel (Mytilus edulis L.) and ragworm (Nereis virens, Sars) both alleviate anaemia in common sole (Solea solea L.). Aquaculture Research. http://dx.doi.org/10.1111/are.12871

Kals J., Blonk R.J.W., Mheen H.W. van der, Schrama J.W. \& Verreth J.A.J. (2015 $)$. Effect of different iron sources on the alleviation of nutritional anaemia in common sole (Solea, solea). Aquaculture. 451: 266270. http://dx.doi.org/10.1016/j.aquaculture.2015.08.036

Kals J., Blonk R.J.W., Palstra A.P., Sobotta T.K., Mongile F., Schneider O., Planas J.V., Schrama J.W. \& Verreth J.A.J. (2015 ). Feeding ragworm (Nereis virens Sars) to common sole (Solea, solea L.) alleviates nutritional anaemia and stimulates growth. Aquaculture Research. http://dx.doi.org/10.1111/are.12919.

Kukita A., Kukita T., Ouchida M., Maeda H., Yatsuki H., Kohashi O. (1999). Osteoclast-derived zinc finger (OCZF) protein with POZ domain, a possible transcriptional repressor, is involved in osteoblastogenesis. Blood. 94, 1987-1997

Koury M.J. \& Ponka P. (2004). New insights into erythropoiesis: The Roles of Folate, Vitamin B12, and Iron. Annual Review of Nutrition. Vol. 24: 105-131.

Kraemer K. \& Zimmermann M.B. (2007). Nutritional anemia. SIGHT AND LIFE Press. c/o SIGHT AND LIFE / DSM. Nutritional Products Ltd. Internet: www.sightandlife.org 400pp.

Kwong R.W.M. \& Niyogi, S. (2009). The interactions of iron with other divalent metals in the intestinal tract of a fresh water teleost, rainbow trout (Oncorhynchus mykiss). Comparative Biochemistry and Physiology C. 150, 442-449.

Lagardere J.P. (1987). Feeding ecology and daily food consumption of common sole, Solea vulgaris, Quensel, juvenile on the French Atlantic coast. Journal of Fish Biology 30, 91-104.

Lydyard P.M., Cole M.F., Holton J., Irving W.L., Porakishvili N., Venkatesan P. \& Ward, N.K. (2010). Case studies in infectious disease. 609 pp. Garland Science, Taylor and Francis Group, New York and London.

Lombardi-Boccia G., Martinez-Dominguez B. \& Aguzzi A. (2002). Total Heme and Non-heme Iron in Raw and Cooked Meats. Journal of Food Sciences. 67, 1738-1741.

Maage A. \& Sveier H. (1998). Addition of dietary iron(III) oxide does not increase iron status of growing Atlantic salmon. Aquaculture International. 6, 249-252.

Miret S., Simpson R.J. \& McKie A.T. (2003). Physiology and molecular biology of dietary iron absorption. Annual Reviews of Nutrition. 23, 283-301.

Nielsen M. J., Rasmussen M. R., Andersen C. B. F. Nexø E. \& Moestrup S. K. (2012). Vitamin B12 transport from food to the body's cells - a sophisticated, multistep pathway. Nature Reviews Gastroenterology Hepatology. 9, 345-354

NRC (2011). Nutrient requirements of fish and shrimp. Ed. by Committee on the Nutrient Requirements of Fish and Shrimp. National Academies Press 376 pp. 
Palstra A.P., Blok M.C., Kals J., Blom E., Tuinhof-Koelma N., Dirks R.P., Forlenza M., Blonk R.J.W. (2015). In- and outdoor reproduction of first generation common sole Solea solea under a natural photothermal regime: temporal progression of sexual maturation assessed by monitoring plasma steroids and gonadotropin mRNA expression. General and Comparative Endocrinology. http://dx.doi.org/j.ygcen.2014.12.004

Pawlak R. James P.S., Raj S., Cullum-Dugan D. \& Lucus D. (2012). Understanding vitamin B12. American Journal of Lifestyle Medicine. 7: 60, 60-65.

Pechova A. \& Pavlata L. (2007). Chromium as an essential nutrient: a review Veterinarni Medicina, 52, (1): 118

Sa R., Bexiga C., Vieira L., Veiga P. \& Erzini K. (2003). Diets of the sole Solea vulgaris Quensel, 1806 and Sola selegalensis Kaup, 1858 in the lower estuary of the Guadiana River (Algarve, southern Portugal): Preliminary results. Boletin del Instituto Espanol de Oceanografia 19 (1-4), 505-508.

Salo D.C., Lin S.W., Pacifici R.E. \& Davies K.J.A. (1988). Superoxide dismutase is preferentially degraded by a proteolytic system from red blood cells following oxidative modification by hydrogen peroxide. Free Radical Biology and Medicine. Vol. 5, 335-339.

Salze P.G. \& Davis D.A. (2015). Taurine: a critical nutrient for future fish feeds. Aquaculture. 437, $215-229$. http://dx.doi.org/10.1016/j.aquaculture.2014.12.006.

Scott J.M. \& Weir D.G. (1981). The methyl folate trap. The Lancet, 318, 8242, 337-340.

Sirdah M.M., El-Agouza I.M.A. \& Abu Shahla A.N.K. (2002). Possible ameliorative effect of taurin in the treatment of iron-deficiency anaemia in female university students of Gaza, Palestine. European Journal of Haematology. 69, 236-242.

Spitze A.R., Wong D.L., Rogers Q.R. \& Fascetti A.J. (2003). Taurin concentrations in animal feed ingredients; cooking influences taurin content. Journal of Animal Physiology and Animal Nutrition 87, 251-262.

Schwarz G. \& Belaidi A.A. (2013). Molybdenum in Human Health and Disease. In Sigel, A., Sigel H., Sigel R.K.O. (eds.), Interrelations between Essential Metal Ions and Human Diseases. doi 10.1007/978-94007-7500-8 Springer Dordrecht Heidelberg New York London, pp 415-450.

Takagi S., Murata H., Goto T., Hayashi M., Hatate H., Endo M., Yamashita H. \& Ukawa, M. (2006). Hemolytic suppression roles of taurine in yellowtail Seriola quinqueradiata fed non-fishmeal diet based on soybean protein. Fisheries Science. 72 (3), 546-555.

Tauson A.H. \& Neil M. (1993). Vitamin B12 Supplementation to Mink (Mustela vison) in the prevention of feed induced iron deficiency Anaemia: II. Effect on Haemotological Parameters and Mineral Content of the Liver. Acta Agriculturae Scandinavica, Section A - Animal Science. 43:2, 123-128, DOI 10.1080/09064709309410154.

Thrall M.A., Weiser G., Allison R.W. \& Campbell T.W. (2012).Veterinary Hematology and Clinical Chemistry. 2nd ed. 792 pp. Wiley-Blackwell Oxford, UK.

Yúfera M. \& Darías, M.J. (2007). Changes in the gastrointestinal pH from larvae to adult in Senegal sole (Solea senegalensis). Aquaculture. 267, 94-99.

van Kampen E.J. \& Zijlstra W.G. (1961). Standardization of Hemoglobinometry II. The Hemiglobincyanide Method. Clinica Chimica Acta 6, 538-544.

Vinogradov S.N., Sharma P.K.\& Walz D.A. (1991). Iron and heme contents of the extracellular hemoglobins and chlorocruorins of Annelids. Comparative Biochemistry and Physiology. Vol. 98B, 187-194.

Ward A.D., Carter C.G. \& Townsend A.T. (2005). The use of yttrium oxide and the effect of faecal collection timing for determining the apparent digestibility of minerals and trace elements in Atlantic salmon (Salmo salar L.) feeds. Aquaculture Nutrition 11, 49-59.

Wood C.M., McMahon B.R. \& McDonald D.G. (1979). Respiratory, ventilatory, and cardiovascular responses to experimental anaemia in the starry flounder, Platichthys stellatus. Journal of Experimental Biology. 82 , 139-162.

Wu S., Rehemtulla A., Gupta N.K. \& Kaufman R.J. (1996). A eukaryotic translation initiation factor 2associated $67 \mathrm{kDa}$ glycoprotein partially reverses protein synthesis inhibition by activated doublestranded RNA-dependent protein kinase in intact cells. Biochemistry. 35 (25): 8275-8280. 


\title{
Chapter 8
}

\section{General Discussion}

\begin{abstract}
Aim of the study
Before the start of this $\mathrm{PhD}$ study, we did some exploratory experiments to sharpen our hypotheses. During these trials, we became aware that common sole (Solea solea L.) develops an anaemia when fed commercial pellets. When the diet of sole was changed from pellet to ragworm, (Nereis virens Sars) this anaemia was alleviated and growth rate increased even up to 70 percent. Based on these trials, the validation of the potential of ragworm to alleviate anaemia in common sole and the dietary requirements of common sole, which would avoid or alleviate anaemia, were identified as the main objectives of the $\mathrm{PhD}$ study, presented in this thesis. We were convinced that such a study would also explain part of the difference in growth between sole fed a commercial pellet and sole fed ragworms.
\end{abstract}

The alleviation of anaemia in common sole: the effect of ragworm, mussel, iron source and vitamin $B_{12}$

In chapter 2 it was demonstrated that feeding ragworm increases the haematocrit (Hct) and haemoglobin $(\mathrm{Hb})$ levels and alleviates the moderate anaemia of common sole within 21 days in contrast to those kept on a diet of commercial pellets, which stayed anaemic. This indicated that the increase of Hct and $\mathrm{Hb}$ in sole is diet related and we suggested that this increase can be a result of a difference in feed intake, or the dietary composition between the commercial pellet and ragworm, and/or of a health promoting effect of ragworm. In chapter 3 we provided evidence that mussel also alleviated the nutritional anaemia in common sole.

In chapter 4 it was demonstrated that sole fed commercial pellets are suffering from a 
nutritional anaemia and validated that feeding ragworm to sole, alleviates this nutritional anaemia. Moreover, the addition of ragworm extract to the commercial pellet improves the feed intake to the same level as in sole fed with ragworm, but has only a limited effect on growth and does not improve the anaemic state of these sole. The findings described in chapter 2 to 4 suggest a mismatch between the requirements of sole and the dietary composition of the commercial pellets.

Many nutritional factors can contribute to a nutritional anemia. However, the dietary levels of crude protein, ether extract, amino acids, phosphorus and calcium do not explain the difference in haematocrit (Hct) levels between sole fed ragworm or pellets (chapter 5). Moreover, excessive intake of milk proteins, soy proteins and phytates or polyphenols from plant ingredients can also be excluded as the commercial pellet tested hardly contained these ingredients. An exploratory experiment before the start of this thesis, evaluating the effect of processing (e.g. boiling) on the nutritional value of ragworm as feed for common sole, revealed that despite the fact that the iron intake of sole fed treated pellets versus sole fed boiled ragworm was comparable, the Hct level of sole fed boiled ragworm was significantly higher (Kals, Blonk, Palstra, Sobotta, Mongile, Schneider, Planas, Schrama \& Verreth $\left(2015^{\mathrm{c}}\right)$. Similarly, the intake of the other minerals mentioned in sole fed boiled ragworm were lower than in sole fed commercial pellets, yet sole fed boiled ragworm recovered from their anaemia while sole fed commercial pellets stayed anaemic. This suggests that the higher Hct level in sole fed boiled ragworm is not due to a higher intake of dietary iron or the other minerals mentioned, yet their absorption is not known (Kals, Blonk, Mheen van der, Schrama \& Verreth $2015^{\mathrm{d}}$ )

Based on the findings in chapter 3 and chapter 5, we suggest that the ability of mussel, ragworm or ragworm meal to alleviate anaemia and improve growth in sole can be explained by a combination of heme iron and high $\mathrm{B}_{12}$ levels, even though we could not exclude an effect of other factors present in mussel, ragworm or ragworm meal.

In chapter $\mathbf{5}$ it is demonstrated that the inclusion level of ragworm meal to maintain Hct levels and growth rates comparable to sole fed fresh ragworm is $100 \%$. In addition, data suggest that feeding fresh ragworm has no added value over feeding a pellet containing $100 \%$ of freeze dried ragworm meal.

In chapter 6 we demonstrated that iron absorption in sole is high and independent of the source of iron. Moreover, the use of different iron sources, including heme iron, does not affect iron absorption in anaemic sole. However, heme iron does increase the absorption of copper. The high absorption of both iron and copper in sole fed heme does not affect Hct and 
$\mathrm{Hb}$, which indicates that the nutritional anaemia in sole is not an iron or a copper deficiency anaemia. The role of copper in iron metabolism is discussed in chapter 6. Without copper, iron transport from the enterocyte towards the blood is blocked. Interesting in my opinion is that both, non-heme iron and copper, need the divalent metal transporter protein 1 (DMT1) to be absorbed from the lumen into the enterocyte (Arredondo \& Núñez 2005; Kramer \& Zimmerman 2007; Kwong \& Niyogi 2009). When dietary iron is mainly available as heme, copper has no, or less, competition from non-heme iron using DMT1 to get absorbed. Heme iron is absorbed directly via the specific heme carrier protein 1 (HCP1), not claiming DMT 1 capacity. Hence, the positive effect of heme iron on copper absorption can be explained by a reduced competitive binding of copper and non-heme iron, both claiming DMT1 to get absorbed.

In chapter 7 we provided evidence that the Hct and $\mathrm{Hb}$ levels in anaemic sole are influenced by dietary $\mathrm{B}_{12}$. However, an increasing level of dietary taurine suppresses the stimulating effect of a high dietary level of $\mathrm{B}_{12}$ on $\mathrm{Hct}$ and $\mathrm{Hb}$ in anaemic sole. The applied $\mathrm{B}_{12}$ levels as well as taurine levels were unable to completely alleviate the nutritional anaemia in sole induced by feeding commercial pellets. Nevertheless, the first hypothesis that sole needs high dietary levels of $\mathrm{B}_{12}$ to alleviate anaemia cannot be rejected.

$\mathrm{B}_{12}$ absorption takes place via an active and/or a passive process. In relation with the first hypothesis, we assumed that sole depends on the passive process of diffusion and that the active process of $\mathrm{B}_{12}$ absorption became rudimentary over time due to the high $\mathrm{B}_{12}$ levels of their natural diet. When, only about $1 \%$ of the free $\mathrm{B}_{12}$ is absorbed through diffusion (Pawlak et al. 2012), sole may need high dietary levels of $B_{12}$ to reach their requirements. When commercial feeds with dietary $B_{12}$ levels far below those of ragworm (1134 to $3033 \mu \mathrm{g} \mathrm{kg}^{-1}$ $\mathrm{dm})$ or mussel $\left(1671 \mu \mathrm{g} \mathrm{kg}^{-1} \mathrm{dm}\right)$ are fed to sole, their $\mathrm{B}_{12}$ uptake might remain below their requirements. Chapter 2, 3, 4 and 5 show that the nutritional anaemia in sole fed commercial pellets could be alleviated by feeding ragworm mussel or ragworm meal. Yet, using comparable levels of $\mathrm{B}_{12}$, even though the effect of dietary $\mathrm{B}_{12}$ on the Hct and $\mathrm{Hb}$ level in anaemic sole is present, the increase was limited (only about 20\%). Consequently, these sole could still be considered (moderately) anaemic. Therefore, the question remains whether $\mathrm{B}_{12}$ is really the compound from ragworm and mussel that plays a role in the alleviation of the nutritional anaemia in sole. Therefore, it is likely that other components from mussel and ragworm are involved in the alleviation of nutritional anaemia in sole. Yet, in spite of the above, vitamin $\mathrm{B}_{12}$ seems to be an important nutrient for common sole. This will be discussed more into depth in paragraph "Vitamin $\mathrm{B}_{12}$ and respiration". The Hct and Hb levels, which 
almost double in sole when fed ragworm or mussel, are hardly affected by the diet formulations used in chapter 6 and 7. Why are Hct and Hb not affected? Which (nutritional) possibilities supporting the alleviation of the nutritional anaemia in sole are left to consider? In the following I will discuss the possibility of vitamin $\mathrm{C}$ and the other vitamins that can play a role in a nutritional anaemia, the possibility of ragworm and mussel as an exogenous source of erythropoietin, a glycoprotein, that is the main regulator of red blood cell production, and the effect of ragworm on the gut microbiota of common sole.

\section{Vitamin $C$ and other vitamins}

Vitamin $\mathrm{C}$ could still be playing a role in the anaemia, just as many other vitamins as mentioned by Kraemer \& Zimmerman (2007). Yet, based on the feed intake and vitamin C content of the diets of the experiment described in chapter 4 , the vitamin $\mathrm{C}$ intake of sole fed fresh worm was higher compared to sole fed treated pellet. Vitamin C stimulates the absorption of iron and counteracts the effects of phytates. However, in chapter $\mathbf{6}$ we provided evidence that iron absorption in sole is not limited. Moreover, the tested commercial pellet hardly contained ingredients that included phytates. Both mussel and ragworm alleviate anaemia in common sole (chapter 3). Mussel contains, approximately $400 \mathrm{mg} \cdot \mathrm{kg}^{-1}$. $\mathrm{dm}$ of vitamin C (USDA 2016), ragworm approximately $100 \mathrm{mg} \cdot \mathrm{kg}^{-1} \cdot \mathrm{dm}$ (own analysis), yet levels vary according to diet and the stomach content of the mussel or ragworm during sampling. We added $500 \mathrm{mg} \cdot \mathrm{kg}^{-1}$ of vitamin $\mathrm{C}$ to all pelleted experimental diets tested in this thesis, yet the Hct and $\mathrm{Hb}$ levels of sole fed ragworm or mussel were almost double the levels of sole fed the pelleted experimental pellets. Hence, it seems unlikely that vitamin C plays an important role in the alleviation of anaemia in common sole. Likewise, vitamin $\mathrm{B}_{1}$ (thiamin), vitamin $\mathrm{B}_{2}$ (riboflavin), vitamin $\mathrm{B}_{5}$ (pantothenic acid) and even vitamin A (retinyl acetate) in the experimental diets, with levels of $10 \mathrm{mg} \cdot \mathrm{kg}^{-1}, 20 \mathrm{mg} \cdot \mathrm{kg}^{-1}, 30 . \mathrm{mg} \cdot \mathrm{kg}^{-1}$ and $8000-9000 \mathrm{IU} \cdot \mathrm{kg}^{-1}$ respectively, added by the premix, were all comparable or higher in the experimental diets than the levels analyzed in mussel (USDA 2016) and higher than the requirements of fish in general as mentioned in NRC (2011). The content of vitamin B1, B2, B5 in ragworm are, as far as we know, hitherto unknown. Yet, the Hct and Hb levels of sole fed ragworm or mussel were almost double the levels of sole fed the pelleted experimental diets. Hence, it seems unlikely that vitamin B1, B2, B5 and vitamin A play an important role in the alleviation of the nutritional anaemia in common sole. 


\section{Ragworm and mussel as an exogenous source of erythropoietin (EPO)}

Erythropoietin (EPO), a glycoprotein, is the main regulator of red blood cell production or erythropoiesis. Hypoxic conditions increase EPO production, which promotes the production of erythrocytes, by binding to the EPO receptor (EPOR). Yet, EPO also has functions in non-hematopoietic tissue, for example neuronal survival in hypoxic conditions (Gocht 2009). She investigated if an analogue to the vertebrate EPO/EPOR signaling pathway was present in organisms without erythropoiesis and found that a system similar to the vertebrate $\mathrm{EPO} / \mathrm{EPOR}$ signaling system is present in the central nervous systems of invertebrates, including annelids. Moreover, the EPO/EPOR proteins of invertebrates matched the size range for the mammalian EPO/EPOR proteins. Chou, Tohari, Brenner \& Venkatesh (2004) detected EPO in several fish species and Pradhan, Saini, Biswas \& Pati (1989) found that erythropoiesis in fish is enhanced by human EPO.

The main stimulus for EPO expression is tissue hypoxia which can be caused by environmental anoxic conditions (Yaqoob, Holotta, Prem, Kopp \& Schwerte (2009). As ragworm lives in mudflats, hypoxic conditions are normal events. At low tide, species which inhabit sandy and/or muddy areas (e.g. ragworm) cease to ventilate, become inert and completely asphyxic (a lack of oxygen in the blood due to restricted respiration). Measurements of dissolved oxygen in water samples from burrows of lugworms (Arenicola marina L.), a marine Annelid, showed levels as low as $0.5 \mathrm{ml} .1^{-1}$ i.e., hypoxic levels (Gocht 2009; Grieshaber, Hardewig, Kreutzer \& Pörtner 1994). Similar for mussel, hypoxic conditions occur at the bottom or during low tide. Especially during low tide species like mussel, that live on the substratum of the intertidal zone, experience severe hypoxia and become anaerobic as they close their shells at low tide to avoid dehydration (Grieshaber et al. 1994). Similar to the vertebrate EPO/EPOR signaling system in the mammalian nervous system the invertebrate analogue of the EPO/EPOR pathway promotes neuronal survival in hypoxic conditions (Gocht 2009). It is therefore likely that both ragworm and mussel do contain high levels of EPO to protect their nervous system during the frequent occurring hypoxic conditions. If true, high levels of EPO possibly could stimulate erythropoiesis in sole and consequently cause the high Hct and $\mathrm{Hb}$ levels in sole fed mussel or ragworm. EPO synthesis does have a feedback loop, for which the blood oxygen concentration, the number of erythrocytes and total serum EPO concentration are important. Yet, an exogenous source will stimulate erythropoiesis as is well known from sport physiology were a high oxygen carrying capacity is of prime importance (e.g. biking). EPO does increase iron absorption by 
suppressing hepcidin (Ashby, 2010). However, as shown in chapter 4, hepcidin was suppressed in sole fed the treated pellet compared to the sole fed ragworm. This suggests that $\mathrm{EPO}$, if present in ragworm at the moment of sampling, did not play a major role in the sole fed ragworm. Moreover, in humans EPO only works when administered by injection, as the glycoprotein will be digested by the digestive system losing its activity. This will most likely be the same in fish. However, in view of the fact that sole lacks pre-digestion in the stomach, has a low pepsin like activity and its intestine has an alkaline character (Clark, MacDonald \& Stark 1985; Lagardere 1987; Yúfera \& Darías 2007) an experiment to test whether the effect of dietary EPO levels is comparable to the effect of the levels found in mussel and ragworm is necessary to exclude EPO from having a role in the alleviation of anaemia in sole fed mussel or ragworm.

\section{Effect of ragworm on gut microbiota}

In chapter 2 we suggested the possibility that the increase of Hct and $\mathrm{Hb}$ in sole can be a result of a health promoting effect of ragworm. In one trial we found that feeding ragworm positively alters the microbiota in the gut of sole by lowering the presence of pathogens (e.g. Vibrio spp.) and increasing the presence of Acinetobacter spp. (Kals, Rurangwa and Haenen, unpublished data). Vibrio spp. have a large impact on growth and survival of fish. This effect of feeding ragworm to sole on gut microbiota could be, amongst others, due to nutritional aspects, epigenetic effects due to bioactive compounds from ragworm, or bioactive compounds from microbes associated with mucus secretion from ragworm (e.g. one of the tasks of mucus is the defense against infections (Stabili, Schirosi, Licciano \& Giangrande 2009)). Multiple authors found that compounds (e.g. arenicins, perinerin and hedistin) or extracts from Annelid spp. have antibacterial and antifungal properties. Moreover, researchers become more aware of the importance of the gut microbiota or microbiome and the symbioses between the microbiome and their host and the effect of this symbiotic relationship on growth, health and wellbeing of the host. Microbial metabolites seem to emerge as crucial messengers in the communication between gut microbiota and their host (Chilloux, Neves, Boulange \& Dumas 2016). In their review, these authors highlighted that the recent advances in the characterization of gut microbiota and the mechanisms involved in this symbiotic relationship will allow the development of nutritional interventions. Referring to the results achieved when feeding ragworm to sole, it seems that the combination of sole and ragworm is an unique tool to study an ecosystem approach of total "nutritional" 
value, including the, basic nutritional value, functional value and or undefined growth or health factors, of an additive, feed ingredient or a diet. In my opinion this is an interesting subject for future research to support the development of innovative aquatic diets to enhance growth, health, welfare in fish.

\section{The "worm effect" and oxygen carrying capacity}

In chapter 3 and 4 we suggested that the slow growth of pellet-fed sole might be the consequence of low Hct and $\mathrm{Hb}$ levels (i.e. their anaemic state), which hampers the uptake of oxygen and lowers therewith the overall metabolic capacity. In chapter 5, we suggested that the sub sequential rise of Hct due the rising inclusion level of ragworm meal, improves the sole's ability to take up oxygen from their environment and as a result stimulates growth, which at the same time gradually increase with the stepwise rising of the ragworm meal inclusion level.

Table 8.1: Diet names used in this thesis and general discussion with their specific features. During this study the diet for sole based on the composition of ragworm changed sequentially, therefore we introduced the term "generation" for the consecutive experimental pellets.

\begin{tabular}{|c|c|c|c|c|c|c|}
\hline \multicolumn{2}{|l|}{ Diet } & $\begin{array}{c}\text { Commercial } \\
\text { pellet }\end{array}$ & $\begin{array}{c}\text { Fresh } \\
\text { ragworm }\end{array}$ & $\begin{array}{c}1^{\text {st }} \\
\text { generation }\end{array}$ & $\begin{array}{c}2^{\text {nd }} \\
\text { generation }\end{array}$ & $\begin{array}{c}3^{\text {rd }} \\
\text { generation }\end{array}$ \\
\hline \multicolumn{2}{|l|}{ Code } & CPEL & RW & RW75 & $\mathrm{HB}_{12}$-LTau & EBLDM \\
\hline \multicolumn{2}{|c|}{ Description } & $\begin{array}{c}\text { Marine diet }> \\
85 \% \\
\text { ingredients } \\
\text { from fish }\end{array}$ & $\begin{array}{l}\text { Fresh } \\
\text { ragworm }\end{array}$ & $\begin{array}{c}75 \% \\
\text { ragworm } \\
\text { meal (freeze } \\
\text { dried) } \\
\end{array}$ & $\begin{array}{l}\text { Mainly plant } \\
\text { ingredients }\end{array}$ & $\begin{array}{l}\text { Mainly plant } \\
\text { ingredients }\end{array}$ \\
\hline \multicolumn{2}{|c|}{ Proximate composition $^{a}$} & $b$ & $b$ & $b$ & $b$ & $c$ \\
\hline $\mathrm{DM}$ & $\left(\mathrm{g} \mathrm{kg}^{-1}\right)$ & 923 & 164 & 770 & 917 & 935 \\
\hline $\mathrm{ASH}$ & $\left(\mathrm{g} \mathrm{kg}^{-1} \mathrm{dm}\right)$ & 120 & 128 & 178 & 91 & 101 \\
\hline $\mathrm{CP}^{a}$ & $\left(\mathrm{~g} \mathrm{~kg}^{-1} \mathrm{dm}\right)$ & 673 & 659 & 539 & 655 & 636 \\
\hline $\mathrm{EE}$ & $\left(\mathrm{g} \mathrm{kg}^{-1} \mathrm{dm}\right)$ & 93 & 79 & 99 & 123 & 115 \\
\hline $\mathrm{CF}^{a}$ & $\left(\mathrm{~g} \mathrm{~kg}^{-1} \mathrm{dm}\right)$ & $<3.0$ & 18 & 17 & 5.5 & 28 \\
\hline NFE & $\left(\mathrm{g} \mathrm{kg}^{-1} \mathrm{dm}\right)$ & 37 & 116 & 168 & 42.4 & 55 \\
\hline GE & $\left(\mathrm{MJ} \mathrm{kg}^{-1}\right)$ & 20.3 & 21.1 & 19.9 & 21.2 & 21.5 \\
\hline $\mathrm{CP} / \mathrm{GE}$ & ---------- & 33.1 & 31.2 & 27.1 & 30.9 & 29.6 \\
\hline \multicolumn{2}{|c|}{ Production process } & $\begin{array}{l}\text { Cooking } \\
\text { extrusion }\end{array}$ & $\begin{array}{c}\text { Not } \\
\text { applicable }\end{array}$ & $\begin{array}{c}\text { Cold } \\
\text { extrusion }\end{array}$ & $\begin{array}{c}\text { Cold } \\
\text { extrusion }\end{array}$ & $\begin{array}{c}\text { Cold } \\
\text { Extrusion }\end{array}$ \\
\hline \multicolumn{2}{|c|}{ Ragworm extract } & No & No & No & Yes & Yes \\
\hline \multicolumn{2}{|c|}{ Iron (mg kg-1 $\mathrm{dm})$} & $277^{\mathrm{b}}$ & $352^{\mathrm{b}}$ & $1406^{b}$ & $320^{\mathrm{b}}$ & $326^{\mathrm{c}}$ \\
\hline \multicolumn{2}{|c|}{ Iron source } & $\begin{array}{c}\text { mineral and } \\
\text { damaged } \\
\text { heme }\end{array}$ & heme & $\begin{array}{l}\text { mineral and } \\
\text { heme }\end{array}$ & heme & heme \\
\hline \multicolumn{2}{|c|}{ Taurin $\left(\mathrm{g} \mathrm{kg}^{-1} \mathrm{dm}\right)$} & $3.5^{\mathrm{b}}$ & $7.6^{b}$ & $4.0^{\mathrm{b}}$ & $3.5^{\mathrm{c}}$ & $3.5^{\mathrm{c}}$ \\
\hline \multicolumn{2}{|c|}{$B_{12}\left(\mathrm{ug} \mathrm{kg}^{-1} \mathrm{dm}\right)$} & $338^{b}$ & $1602^{b}$ & $571^{\mathrm{b}}$ & $1330^{b}$ & $3335^{\mathrm{c}}$ \\
\hline
\end{tabular}


Consequently, Hct and growth were highly correlated in this trial. In a follow-up growth trial (not described in this thesis) we compared the so called $3^{\text {rd }}$ generation pellet (table 8.1) with fresh ragworm (Topsy Baits, the Netherlands). In chapter 7 we demonstrated that the applied level of $\mathrm{B}_{12}$ was unable to completely alleviate the nutritional anaemia in sole, even though it had a significant effect on the Hct and Hb level. Diets were fed ad lib. The specific growth rate (SGR) of sole fed the so called $3^{\text {rd }}$ generation experimental pellet was $1.29 \pm 0.008 \% . \mathrm{d}^{-1}$ and comparable $(\mathrm{p}>0.05)$ to the SGR of sole fed fresh ragworm $\left(1.24 \pm 0.12 \% . \mathrm{d}^{-1}\right)$. However, the Hct $(20.1 \pm 0.8 \%, \mathrm{p}<0.05)$ and $\operatorname{Hb}\left(38.0 \pm 0.98 \mathrm{~g} . \mathrm{l}^{-1}, \mathrm{p}<0.05\right)$ level of the sole fed fresh worm were much higher than the Hct $(12.7 \pm 0.95 \%)$ and $\mathrm{Hb}$ $\left(16.1 \pm 1.24\right.$ g. $\left.1^{-1}\right)$ level of the sole fed the $3^{\text {rd }}$ generation experimental pellet. This result does not fit with the hypothesis that the slow growth of pellet fed sole might be the consequence of low Hct and $\mathrm{Hb}$ levels, which hampers oxygen uptake and lowers therewith overall metabolic capacity, including the scope for growth (chapter 4). Maximum oxygen uptake $\left(\mathrm{VO}_{2} \max \right)$ falls off sharply with lower Hct and Hb levels as the oxygen carrying capacity (OCC) of blood is primarily determined by the concentration of $\mathrm{Hb}$ in the red blood cells (Gallaugher \& Farrell, 1998). Therefore, lower Hct and Hb levels in sole are likely to cause a decrease in the OCC of the blood and as a result a reduction in the metabolic scope of sole, including the scope for growth. Nevertheless, the growth rate achieved in sole fed the $3^{\text {rd }}$ generation experimental pellet, which was comparable to the growth rate of sole fed fresh ragworm, could not have been the consequence of increasing Hct and Hb levels as these were comparable to the levels found in sole fed commercial pellets. The average water temperature during this experiment, were the sole was fed the $3^{\text {rd }}$ generation experimental pellet, was 18.4 $\pm 0.4^{\circ} \mathrm{C}$.

In this respect, the relation between feed intake (dry matter basis) and water temperature in my opinion is interesting (Figure 8.1). The positive effect of ragworm on feed intake increases with rising culture temperatures and seems to disappear at temperatures below $12^{\circ} \mathrm{C}$. This is quite plausible taking into account the theory of an increasing OCC with increasing levels of Hct and $\mathrm{Hb}$. The apparent relation between Hct and the metabolic growth rate at different temperatures, $14.7^{\circ} \mathrm{C}, 16.0^{\circ} \mathrm{C}$ and $17.2^{\circ} \mathrm{C}$, respectively (Figure 8.2), suggests that higher Hct levels give sole the possibility to improve growth, especially at higher culture temperatures. The latter may result in more economically interesting growth rates. 


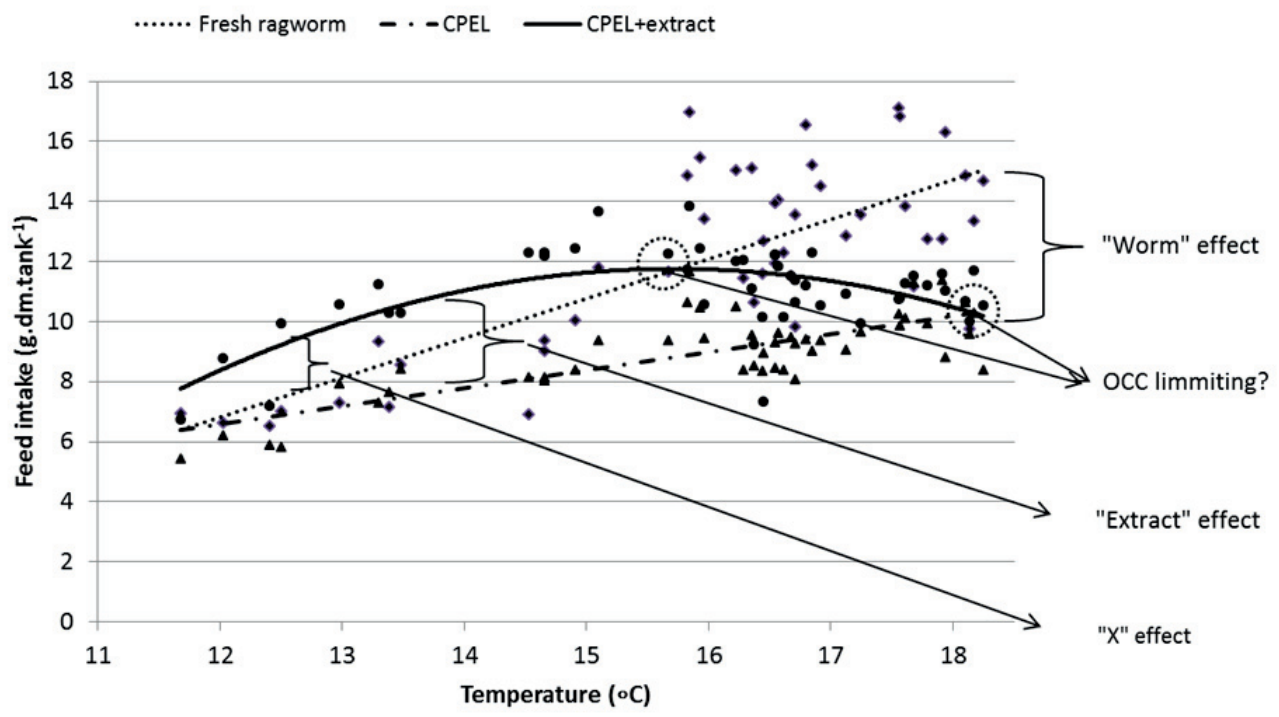

Figure 8.1: Relation between feed intake on dry matter basis and temperature for sole fed the commercial pellet $\left(y=0.5986 x-0.59, R^{2}=0.59, p=0\right)$; treated pellet $\left(y=-0.2448 x^{2}+7.694 x-48.701, R^{2}=0.40, p=0\right)$ and fresh ragworm ( $\left.y=1.3198 x-9.0295, R^{2}=0.58, p=0\right)$ (unpublished data). The "worm" effect in relation to temperature on feed intake between fresh ragworm and the commercial pellet can be calculated by $y=0.7212 \mathrm{X}$ -8.44 , the effect of adding the extract onto the commercial pellet in relation to temperature on feed intake can be calculated by $y=-0.2448 x^{2}+7.095 x-48.111$ and de difference in feed intake between the treated pellet and fresh ragworm in relation to temperature can be calculated by $y=-0.2448 x^{2}+6.374 x-39.672$. Temperature $\left({ }^{\circ} \mathrm{C}\right)$ is represented on the $x$-axis and feed intake $\left(\right.$ g.dm.tank $\left.k^{-1}\right)$ on the $y$-axis. Proximate composition of commercial pellet (crude protein $63 \%$, ether extract $14 \%$ and ash $12 \%$ ) and ragworm (crude protein $71 \%$, ether extract $13 \%$ and ash $12 \%$ ).

This observation fits with the data of Mas Muñoz (2013). She found an interaction between type of feed (pellet $v s$. ragworm) and culture environment (inside $v s$. outside) on growth. In her study, the average temperature between the culture environments differed $3.3^{\circ} \mathrm{C}\left(19.2 \pm 0.5^{\circ} \mathrm{C} v s .15 .9 \pm 1.5^{\circ} \mathrm{C}\right)$. The positive effect of feeding ragworm on the growth rate of common sole disappears at lower water temperatures even though the Hct levels of these fish were 85 to $98 \%$ higher than in sole fed with untreated pellets (chapter 2). The effect disappears, probably due to a combination of a lower standard metabolic rate and the rising oxygen levels in the culture water with the lower temperature. Schram, Bierman, Teal, Haenen, Vis van de, \& Rijnsdorp (2013) tested four different water temperatures, $19^{\circ} \mathrm{C}, 22^{\circ} \mathrm{C}$, $25^{\circ} \mathrm{C}$ and $28^{\circ} \mathrm{C}$, respectively to study the thermal preferences of sole. They found that, the optimal water temperature is $22.7^{\circ} \mathrm{C}$ for common sole (30 to $50 \mathrm{~g}$ ), when feed intake, specific growth rate and feed conversion rate are used as parameters. 


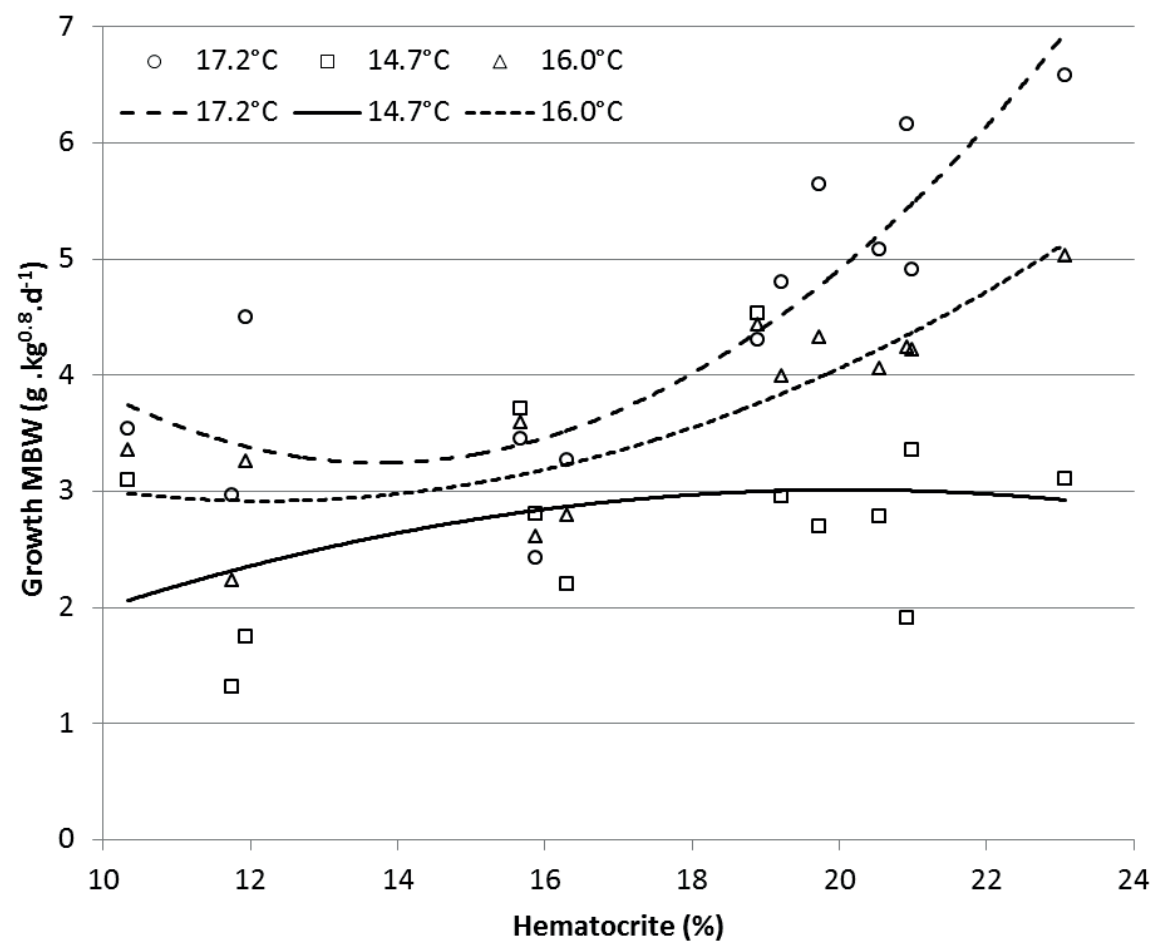

Figure 8.2: The relation between Hct (\%) and metabolic growth rate $\left(g . \mathrm{kg}^{0.8} \cdot \mathrm{d}^{-1}\right)$ at $14.7^{\circ} \mathrm{C}, 16.0^{\circ} \mathrm{C}$ and $17.2^{\circ} \mathrm{C}$, respectively.

In this respect it is interesting to note that the soles were fed ragworm using an ad lib feeding strategy. Most likely these soles had high Hct and $\mathrm{Hb}$ levels as found repeatedly in the sole fed ragworm in this thesis. It would have been interesting to execute this study also with sole fed the commercial pellet, measuring $\mathrm{Hct}$ and $\mathrm{Hb}$ and compare the results subsequently. Based on our reasoning of above and knowing that soles fed with commercial pellets suffer from an anaemia, we expected that in this case, the "optimal" temperature would have been lower. Our hypothesis is supported by the results from another trial executed by Teal, Schram, de Laat \& Rijnsdorp (2014). In the latter trial the effect of four different water temperatures: $16^{\circ} \mathrm{C}, 20^{\circ} \mathrm{C}, 23^{\circ} \mathrm{C}$ and $26^{\circ} \mathrm{C}$ were tested amongst others, on growth of sole $(122 \pm 32 \mathrm{~g})$. In the latter experiment, the soles were fed the diet $\mathrm{HB}_{12}$-LTau (chapter 7). The Hct and $\mathrm{Hb}$ levels (varying between 12.6 and $13.9 \%$ and 16.7 to $19.3 \mathrm{~g} / \mathrm{l}$, respectively) were not affected by water temperature (table 8.2) (Kals unpublished data). Growth was affected by water 
temperature $(\mathrm{p}<0.05)$. Interestingly, this time the optimal temperature for growth was $16^{\circ} \mathrm{C}$ (Figure 8.3) and almost $7^{\circ} \mathrm{C}$ lower compared to the optimal temperature found for sole in the first study of Schram et al. (2013) were the soles were fed ragworm. A water temperature of $16^{\circ} \mathrm{C}$ was also the optimal temperature for feed intake of sole fed the treated pellet (Figure 8.1).

Table 8.2. Levels of Haematocrit (Hct) and values of Haemoglobin (Hb) and standard deviations in sole at start and after 49 days at four different temperature, $\mathrm{T}$ in ${ }^{\circ} \mathrm{C}$ when fed the $2^{\text {nd }}$ generation pellet $\left(H B_{12}\right.$-LTau from chapter 7 ) (Kals unpublished data).

\begin{tabular}{cccc}
\hline $\mathbf{T}\left({ }^{\circ} \mathbf{C}\right)$ & Day & Het(\%) & Hb $\left.\mathbf{g ~ I}^{-1}\right)$ \\
\hline 16 & 0 & $12.3 \pm 2.3$ & $16.1 \pm 4.0$ \\
16 & 49 & $13.0 \pm 1.1$ & $18.1 \pm 1.4$ \\
20 & 49 & $12.6 \pm 0.3$ & $16.7 \pm 3.6$ \\
23 & 49 & $13.7 \pm 1.1$ & $17.0 \pm 4.3$ \\
26 & 49 & $13.9 \pm 0.4$ & $19.3 \pm 2.1$ \\
p-value & --- & 0.31 & 0.83 \\
\hline
\end{tabular}

Means within columns are not significantly different using one way ANOVA $(P<0.05)$.

In feeding trials, usually the temperature is fixed and performance parameters such as feed intake, specific growth rate and feed conversion rate are determined for the different dietary treatments. However, Hct and or Hb levels are often not measured and hence the information about the anaemic status of the experimental fish is unknown. Yet, as shown in this thesis, diet can have a significant effect on the Hct and or Hb level and consequently on the performance data. Vice versa, the anaemic status of the fish in combination with temperature and oxygen content of the water will influence feed intake, assimilation efficiency and growth of the tested fish. Therefore, we infer that when Hct and or Hb levels are not measured, interpretation of the results of growth and feeding experiments may lead to wrong interpretations. 


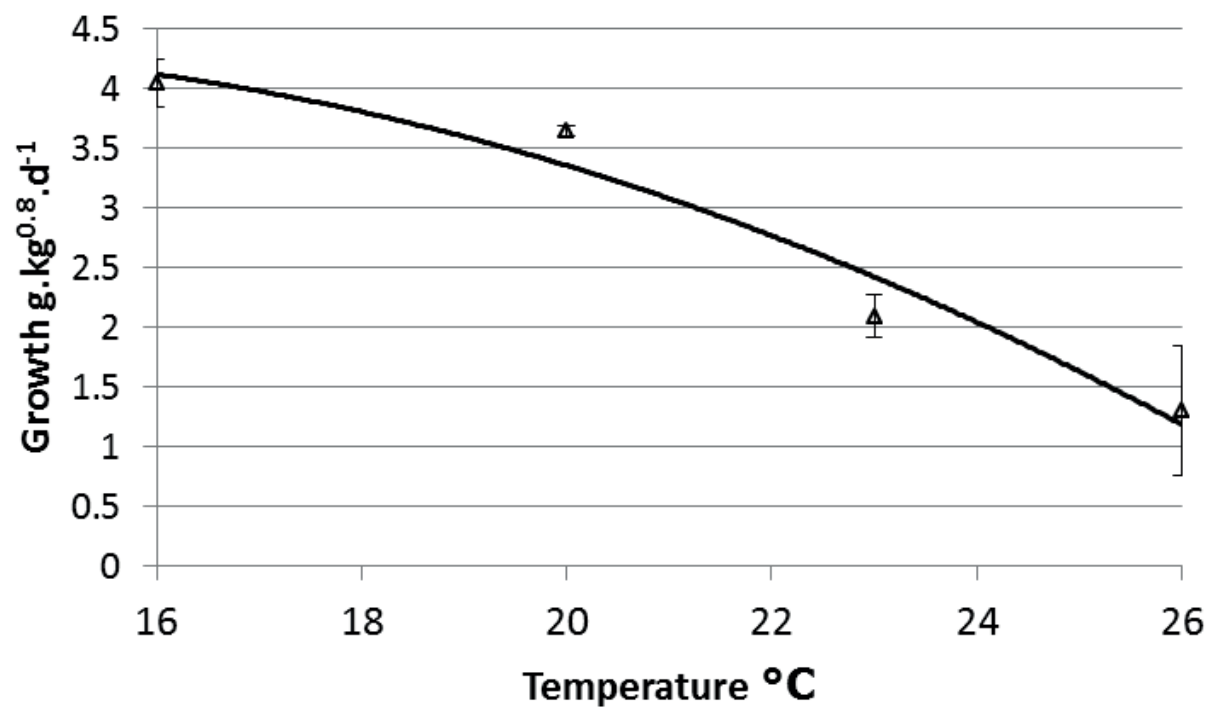

Figure 8.3: Growth of sole in g. $\mathrm{kg}^{0.8} \cdot \mathrm{d}^{-1}$ in relation to temperature fed diet $\mathrm{HB}_{12}$-LTau (chapter 7) (data from Teal, Schram, de Laat \& Rijnsdorp 2014).

\section{The "extract" effect}

The "extract" effect on the feed intake of sole in figure 8.1 is most likely caused by attractants and feed stimulating compounds within the ragworm extract as previously reported by Barata, Hubert, Conceição, Velez, Rema, Hubbard \& Canário (2009) for a polychaete homogenate. Moreover, Velez, Hubbard, Hardege, Welham, Barata \& Canário (2011) specifically identified 1-methyl-L-tryptophan as a food related odorant for sole which is excreted by ragworm. For the mechanisms of feed intake regulation and the role of feed attractants and stimulants we refer to the papers of Mackie, Adron \& Grant (1980), Mackie \& Mitchell (1982, 1983, 1985), Schwartz, Woods, Porte, Seeley \& Baskin (2000), Volkoff \& Peter (1999, 2000, 2001), Volkoff, Bjorklund \& Peter (1999), Volkoff, Eykelbosh \& Peter (2003) and Volkoff, Canosa, Unniappan, Cerda-Reverter, Bernier, Kelly \& Peter (2005). The extract effect on feed intake seems to work until the oxygen carrying capacity (OCC) or the available oxygen is limiting (figure 8.1). 


\section{The "X" effect}

We cannot explain the "X" effect on the feed intake of sole in figure 8.1. Yet, the higher feed intake of sole fed the treated pellet compared to sole fed ragworm could have been caused by a difference in the dry matter, and therefore the energy density between ragworm and the treated pellet. The limited volume of the "stomach" or anterior intestine may have limited the feed intake of sole fed ragworm as suggested by Ende, Kroeckel, Schrama, Schneider \& Verreth (2014). This effect might be larger at low temperatures as metabolic activity and mobility (of the gut) is expected to be lower. They also found that both the nutrient as well as the energy efficiency are higher in sole fed ragworm, compared to sole fed commercial pellets. Assuming feed intake is regulated by the sole's demand of digestible energy and or nutrients, the feed intake of the treated commercial pellet should be higher until the oxygen carrying capacity (OCC) becomes limiting, which seems to be the case at about $16.0^{\circ} \mathrm{C}$ when feeding the treated pellet.

\section{Vitamin $B_{12}$ and respiration}

Why do mussel and ragworm contain relatively high concentrations of vitamin $\mathrm{B}_{12}$ ? As mentioned earlier both mussel and ragworm often experience hypoxic conditions (Grieshaber et al. 1994). Maxwell, (1951) suggested that vitamin $B_{12}$ may be a factor in species (sometimes) living in conditions with low oxygen tension. He discovered that in the sea mouse (Aphrodite negligens, Moore), a polychaete living in muddy sea bottoms $60 \%$ of the total vitamin $\mathrm{B}_{12}$ content is found in the skin. This suggests a specific metabolic function or role of vitamin $\mathrm{B}_{12}$ in respiration. It might be that vitamin $\mathrm{B}_{12}$ has a function in respiration at critical oxygen levels.

Vitamin $\mathrm{B}_{12}$ is a collective term for a group of cobalt-containing compounds, which are known as cobalamins. The known different types of cobalamins are cyanocobalamin, hydroxocobalamin, methylcobalamin, adenosylcobalamin and aqua cobalamin. Cobalamins belong to the group of corrinoids which are based on corrin, a cyclic compound containing four pyrrole groups similar to porphyrins (Valentin \& Ruma 2013). The respiratory pigment heme from haemoglobin is a porphyrin. Under physiological conditions i.e. the physiological conditions within most organisms $\mathrm{Co}^{3+}, \mathrm{Co}^{2+}$, and $\mathrm{Co}^{1+}$ forms/states of cobalamins do occur. 


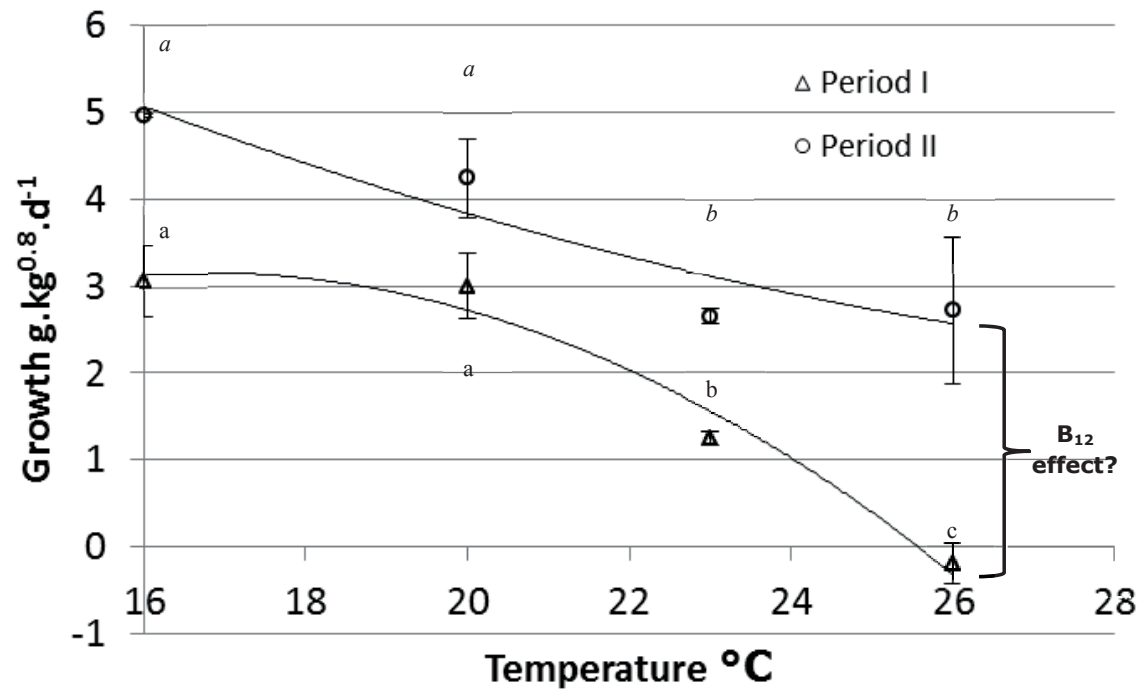

Figure 8.4: Growth of sole in $\mathrm{g} . \mathrm{kg}^{0.8} . \mathrm{d}^{-1}$ in relation to temperature fed the $2^{\text {nd }}$ generation pellets (HB $12-L T a u$ of chapter 7) during period I and II (data from Teal, Schram, de Laat \& Rijnsdorp 2014). ${ }^{a b c}$ Means within a period (I or II) with a common superscript are not significantly different using the Fisher LSD post hoc test $(p<0.05)$

The conversion of aqua- $\mathrm{Co}^{3+}$-corrinoids to $\mathrm{Co}^{2+}$ complexes occurs relatively easily. $\mathrm{Co}^{2+}$-corrinoids react with oxygen through a fast reversible oxygen binding step, eventually yielding the $\mathrm{Co}^{3+}$ state through the reaction formula $\mathrm{Co}^{2+}+\mathrm{O}_{2} \leftrightarrow \mathrm{Co}^{3+}-\mathrm{O}_{2} \bullet-\longrightarrow \mathrm{Co}^{3+}-$ solv. + $\mathrm{H}_{2} \mathrm{O}_{2}+\mathrm{O}_{2}$ (Derevenkov, Salnikov, Silaghi-Dumitrescu, Makarov \& Koifman 2016) which could possibly provide an alternative oxygen source.

Data from a trial executed by Teal et al. (2014) show that the growth of sole fed diet $\mathrm{HB}_{12}$-LTau from chapter 7 with high dietary $\mathrm{B}_{12}$ differed between the first (period I or the first 24 days) and second period (period II or the second 25 days) (figure 8.4). However, even though the Hct and $\mathrm{Hb}$ levels were not different from the values at the start ( $p>0.05)$, and not different between the different culture temperatures $(p>0.05)$ (table 8.1$)$, the growth was significantly higher in period II ( $\mathrm{p}=0.01)$ compared to period I (figure 8.4$)$. Therefore, in my opinion, it would be interesting to test the hypothesis that vitamin $\mathrm{B}_{12}$ has a function in respiration at critical oxygen levels in sole.

We measured total vitamin $\mathrm{B}_{12}$ in blood plasma of sole and found average values 71.6 ng. $\mathrm{ml}^{-1}$ (unpublished data), which is about 80 to 350 times higher than the reference values for humans (0.2-0.9 ng. $\left.\mathrm{ml}^{-1}\right)$ and about 30 to 200 times the values found for Channel catfish (Ictalurus punctatus) and Nile Tilapia (Oreochromis niloticus) (Limsuwan \& Lovell (1981); 
Lovell \& Limsuwan (1982)). It would be interesting to analyse the vitamin $\mathrm{B}_{12}$ content of the skin of sole and at the same time test the hypothesis if vitamin $\mathrm{B}_{12}$ has a specific metabolic function in the respiration of sole, as suggested for the seamouse (Aphrodite negligens, Moore) by Maxwell (1951). This hypothesis could be tested by conducting a feeding trial using respiration cells as experimental units and diets with two or more different dietary $\mathrm{B}_{12}$ levels in sole. The results of such a trial might explain part of the improved growth achieved with the $3^{\text {rd }}$ generation pellet, containing a high level of $B_{12}$, without increasing the Hct and $\mathrm{Hb}$ levels of the sole fed this diet.

\section{Vitamin $B_{12}$ as a hydrogen sulfide antidote}

In acidic- and neutral environments under anaerobic conditions, aqua cobalamin reacts with hydrogen sulfide $\left(\mathrm{H}_{2} \mathrm{~S}\right)$. Therefore, aqua cobalamin might work as an antidote for $\mathrm{H}_{2} \mathrm{~S}$. An antidote is a compound counteracting the effects of a toxin or disease. Hydrogen sulfide is a potent toxin. Several recent studies report that high doses of $\mathrm{Cbl}^{3+}-\mathrm{OH}_{2}\left(\mathrm{Co}^{3+}\right.$ aqua cobalamin or Cbl (III) aqua cobalamin) can decrease mortality associated with $\mathrm{H}_{2} \mathrm{~S}$ exposure (Truong, Mihajlovic, Gunness, Hindmarsh \& O'Brien 2007; Haouzi, Chenuel \& Sonobe 2015; Brenner, Benavides, Mahon, Lee, Yoon, Mukai, Viseroi, Chan, Jiang, Narula, Azer, Alexander \& Boss 2014). Suggested mechanisms of actions of $\mathrm{Cbl}^{3+}$ as an antidote includes the binding of $\mathrm{H}_{2} \mathrm{~S}$ to $\mathrm{Co}^{3+}$ or oxidation of $\mathrm{H}_{2} \mathrm{~S}$ by $\mathrm{Co}^{3+}$ (Salnikov, Makarov, Eldik, Kucherenko \& Boss, 2014; Haouzi, Chenuel \& Sonobe, 2015). Ragworm exhibits a relatively high sulfide tolerance (Abele-Oeschger, Oeschger \& Theede, 1994). The question, whether cobalamin protects for $\mathrm{H}_{2} \mathrm{~S}$ exposure in demersal marine species like mussel, ragworm and sole would be interesting to study.

\section{Practical implications}

\section{The economic impact of improved growth rate in sole culture}

The commercial culture of sole is hampered by slow growth (Mas-Muñoz, 2013). According to Ende et al. (2014), the absence of an adequate feed for sole is a major obstacle towards a viable cultivation of sole. When sole is fed the right diet, the growth can increase 
with $70 \%$ compared compared to the most common commercial diets at the start of this study. This thesis shows that the slow growth is indeed due to the absence of an adequate feed for sole which is currently solved by the $3^{\text {rd }}$ generation pellet.

It is difficult to estimate economic values of biological parameters which enable to assess the economic effect of zootechnical interventions (e.g. a breeding program to improve growth, or the introduction of an improved feed). Blonk (2010) compared the effect of different breeding strategies with the focus on stimulating growth to improve the profitability of a sole farm. The economic value of the "trait" growth rate in common sole is $€ 2.63 /$ g. $\mathrm{d}^{-1}$ per individual. Further assumptions were: FCR 1.2, Feed price $€ 1,00 \mathrm{~kg}^{-1}$, sale price sole $€$ $9,00 \mathrm{~kg}^{-1}$ (Blonk 2010). When sole was fed the $3^{\text {rd }}$ generation pellet we achieved an average growth rate of $1.29 \pm 0.008 \% . \mathrm{d}^{-1} \approx 0.89$ g. $\mathrm{d}^{-1}$, which is comparable with the average growth rate of $1.24 \pm 0.12 \% . \mathrm{d}^{-1} \approx 0.86{\mathrm{~g} . \mathrm{d}^{-1}}^{-1}$ for sole fed ragworm (Figure 8.5 left). Weight of the fish at start was about $40 \mathrm{~g}$. Harvest weight was about $90 \mathrm{~g}$. The extrapolated increase in weight based on the results achieved with the executed growth trials is shown in figure 8.5 (right).

The expected average growth in $\mathrm{g} \cdot \mathrm{d}^{-1}$ for sole fed commercial pellets growing from $40-90 \mathrm{~g}$, using the formula for SGR $\left(\mathrm{SGR}=6 * \mathrm{BW}^{\wedge-0.6}\right)$, is $0.32 \mathrm{~g} \cdot \mathrm{d}^{-1}$. The expected average growth in $\mathrm{g} . \mathrm{d}^{-1}$, using the formula for the $3^{\text {rd }}$ generation pellet $\left(\mathrm{SGR}=27.783 * \mathrm{BW}^{\wedge-0.761}\right)$, is $0.76 \mathrm{~g} . \mathrm{d}^{-1}$. This implies an improvement of $140 \%$.
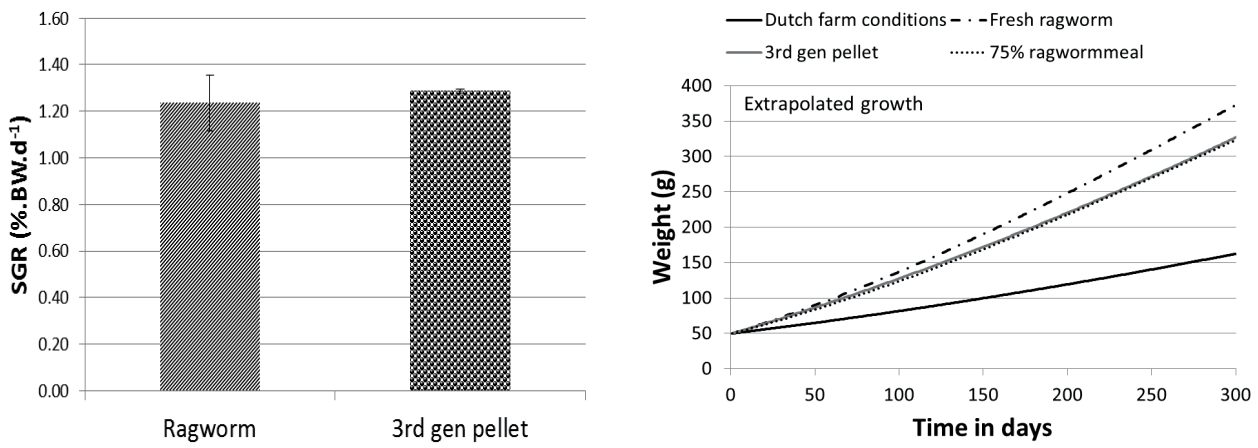

Figure 8.5: the growth of sole fed ragworm or the $3^{\text {rd }}$ generation pellet ( Left). The extrapolated weight increase is based on results achieved with the executed growth trails (Right), with "Dutch farm conditions" representing the average performance of sole grown at Solea B.V., " 3 rd gen pellet representing the extrapolated results achieved with feeding sole the $3^{\text {rd }}$ generation pellet, "Fresh ragworm", the results achieved with feeding sole fresh ragworm and "75\% ragwormmeal" the extrapolated results achieved with feeding sole recipe RW75 from chapter 5 . 
Over the whole grow-out period of sole (i.e. 50-300g) the numbers are 0.33 g.d $\mathrm{d}^{-1} v s$. 0.71 g. $\mathrm{d}^{-1}$, based on the formulas $\mathrm{SGR}=6 * \mathrm{BW}^{\wedge-0.6}$ and $\mathrm{SGR}=27.783 * \mathrm{BW}^{\wedge-0.761}$, respectively. The increase in growth is then $0.71-0.33{\mathrm{~g} . \mathrm{d}^{-1}}^{-1}$ Consequently, the time needed to achieve a $300 \mathrm{~g}$ sole halved, making it possible to produce more fish in the same time. In economic terms using the data from Blonk (2010) and Hoon (2009), the increase in economic value would be $(0.71-0.33) * € 2.63=€ 1,0$ per individual or $€ 900.000$ annually, in a farm with a standing stock of 900.000 soles. When corrected for the feed price of $€ 1,65$ per $\mathrm{kg}$ for the $3^{\text {rd }}$ generation pellet after optimisation for cost price, instead of the assumed feed price of $€ 1,0$ per $\mathrm{kg}$, the obtained economic value would be $€ 0,81$ per individual sole $(=€ 1,0-((0.300 \mathrm{~kg}$ $-0.050 \mathrm{~kg}) * 1.2) *(€ 1,65-€ 1,-))$ or $€ 729.000$ annually, in a farm with a standing stock of 900.000 soles. Based on these numbers, the availability of a proper commercial feed for sole will stimulate the culture of sole as the expected obtained economic value per individual would be $\left(€ 2,63 * 0.71\right.$ g.d $\mathrm{d}^{-1}-(€ 1,0-€ 0,81)=€ 1,66$ instead of the $\left(€ 2,63 * 0.33\right.$ g. $\left.\mathrm{d}^{-1}\right)=€$ 0,87 calculated under "current" Dutch farm conditions. This represents an increase of $91 \%$ compared to the "current" Dutch farm conditions. Apart from this it can be expected that with a proper diet and a shorter grow-out period the survival rate, also a major determinant of profitability according to Hoon (2009), will increase as well. In addition, it is expected that animal welfare under farm conditions will be improved because sole will be fed a more suitable diet.

\section{Suggestions for further research}

An experiment to test whether the effect of dietary EPO levels is comparable to the effect of the levels found in mussel and ragworm is necessary to exclude EPO from having a role in affecting the $\mathrm{Hct}$ and $\mathrm{Hb}$ levels and therefore, having a role in the alleviation of anaemia in sole fed mussel or ragworm.

The combination of sole and ragworm is a unique tool to study an ecosystem approach of the total "nutritional" value, including the, basic nutritional value, functional value and or undefined growth or health factors, of an additive, feed ingredient or a diet. This is an interesting subject for future research to support the development of innovative aquatic diets to enhance growth, health and welfare of sole.

It would be interesting to test the hypothesis whether vitamin $\mathrm{B}_{12}$ has a specific metabolic function in the respiration in sole. This hypothesis could be tested by conducting a 
feeding trial using respiration cells as experimental units and diets with different dietary $\mathrm{B}_{12}$ levels affecting and not affecting the Hct and $\mathrm{Hb}$ levels in sole. The results of such a trial might explain part of the improved growth achieved with the $3^{\text {rd }}$ generation pellet without increasing $\mathrm{Hct}$ and $\mathrm{Hb}$ levels of the sole fed this diet.

In acidic- and neutral environments under anaerobic conditions, aqua cobalamin reacts with hydrogen sulfide $\left(\mathrm{H}_{2} \mathrm{~S}\right)$. Ragworm exhibits a relatively high sulfide tolerance. Aqua cobalamin might work as an antidote for $\mathrm{H}_{2} \mathrm{~S}$. The question, does cobalamin have a protective function associated with $\mathrm{H}_{2} \mathrm{~S}$ exposure in demersal marine species like mussel, ragworm and sole or not, seems an interesting hypothesis.

Feeding trials that evaluate the necessity of the ingredients added to mimic the composition of ragworm (e.g. astaxanthin) when fed the $3^{\text {rd }}$ generation pellet, could show that some of these ingredients can be left out.

An experiment testing the effect of cold extrusion $v s$. cooking extrusion and or steam pelleting on the nutritional value of the artificial diet for sole is economically interesting. If the process of cold extrusion appears to be redundant the cost of the recipe is expected to decrease with about $30 \%$. Moreover, scaling up production will be more easier as the production process can be implemented in current extrusion lines. In total there seems to be potential to decrease costs up to about $50 \%$ compared to the $€ 3,25$ mentioned earlier getting to a price of about $€ 1,65$ per $\mathrm{kg}$. If, with a feed price of $€ 1,65$ per $\mathrm{kg}$, the commercial implementation of the feed has potential, the production process has to be scaled up and tuned to meet demand.

\section{Concluding remarks}

The following conclusions can be drawn from the present study:

- Sole fed commercial pellets are suffering from a nutritional anaemia, which can be alleviated by subsequently feeding ragworm (Nereis virens Sars.) or Mussel (Mytilus edulis L.).

- Iron absorption in sole is high and independent of the iron source.

- The nutritional anaemia in sole is not due to an iron or copper deficiency. 
- Haematocrit and haemoglobin levels in anaemic sole are influenced by a "high" level of dietary $\mathrm{B}_{12}$.

Practically, this study developed an artificial diet based on the composition of ragworm. This formulation supports a growth performance comparable to sole fed fresh ragworm when fed under experimental conditions. The challenge at this moment is the economical optimization and commercial implementation of this formulation. 


\section{References}

Abele-Oeschger D., Oeschger R. \& Theede H. (1994). Biochemcial adaptations of Nereis diversicolor (Polychaeta) to temporarily increased hydrogen perioxide levels in intertidal sandflats. Marine Ecology Progress Series 106:101-110.

Arredondo M \& Núñez M.T. Iron and copper metabolism. (2005). Molecular Aspects of Medicine. 26 (4-5):31327.

Ashby D.R, Gale D.P., Busbridge M., Murphy K.G., Duncan N.D., Cairns T.D., Taube D.H., Bloom S.R., Tam F.W., Chapman R., Maxwell P.H. \& Choi P. (2010). Erythropoietin administration in humans causes a marked and prolonged reduction in circulating hepcidin. Haematologica 95 (3): 505-8. doi:10.3324/haematol.2009.013136.

Barata E.N., Hubert F., Conceição L.E.C., Velez Z., Rema P., Hubbard P.C. \& Canário A.V.M. (2009). Prey odour enhances swimming activity and feed intake in the Senegalese sole. Aquaculture 293,100-107.

Blonk R.J.W. (2010). Selecting sole: breeding programs for natural mating populations. $\mathrm{PhD}$ thesis, Wageningen University, Wageningen, The Netherlands, $174 \mathrm{pp}$.

Brenner M., Benavides S. Mahon S.B., Lee J., Yoon D. Mukai D., Viseroi M., Chan A., Jiang J., Narula N., Azer S.M., Alexander C. \& Boss G.R. (2014). The vitamin B12 analog cobinamide is an effective hydrogen sulfide antidote in a lethal rabbit model. Clinical Toxicology 52 (5): 490-497.DOI: $10.3109 / 15563650.2014 .904045$

Chou C.F., Tohari S., Brenner S. \& Venkatesh B. (2004). Erythropoietin gene from a teleost fish, Fugu rubripes. Blood 104: 1498-1503; doi:10.1182/blood-2003-10-3404.

Chilloux J., Neves A.L., Boulange C.L. \& Dumas M.E. (2016). The microbial-mammalian metabolic axis: a critical symbiotic relationship, Current opinion in clinical nutrition and metabolic care. 19, 250-256, ISSN: 1363-1950

Clark J., MacDonald N. \& Stark J.R. (1985). Metabolism in marine flatfish. II. Protein digestion in Dover sole (Solea solea L.). Comparative Biochemistry and Physiology B. 81, 217-222.

Derevenkov I.A., Salnikov D.S., Silaghi-Dumitrescu R., Makarov S.V. \& Koifman, O.I. (2016). Redox chemistry of cobalamin and its derivatives. Coordination Chemistry Reviews 309, 68-83. doi: 10.1016/j.ccr.2015.11.001

Ende S.S.W., Kroeckel S., Schrama J.W., Schneider O. \& Verreth J.A.J. (2014) Feed intake, growth, and nutrient retention of common sole (Solea, solea L.) fed natural pray and an artificial feed. Aquaculture Research 1-8.

Gallaugher P. \& Farrell A.P. (1998). Hematocrit and blood oxygen carrying capacity. In: Perry SF., Tufts B., (Eds.), Fish Physiology, vol. 17. Fish respiration. Academic Press, New York, pp 185-219.

Gocht, D. (2009). Expression and function of erythropoietin and its receptor in invertebrate nervous systems. Dissertation zur Erlangung des mathematisch-naturwissenschaftlichen Doktorgrades "Doctor rerum naturalium" der Georg-August-Universität Göttingen. 126 pp.

Grieshaber M.K., Hardewig I., Kreutzer U. \& Pörtner (1994). Physiological and metabolic responses to hypoxia in invertebrates. Reviews of physiology biochemistry and pharmacology, 125, 43-147.

Haouzi P., Chenuel B. \& Sonobe T. (2015). High-dose hydroxocobalamin administered after $\mathrm{H}_{2} \mathrm{~S}$ exposure counteracts sulfide-poisoning-induced cardiac depression in sheep. Clinical Toxicology 53(1): 28-36. doi: $10.3109 / 15563650.2014 .990976$.

Hoon, C. (2009). Derivation of economic weights in a breeding program for sole, Solea solea. BSc thesis. Wageningen University. 22pp.

Kals J., Blonk R.J.W., Mheen H.W. van der, Schrama J.W. \& Verreth J.A.J. (2015 ${ }^{\mathrm{a}}$ ). Feeding ragworm (Nereis virens Sars) increases haematocrit and haemoglobin levels in common sole (Solea solea L.). Aquaculture Research. http://dx.doi.org/10.1111/are.12767.

Kals J., Blonk R.J.W., Mheen H.W. van der, Schrama J.W. \& Verreth J.A.J. (2015 b). Mussel (Mytilus edulis L.) and ragworm (Nereis virens, Sars) both alleviate anaemia in common sole (Solea solea L.). Aquaculture Research. http://dx.doi.org/10.1111/are.12871

Kals J., Blonk R.J.W., Palstra A.P., Sobotta T.K., Mongile F., Schneider O., Planas J.V., Schrama J.W. \& Verreth J.A.J. $\left(2015^{\mathrm{C}}\right)$. Feeding ragworm (Nereis virens Sars) to common sole (Solea, solea L.) alleviates nutritional anaemia and stimulates growth. Aquaculture Research. http://dx.doi.org/10.1111/are.12919.

Kals J., Blonk R.J.W., Mheen H.W. van der, Schrama J.W. \& Verreth J.A.J. (2015 ${ }^{\mathrm{d}}$ ). Effect of different iron sources on the alleviation of nutritional anaemia in common sole (Solea, solea). Aquaculture. 451: 266270. http://dx.doi.org/10.1016/j.aquaculture.2015.08.036

Kemna E.H.J.M, Tjalsma H., Willems H.L., Swinkels D.W. (2008). Hepcidin: from discovery to differential diagnosis. Haematologica. 93:(1)90-97. DOI:10.3324/haematol.11705 
Kraemer K. \& Zimmermann M.B. (2007). Nutritional anemia. SIGHT AND LIFE Press. c/o SIGHT AND LIFE / DSM. Nutritional Products Ltd. Internet: www.sightandlife.org 400pp.

Kwong R.W.M. \& Niyogi, S. (2009). The interactions of iron with other divalent metals in the intestinal tract of a fresh water teleost, rainbow trout (Oncorhynchus mykiss). Comparative Biochemistry and Physiology C. 150, 442-449.

Lagardere J.P. (1987). Feeding ecology and daily food consumption of common sole, Solea vulgaris, Quensel, juvenile on the French Atlantic coast. Journal of Fish Biology 30, 91-104.

Lexa D. \& Saveant J.M. (1983). The electrochemistry of vitamin B12. Accounts of Chemical Research16 (7), 235-243 DOI: 10.1021/ar00091a001

Limsuwan T. \& Lovell R.T. (1981). Intestinal Synthesis and Absorption of Vitamin B-12 in Channel Catfish. Journal of Nutrition 1: 2125-2132.

Lovell R.T. \& Limsuwan T. (1982). Intestinal Synthesis and Dietary Non-essentiality of Vitamin B12 for Tilapia nilotica. Transactions of the American Fisheries Society 111, Issue 4.

Mackie A.M. (1982). Identification of gustatory feeding stimulants. In: Hara, T.J. (Ed.), Chemoreception in Fishes. Elsevier Science, Amsterdam, pp. 275-291.

Mackie A.M. \& Mitchell A.I. (1982). Further studies on the chemical control of the feeding behaviour in the Dover sole, Solea solea. Comparative Biochemistry and Physiology, 73, 89-93.

Mackie A.M. \& Mitchell A.I. (1983). Studies on the chemical nature of feeding stimulants for the juvenile Europeon eel, Anguilla anguilla (L.). Journal of Fish Biology, 22, 425-430.

Mackie A.M. \& Mitchell A.I. (1985). Identification of gustatory feeding stimulants for fish applications in aquaculture. In: Cowey, C.B., Mackie, A.M., Bell, G.J. (Eds.), Nutrition and Feeding in Fish. Academic Press, London, UK, pp. 177-190.

Mackie A.M., Adron J.W. \& Grant, P.T. (1980). Chemical nature of feeding stimulants for the juvenile Dover sole, Solea solea. L. Journal of Fish Biology, 16, 701-708.

Mas-Muñoz J. (2013). Variation in behaviour and growth of common sole: genetic and environmental influences. PhD thesis, Wageningen University, Wageningen, The Netherlands, 165pp.

Maxwell B.E. (1951). A study of vitamin B12 in some marine invertebrates. Thesis from the University of British Columbia Canada. $71 \mathrm{p}$.

NRC (2011). Nutrient requirements of Fish and Shrimp, Committee on Nutrient requirements of Fish and Shrimp, National Research Council. National Academies Press, Washington, D.C. 2011, 376pp.

Pawlak R., James P.S., Raj S., Cullum-Dugan D. \& Lucus D. (2012). Understanding vitamin B12. American Journal of Lifestyle Medicine 7,60-65.

Pradhan R.K., Saini S.K. Biswas J. \& Pati A.K. (1989). Influence of human urinary erythropoietin and Lthyroxine on blood morphology and energy reserves in two tropical species of fed and starved teleosts. General and Comparative Endocrinology 76: 382-389.

Salnikov D.S., Makarov S.V., Eldik R. van., Kucherenko P.N. \& Boss G.R. (2014). Kinetics and Mechanism of the Reaction of Hydrogen Sulfide with Cobalamin in Aqueous Solution. European Journal of Inorganic Chemistry, 25 4123-4133. doi: 10.1002/ejic.201402082 DOI: 10.1002/ejic.201301340.

Schram, E., Bierman, S., Teal, L.R., Haenen., O. van de Vis H. \& Rijnsdorp A.D. (2013). Thermal Preference of Juvenile Dover Sole (Solea solea) in Relation to Thermal Acclimation and Optimal Growth Temperature. PLoS ONE 8(4): e61357. doi:10.1371/journal.pone.0061357.

Stabili L., Schirosi R., Licciano M. \& Giangrande A. (2009). The mucus of Sabella spallanzanii (Annelida, Polychaeta): Its involvement in chemical defence and fertilization success. Journal of Experimental Marine Biology and Ecology 374, 144-149. DOI: 10.1016/j.jembe.2009.04.016

Schwartz M.W., Woods S.C., Porte D., Jr., Seeley R.J., \& Baskin D.G. (2000). Central nervous system control of food intake. Nature 404, 661-671.

Teal L.R., Schram E., Laat H. de; Rijnsdorp A.D. (2014). Response of dover sole to climate change: physiological and behavioral considerations. 9th International Flatfish Symposium, Washington, USA, 2014-11-09/2014-11-14

Truong D.H., Mihajlovic A., Gunness P., Hindmarsh W. \& O'Brien P.J. (2007). Prevention of hydrogen sulfide (H2S)-induced mouse lethality and cytotoxicity by hydroxocobalamin (vitamin B(12a)). Toxicology. 5; 242(1-3):16-22.

USDA (2016). National Nutrient Database for Standard Reference Release 28. https://ndb.nal.usda.gov/ndb/

Valentin C. \& Ruma B. (2013). "Chapter 10 Cobalt and Corrinoid Transport and Biochemistry". In Banci, Lucia (Ed.). Metallomics and the Cell. Metal Ions in Life Sciences 12. doi:10.1007/978-94-007-5561-10_9.

Velez Z., Hubbard P.C., Hardege J.D., Welham K.J., Barata E.N. \& Canário A.V.M. (2011). Evidence that 1methyl-L-tryptophan is a food-related odorant for the Senegalese sole (Solea senegalensis).

Aquaculture 314. 153-158. 
Volkoff H. \& Peter R.E. (2000). Effects of CART peptides on food consumption, feeding and associated behaviors in the goldfish, Carassius auratus: actions on neuropeptide Y-and orexin A-induced feeding. Brain Research. 887, 125-133.

Volkoff H. \& Peter R.E. (2001 $\left.{ }^{\mathrm{a}}\right)$. Characterization of two forms of cocaine- and amphetamine-regulated transcript (CART) peptide precursors in goldfish: molecular cloning and distribution, modulation of expression by nutritional status, and interactions with leptin. Endocrinology 142, 5076-5088.

Volkoff H. \& Peter R.E. $\left(2001^{b}\right)$. Interactions between orexin A, NPY and galanin in the control of food intake of the goldfish, Carassius auratus. Regulatory Peptides. 101, 59-72.

Volkoff H., Bjorklund J.M. \& Peter R.E. (1999). Stimulation of feeding behaviour and food consumption in the goldfish, Carassius auratus, by orexin-A and orexin-B. Brain Research. 846, 204-209.

Volkoff H., Eykelbosh A.J. \& Peter R.E. (2003). Role of leptin in the control of feeding of goldfish Carassius auratus: interactions with cholecystokinin, neuropeptide $\mathrm{Y}$ and orexin A, and modulation by fasting. Brain Research. 972, 90-109.

Volkoff H., Canosa L.F. Unniappan S., Cerda-Reverter J.M., Bernier N.J., Kelly S.P. \& Peter R.E. (2005). Neuropeptides and the control of food intake in fish. General and Comparative Endocrinology 142, 3 19.

Yaqoob N., Holotta M., Prem C., Kopp R. \& Schwerte T. (2009). Ontogenetic development of erythropoiesis can be studied non-invasively in GATA-1:DsRed transgenic zebrafish. Comparative Biochemistry and Physiology Part A: Molecular \& Integrative Physiology, 154, 2:270-278 http://dx.doi.org/10.1016/j.cbpa.2009.06.024.

Zelewsky A. von (1972). Ein Kobalt(II)-Corrin-Komplex als reversibler Sauerstoffträger. Eine ESR.spektroskopische Untersuchung. Helvetica Chimica Acta 55, 8, 2941-2947.

DOI: $10.1002 /$ hlca. 19720550825 


\section{Summary}

Before the start of this $\mathrm{PhD}$ study we did some exploratory experiments to sharpen our hypotheses. During these trials, we became aware that common sole (Solea solea L.) fed commercial pellets developed anaemia. When the diet of sole was changed from pellet to ragworm, (Nereis virens Sars) this anaemia was alleviated and the growth rate increased with 70 percent. Therefore, this study aimed to validate the potential of ragworm to alleviate anaemia in common sole and to identify the dietary requirements of common sole to alleviate this anaemia. At the same time it was aimed to explain part of the difference in growth between sole fed a commercial pellet and sole fed ragworm. Practically, this study aimed to develop a diet based on the composition of ragworm that will prevent anaemia and support a growth performance comparable to sole fed ragworm.

In chapter 2 we tested if the haematocrit (Hct) and haemoglobin ( $\mathrm{Hb})$ level will increase when the diet of common sole is changed from commercial pellets to ragworm. We showed a clear effect of ragworm on the Hct and $\mathrm{Hb}$ levels in sole. Feeding ragworm increases the Hct and $\mathrm{Hb}$ levels and alleviates the anaemia of common sole within 21 days in contrast to those kept on a diet of commercial pellets, which stayed anaemic. This indicated that the increase of Hct and $\mathrm{Hb}$ in sole is diet related. We suggested that the increase of Hct and $\mathrm{Hb}$ in sole can be a result of a difference in feed intake or the dietary composition between the commercial pellet and ragworm, and/or of a health promoting effect of ragworm.

In chapter 3 we provided evidence that feeding mussel also alleviated the anaemia in common sole. In chapter 4 three hypotheses were tested: (1) feeding ragworm alleviates the anaemia and positively affects the sole's metabolic performance reflected in feed intake, feed efficiency and growth; (2) the anaemia is alleviated by a higher feed intake when feeding ragworm, and (3) the anaemia is caused by an inflammatory response to infection. We demonstrated that pellet-fed sole are suffering from a nutritional anaemia and validated that feeding ragworm to sole, alleviates this nutritional anaemia. Moreover, the addition of a ragworm extract to the commercial pellet improves the feed intake to similar levels as in sole fed ragworm, but has only a limited effect on growth and does not improve the anaemic state of sole. The findings described in chapter 2 to $\mathbf{4}$ suggest a mismatch between the requirements of sole and the dietary composition of the commercial pellets.

Many nutritional factors can contribute to a nutritional anemia. However, the dietary level of crude protein, ether extract, amino acids, calcium or phosphate do not explain the 
difference in Hct levels between sole fed ragworm or pellets (chapter 5). Moreover, excessive intake of milk proteins, soy proteins and phytates or polyphenols from plant ingredients can also be excluded as the tested commercial pellet hardly contained these ingredients. In the exploratory experiments we compared the intake of iron, copper, cobalt, chrome, manganese, selenium and zinc between sole fed commercial pellets or boiled ragworm. Despite the fact that the iron intake of sole fed treated pellets versus sole fed boiled ragworm was comparable, the Hct level of sole fed boiled ragworm was significantly higher. Similarly, the intake of the other minerals mentioned in sole fed boiled ragworm were lower than in sole fed commercial pellets, yet sole fed boiled ragworm recovered from their anaemia, while sole fed commercial pellets stayed anaemic. This suggests that the higher Hct level in sole fed boiled ragworm is not due to a higher intake of dietary iron or the other minerals mentioned. Based on the findings in chapter $\mathbf{3}$ and chapter $\mathbf{5}$, we suggested that the ability of mussel, ragworm or ragworm meal to alleviate anaemia and improve growth in sole can be explained by a combination of heme iron and high levels of vitamin $\mathrm{B}_{12}$. To maintain the same Hct and growth levels as in sole fed fresh ragworm, pure ragworm meal should be fed tot the fish, instead of a compound diet. Moreover, data in chapter $\mathbf{5}$ suggests that feeding fresh ragworm has no added value over feeding a pellet containing $100 \%$ of freeze dried ragworm meal.

In chapter 6 we tested four hypotheses: 1) the nutritional anaemia in sole fed commercial pellets is caused by an iron deficiency, 2) the assumed iron deficiency is due to an inadequate absorption of iron, 3 ) an increase in iron absorption due to a higher bioavailability of heme and/or iron chelates, will alleviate anaemia in sole and 4) Hct and Hb levels, as sensitive indicators of recovery from iron depletion, are expected to follow iron absorption patterns. In addition, we estimated the absorption of copper, cobalt, chromium, manganese, molybdenum and zinc, since it is known that there might be an interaction (antagonism) between the iron sources and the absorption of other divalent minerals. We demonstrated that iron absorption in sole is high and independent of the source of iron. Moreover, the use of different iron sources, including heme iron, does not affect iron absorption in anaemic sole. Still, heme iron does increase the absorption of copper. The high absorption of both iron and copper in sole fed heme does not affect $\mathrm{Hct}$ and $\mathrm{Hb}$, which indicates the nutritional anaemia in sole is not an iron or a copper deficiency anaemia.

In chapter 7 we tested two hypotheses: 1) sole needs high dietary levels of $\mathrm{B}_{12}$ to alleviate or prevent anaemia and 2) there is interaction between dietary taurine and $\mathrm{B}_{12}$, which affect Hct and $\mathrm{Hb}$ levels. The Hct and Hb levels in anaemic sole are influenced by dietary $\mathrm{B}_{12}$. 
However, an increasing level of dietary taurine suppresses the stimulating effect of a high dietary level of $\mathrm{B}_{12}$ on $\mathrm{Hct}$ and $\mathrm{Hb}$ in anaemic sole. The applied $\mathrm{B}_{12}$ levels, as well as taurine levels, were unable to completely alleviate the nutritional anaemia in sole induced by feeding commercial pellets. Nevertheless, the first hypothesis that sole needs high dietary levels of $\mathrm{B}_{12}$ to alleviate anaemia cannot be rejected.

Chapter 2, 3, 4 and 5 show that the nutritional anaemia in sole fed commercial pellets can be alleviated by feeding ragworm, mussel or ragworm meal. Yet, in spite of using comparable levels of $\mathrm{B}_{12}$, the increase of Hct and $\mathrm{Hb}$ was limited. Consequently, the sole remained (moderately) anaemic. It is likely that one or more other dietary components which are present in mussel and ragworm are involved in the alleviation of nutritional anaemia in sole as Hct and $\mathrm{Hb}$ levels almost double in sole when fed ragworm or mussel.

In chapter 8, more options to alleviate the nutritional anaemia in common sole are discussed. Nutrients as vitamin C, B1, B2, B5 and a possible role of dietary EPO are discussed. We suggested that the slow growth of pellet-fed sole might be the consequence of low Hct and Hb levels, which hampers the uptake of oxygen, and thus also of the overall metabolic capacity, including the scope for growth. We further discussed the difference in the "optimal" culture temperature of $\pm 7^{\circ} \mathrm{C}$ between sole fed ragworm and sole fed the $2^{\text {nd }}$ generation pellet. The growth rate achieved in sole fed the $3^{\text {rd }}$ generation pellet at $18.4^{\circ} \mathrm{C}$ was comparable to the growth rate of sole fed fresh ragworm, which could not have been the consequence of increasing $\mathrm{Hct}$ and $\mathrm{Hb}$ levels as these were comparable to levels found in sole fed commercial pellets. As $\mathrm{Co}^{2+}$-corrinoids do react with oxygen through a fast reversible oxygen binding step, eventually yielding $\mathrm{Co}^{3+}$-corrinoids and $\mathrm{O}_{2}$ we inferred on the possibility of a specific metabolic function of vitamin $\mathrm{B}_{12}$ in respiration.

This thesis shows that it is possible to formulate an artificial dry diet that achieves similar growth rates in sole when fed ragworm. This implies an improvement in growth of $140 \%$ compared to "current" Dutch farm conditions. The economic and practical impact of the improved growth rate in sole culture is discussed. Finally, several suggestions for future research are given. Scientifically, from the work done in this thesis, the following conclusions can be drawn:

- Feeding ragworm (Nereis virens Sars.) or Mussel (Mytilus edulis L.) to common sole fed commercial pellets increases their Hct and Hb levels.

- Sole fed commercial pellets develop a nutritional anaemia; feeding ragworm (Nereis virens Sars.) or Mussel (Mytilus edulis L.) to sole alleviates this nutritional anaemia.

- The addition of ragworm extract to the commercial pellet improves the feed intake to 
similar levels as in sole fed ragworm, yet it has only a limited effect on growth and does not improve the anaemic state of the sole.

- Iron absorption in sole is high and independent of the iron source.

- The nutritional anaemia in sole is not due to an iron or copper deficiency.

- Hct and $\mathrm{Hb}$ levels in anaemic sole are influenced by a "high" level of dietary $\mathrm{B}_{12}$.

Practically, this study developed an artificial diet in the form of a dry pellet based on the composition of ragworm. This formulation supports a growth performance comparable to sole fed fresh ragworm when fed under experimental conditions. 


\section{Dankwoord}

Een proefschrift schrijf je niet alleen. Het proces van een promotie omvat meer dan alleen het doen van onderzoek, het schrijven van artikelen en van een proefschrift. Het is een proces waarin je niet alleen wetenschappelijk groeit, maar ook op persoonlijk vlak een ontwikkeling doormaakt. Velen hebben hier, bewust of onbewust, een belangrijke rol bij gespeeld en direct of indirect een bijdrage aan geleverd. Allen wil ik hiervoor hartelijk bedanken. Verschillende mensen zal ik bij naam noemen. Het is echter onmogelijk compleet te zijn omdat zelfs kleine gebeurtenissen grote gevolgen kunnen hebben gehad.

Een aantal mensen heeft een essentiële rol gespeeld in het creëren van de mogelijkheid voor de uitvoering van dit promotieonderzoek. Ten eerste Jan Ketelaars, de man achter het idee van het project de "Zeeuwse tong". Jan vroeg mij destijds of ik geïnteresseerd was een bijdrage te leveren aan dit project in Zeeland. Zonder zijn vraag was dit promotieonderzoek er waarschijnlijk nooit gekomen. Ten tweede wil ik graag Oliver Schneider bedanken. Oliver vroeg mij of ik binnen het project Zeeuwse Tong een promotieonderzoek wilde doen met als doel de ontwikkeling van een tongvoer. Oliver, hartelijk dank dat je geloofde in mijn ideeën en capaciteiten om deze uitdaging tot een goed einde te brengen.

Ik wil mijn promotor Johan Verreth, en beide copromotors Johan Schrama en Robbert Blonk bedanken voor het vertrouwen in mij, voor hun begeleiding en kritische houding. Ik ben me ervan bewust dat het niet altijd eenvoudig was om mij te overtuigen. Dank voor jullie geduld en vasthoudendheid die nodig waren om mijn eigen vastberadenheid te doorbreken.

Reint Kuiper en Paul van Helvert wil ik bedanken voor hun ondersteuning in relatie tot het patent en het spanningsveld tussen de validatie van kennis en het delen van wetenschappelijke informatie. Prof. dr. Jan Lindemans van het Erasmus MC bedank ik voor de discussies rondom vitamine $\mathrm{B}_{12}$ en de analyses van methylmalonzuur en totaal vitamine $\mathrm{B}_{12}$ in bloedplasma van tong. Gerard Beelen wil ik bedanken voor de fysieke productie van de experimentele voeders: bedenken is één; maken is twee.

Verder wil ik mijn collega's, de betrokken studenten en vrienden van Wageningen Research, waaronder Sander Ruizeveld de Winter, Ainhoa Blanco Garcia, Hans van de Vis, Stephan Ende, Saskia Kroeckel, Vanessa Hemsing, Jacob Capelle, Siep Busink, Tim Sobotta, 
Fulvio Mongile, Julia Mas-Muñoz, Ewout Blom, Jan van der Heul, Andries Kamstra, Edward Schram, Henk van der Mheen, Yoeri van Es, Noortje Ros, Angelo Hofman, Hans Zeedijk, Emiel Brummelhuis, Johan Jol, Ad van Gool, Douwe van de Ende, Paul Bartels, Marnix Poelman, Wout Abbink, Arjan Palstra, Jeanet Allewijn en Robert Trouwborst hartelijk bedanken voor hun aandacht, discussies, hulp, ondersteuning, vertrouwen en inzet tijdens de uitvoering van de experimenten die regelmatig ook buiten de normale werkuren noodzakelijk bleken.

Eén persoon wil ik in het bijzonder bedanken: Eugene Rurangwa, my friend and former roommate, thank you for all our discussions, walks to the supermarket and endorsing the importance of finishing my thesis. Daarnaast alle personen, waaronder Ard Duits, Robin Smit, Jaap Jan Zeeberg, Jacques Wijnoogst en Ivo Vervaeck die me regelmatig vroegen hoe het er mee stond.

Bert Terpstra, Marjolein Rovers, Richard Griffioen en de deelnemers van de Masterclass Leadership in 2014 wil ik bedanken voor de aandacht, interesse, het respect, het vertrouwen, de reflectie en de benodigde commotie voor het stimuleren van mijn persoonlijke groei.

Paul Hendrix, mijn beste (vis)vriend, al meer dan 30 jaar, en mijn broer Maarten wil ik, naast het feit dat ik dankbaar ben dat ze onderdeel zijn van mijn leven, hartelijk bedanken voor hun rol als paranimf tijdens de verdediging van dit proefschrift.

Ik wil mijn ouders Huub, Vera, Lous en Rob, die tijdens de opvoeding ieder hun eigen wereldbeeld hebben uitgedragen en zo zorgden voor extra diversiteit in mijn perceptie, hartelijk bedanken voor hun aandacht, liefde en steun al die jaren.

Jennifer, mijn partner, wil ik hartelijk bedanken voor alle liefde, steun, geduld en de ruimte die ze mij gaf om te kunnen schrijven. Ik ben dankbaar voor de natuur, mijn boot Clarissa en de rust van het verblijf op het water. In deze situatie heb ik grote delen van mijn proefschrift mogen schrijven. Ook de Peugeot 306 GTI die me fysiek bracht waar ik moest zijn, soms met snelheden die me mentaal tot rust brachten, wat een heerlijke auto!

Dit werk was niet mogelijk geweest zonder de bijdrage van de vakgroep Visteelt en Visserij (AFI), Plant Research International (PRI), het project Zeeuwse Tong en het Institute for Marine Resources \& Ecosystem Studies (IMARES).

Hartelijk bedankt allemaal!

Jeroen. 


\section{About the author}

Jeroen Kals was born on the $4^{\text {th }}$ of March 1970 in Geldrop, The Netherlands. He was raised in a rural area were Jeroen experienced the fascinating life in and around fosses and ponds. During the hikes with his grandfather he learned to observe, wonder and developed respect for nature. Jeroen finished high school at the Eckartcollege in Eindhoven. In 1990, he started to study Animal Sciences at Wageningen University and finalized two theses. One entitled: "The effects of flumequine on the gonadal development of common carp, Cyprinus carpio using in- and outbred strains", was carried out at the Department of Aquaculture and Fisheries (AFI). The second: "The effects of different killing and processing methods on the quality of African Catfish, Clarias gariepinus, was conducted at The Netherlands Institute for Fisheries Research (RIVO) under supervision of Dr. Hans van de Vis and Prof. dr. Ir. Wim de Wit. After his internship at the University of Tasmania Jeroen crossed the Australian desert and learned to respect the "dry" site of nature. Jeroen graduated in 1996 for his master in Animal Sciences with the focus on aquaculture and started, with an associate, a feasibility study for an integrated farm culturing fish, algae and shellfish in The Netherlands, which turned out to be not economical feasible. In 1998, he started as a researcher fish processing at the Agrotechnological research Institute (ATO) in Wageningen. In 1999, he took a position as project leader fish processing and the use of by products at RIVO. In 2003, he switched back to aquaculture and focused on fish nutrition. In 2007, Jeroen moved to the department of Aquaculture at the Institute for Marine Resources \& Ecosystem Studies (IMARES) in Yerseke. In 2009, Jeroen started a PhD project at AFI in cooperation with IMARES with the aim to develop a feed for sole, with this thesis, a patent and a sole feed as result. Currently, Jeroen is working as researcher Seafood, Aquaculture and Fish Nutrition at Wageningen Livestock department of Animal Nutrition. During this process he learned that we observe, discover and create in a system, the universe, that is far more intelligent than mankind and that the truth and reality goes as far as the individual who observes it.

Contact: jkpisces2013@gmail.com 


\section{List of publications}

Kals J. (2016) Feeding ragworm (N. virens) or mussel (M. edulis) to sole (S. solea) alleviates nutritional anaemia. Oral. Book of Abstracts of the 67th Annual Meeting of the European Federation of Animal Science. Belfast, United Kingdom, 29 August - 2 September 2016

Kals J., Blonk R.J.W., Mheen H.W. van der, Schrama J.W. \& Verreth J.A.J. (2016). Effect of iron source on the alleviation of nutritional anaemia in common sole (Solea solea). Oral Book of Abstracts of the 67th Annual Meeting of the European Federation of Animal Science. Belfast, United Kingdom, 29 August - 2 September 2016

Kasper G.J., Duinkerken G. van., Krimpen M.M. van., Wagenberg C.P.A. van., Kals J., Sanders J.P.M. \& Visser C.L.M. de (2016). Efficiënter gebruik van voedermiddelen en (geïmporteerde) diervoedergrondstoffen. Mogelijkheden als grondstoffenbron voor de Biobased Economy. Efficiënter gebruik van voedermiddelen en (geïmporteerde) diervoedergrondstoffen. Wageningen, Wageningen UR (University \& Research centre) Livestock Research, Livestock Research Rapport 946, 63 pp.

Rurangwa E., Schram E., Goudswaard K., Kals J. \& Bolman B.C. (2015). Environmental Impact of Intensive Aquaculture in East Africa. IMARES report no. C096/15. LEI report no. VR2015-088.

Kals J. \& Blonk R.J.W (2015). Fish nutrition and formulation. Back to office report. Fisheries and Aquaculture for food security in Indonesia, $70 \mathrm{pp}$.

Kals J. \& Poelman M. (2015). Mogelijkheden voor verwaarding van bijproducten van garnalen. Factsheet Kenniskring Garnalen. https://www.wur.n1/upload_mm/7/8/0/65a3ee3a-a8b0-4ac9a198-731f97b8ee9f_38.\%20201507\%20Garnalen\%20bijproducten.pdf

Palstra A.P., Kals J. Blanco G.A., Dirks R.P., Poelman M. Immunomodulatory effects of dietary seaweeds in LPS challenged Atlantic salmon (salmo salar) as determined by deep RNA sequencing of the head kidney transcriptome. Poster Aquaculture Europe, October 20-23, Rotterdam (Netherlands). 
Kals J. Feeding Ragworm (Nereis virens) or Mussel (Mytilus Edulis) to Common sole (solea solea) alleviates nutritional anaemia. Oral. Aquaculture Europe 2015 - Rotterdam, Netherlands.

Kals J., Blonk R.J.W., Mheen H.W. van der, Schrama J.W. \& Verreth J.A.J. (2015 $)$. Effect of different iron sources on the alleviation of nutritional anaemia in common sole (Solea, solea). Aquaculture. 451: 266-270. http://dx.doi.org/10.1016/j.aquaculture.2015.08.036

Kals J., Blonk R.J.W., Palstra A.P., Sobotta T.K., Mongile F., Schneider O., Planas J.V., Schrama J.W. \& Verreth J.A.J. (2015 ${ }^{\mathrm{d}}$ ) Feeding ragworm (Nereis virens Sars) to common sole (Solea, solea L.) alleviates nutritional anaemia and stimulates growth. Aquaculture Research. http://dx.doi.org/10.1111/are.12919.

Kals, J., Blonk, R.J.W., van der Mheen, H., Schrama, J.W. and Verreth, J.A.J. (2015). Mussel (Mytilus edulis L.) and ragworm (Nereis virens, Sars) both alleviate anaemia in common sole (Solea solea L.). Aquaculture Research. doi:10.1111/are.12871

Kals J. \& Broeze J. (2015) Sterols in fish and shrimp, evaluating product JT15C25-K for the use as cholesterol supplement in aquaculture feeds. Report number C093/15, confidential.

Kals J., Poelman M. en Goudswaard K. De samenstelling van discards in de pelagische visserij voor valorisatie doeleinden”. IMARES Rapport C023/15.

Kals J., Poelman M. en Goudswaard K. De samenstelling van discards in de demersale visserij voor valorisatie doeleinden”. IMARES Rapport C99/15.

Kals J., Blonk R.J.W., van der Mheen H., Schrama J.W. \& Verreth, J.A.J. (2015). Feeding ragworm (Nereis virens Sars) increases haematocrit and haemoglobin levels in common sole (Solea solea L.). Aquaculture Research doi:10.1111/are.12767.

Kals J. (2015). Nematoden in Europese zeevis. Report number C0/15, confidential.

Rurangwa E., Sipkema D., Kals J., ter Veld M., Forlenza M., Bacanu G.M., Smidt H. \& Palstra A.P. (2015). Impact of a novel protein meal on the gastrointestinal microbiota and host transcriptome of larval zebrafish Danio rerio. Frontiers in Physiology, section Aquatic Physiology. http://journal.frontiersin.org/article/10.3389/fphys.2015.00133/abstract.

Kamermans P., Blanco, A. \& Kals J. Use of flue gas and glycol to grow microalgae for production of fish and shellfish. Report C051/15, confidential. 
Palstra A.P., Blok M.C., Kals J., Blom E., Tuinhof-Koelma N., Dirks R.P., Forlenza M. \& Blonk R.J.W. (2015). In- and outdoor reproduction of first generation common sole Solea solea under a natural photothermal regime: temporal progression of sexual maturation assessed by monitoring plasma steroids and gonadotropin mRNA expression. General and Comparative Endocrinology.

Vis H. van de, Kals J., Schelvis-Smit R., \& Poelman M. (2014). Total Quality Control Management Tool D4.11. Improving Food security by reducing post-harvest losses in the fisheries sector. KBBE.2011.2.5-02.

Kals J. Alleviation of anaemic growth suppression in fish. PCT/EP2013/06419 Stichting Dienst Landbouwkundig Onderzoek, The Netherlands. Octrooinummer: WO2014/032837 A1, verleend: 2014-03-06.

Kals J. Development of a sustainable sole feed based on ragworms part IV (Oral). Workshop Zeeuwse Tong, Rusthoeve Colijnsplaat, 14 februari 2013.

Burg S.W.K. van den, Stuiver M., Veenstra F.A., Bikker P., Lopez Contreras A.M., Palstra A.P., Broeze J., Jansen H.M., Jak R.G., Gerritsen A.L., Harmsen P.F.H., Kals J., Blanco Garcia A., Brandenburg W.A., Krimpen M.M. van, Duijn A.P. van, Mulder W.J. \& Raamsdonk L.W.D. van (2013). A Triple P review of the feasibility of sustainable offshore seaweed production in the North Sea. (LEI Report13-077 ). Wageningen: Wageningen UR.

Palstra A.P., Blok M.C., Kals J., Blom E. \& Blonk, R.J.W. (2013). In- and outdoor reproduction in captivity of first generation common sole Solea solea under a natural photothermal regime: Temporal progression of sexual maturation determined by GSI and plasma teroids. In Book of abstracts of the 6th Fish \& Shellfish larviculture symposium, 02-05 September 2013, Ghent, Belgium.

Palstra A.P., Kals J., Veld M. ter, Forlenza M. \& Rurangwa E. (2013). Nutritional impact of dietary iron on the molecular regulation of iron uptake and homeostasis in larval and adult zebrafish Danio rerio. In 8th European Zebrafish Meeting, Barcelona, Spain, 9-13 July 2013.

Kals J. Development of a sustainable sole feed based on ragworms part IV (Oral). Workshop Zeeuwse Tong, Rusthoeve Colijnsplaat, 14 februari 2013. WIAS

Kals J., Heinsbroek L.T.N. \& Zwart S. (2012). Phosphorus digestibility and retention of three inorganic phosphorus sources in rainbow trout (Oncorhynchus mykiss); Does MAP outperform 
DCP and MCP. XV International Symposium on Fish Nutrition and Feeding: Molde (2012, juni 04 - 2012, juni 07).

Kals J. Development of a sustainable sole feed based on ragworms part III (Oral). Workshop Zeeuwse Tong, Rusthoeve Colijnsplaat, 21 maart 2012.

Schneider O., Schram E., Kals J., Heul J.W. van der, Kankainen M. \& Mheen H.W. van der (2012). Welfare interventions in flatfish recirculation aquaculture systems and their economical implications. Aquaculture Economics \& Management, 16(4), 399-413.

Heinsbroek L. \& Kals, J. (2011). Phosphorus digestibility and retention of three selected inorganic phosphorus sources in Rainbow Trout. Report number C144/11 - Confidential.

Lemme A. Kals J. \& Schrama J.W. Common Carp, (Cyprinus Carpio L.) can utilize supplemental DL-methionine to more than $90 \%$ for methionine and cysteine retention. Abstracts Aquaculture Europe, Rhodes Greece, October 18-21, p. 628-629, 2011.

Kals J. Development of a sustainable sole feed based on ragworms part II. (Oral) Workshop Zeeuwse Tong, Rusthoeve, Colijnsplaat, 16 maart 2011.

Kals J. Vereijken P. Rurangwa E. Schrama J.W. Busink S. \& Schneider O. Use of Olfactory attractants from mussel (Mytilus edulis) and ragworm (Nereis virens) does not increase feed intake of Dover Sole, (Solea solea). Abstracts Aquaculture Europe, Porto, Portugal, October 58, p. 633-634, 2010.

Kals J. \& J. Schrama. (2010). Biological effectiveness of novel Methionine sources compared to DL Methionine in carp. Report C16/10. Confidential

Kals J. \& J. Schrama. (2010). Biological effectiveness of two novel Methionine sources compared to DL Methionine in carp. Report C097/10. Confidential

Kals J. The development of a sole feed based on ragworms part I; Identification of the intrinsic factors of the ragworm responsible for the excellent growth of Sole. plus The effect of mussel and ragworm attractants on the feed intake of Dover Sole, Solea, solea. (Oral) Workshop Zeeuwse Tong, Zaete, Yerseke 01 april 2010

Kals J., B. van Hese E. Schram en J. van der Heul. Handleiding voor de pootvisproductie van tong (Solea solea). (2009). Rapport C020/09 
Kals J. en J. van der Heul. Opbouw broodstock populatie en productie van pootvis van tong (Solea solea). (2009). Rapport C040/09

Kals J., Capelle J., en Hemsing, V. Conversie zagervoer - zagers - tong. Rapportage Zeeuwse tong deelproject 2. (2009). Rapport C041/09

Kals J. Ruizeveld de Winter S., en Schiphouwer M. (2009). Doorkweek Tong. Rapport C046/09

Capelle J. and Kals J. The interaction between sole and ragworms; The effect of the (indirect) presence of sole on the behaviour and performance of the ragworm. Nereis virens. (2008). Report 08.020

Ende S.S.W. Kals J., Schram E. \& Schneider O. Towards the development of suitable feeds for the common sole, Solea, solea. Proceedings of the 4th Workshop on the Cultivation of Soles. Centre of Marine Sciences (CCMAR ), University of the Algarve in Faro. 11-14 November 2008.

Reijs Th.A.M., Oorschot R.W.A., Poelman M. Kals J. \& Immink, I. (2008). Aquacultuur op open zee. TNO-rapport 2008-D-R1048/A

Kals J. Concept(en) voor nutriënt neutrale aquacultuur in de Noordzee. Aquacultuur in de Noordzee, 15 juni 2007 Scheveningen.

Bartels P. \& Kals J.. Improving the utilization of Silver carp (Hypopthalmichthys Molitrix) and or other under-utilized fish species, especially Fresh water Bream (Abramis brama).

Possibilities for value adding supply chains and international trade of Silver carp (Hypopthalmichthys Molitrix) in the Islamic Republic of Iran. Final report of the research 20052007. Rapport nr. 767

Kals J. \& de Vries P. Ontwikkeling van dynamische aquatische test ecosystemen: experimentele modellen voor kokkelkweeksystemen. Dynaqua kokkelkweek F rapport (2006). TNO-rapport R 2006/DH/0321/B vertrouwelijk.

Vries L.B. de, Veenstra F.A., Kals J. Bakker A.G. (2007). Offshore Mariene Productie Unit (MPU) Proeven 2006. TNO-rapport B\&O - 2007-D-R0229. Vertrouwelijk.

Kals J. Bakker A. \& de Vos R. (2006). Mosselzaadinvang Prins en Dingemanse 2006. TNOrapport 2007-A-R09921B. Vertrouwelijk. 
Kals J., Schram E., Brummelhuis E., \& Bakel B. van. (2007). Report Task 2.3: Particulate waste and turbidity in (marine) RAS. Report C070/06.

Jansen H.M \& Kals J. (2006). Task 2: Broodstock management. Sub-task 2.1: Extension of the natural reproduction period - early or delayed spawning (WP2). Report C080/06

Bartels P. \& Kals J. (2006). Improving the utilization of Silver carp (Hypothalmichthys molitrix) and or other under-utilized fish species, especially Fres water Bream (Abramis brama): possibilites for value adding supply chains and international trade of silver carp (Hypothalmichthys molitrix) in the Islamic Republic of Iran. Report C006B/06

Mheen H. van der, Kals J. en Schram E. (2006). Meest kansrijke soorten voor visteelt in Nederland. AQUAcultuur 21(1): 13-19.

Zeeberg J.J., Bult T.P., van Densen W.L.T. van Hoof, L.J.W. \& Kals J. (2006). Een beschouwing van nationale en internationale beheermaatregelen ten behoeve van een duurzame visserij en visproductie in mariene ecosystemen. Rapport C041/06

Schram E., Kals J., Toner D.R. \& Policar, T. (2006). Production costs of perch (Perca fluvialitis) juveniles. Securing juvenile production of Eurasian perch by improving reproduction and larval rearing, Percatech. Report C071/06

Marlen, B. van, van de Vis J.W., Groeneveld K., Groot P.J., Warmerdam M.J.M., Dekker R., Lambooij E., Kals J., Veldman M. en Gerritzen M., (2005). Overleving en fysieke conditie van tong en schol gevangen met een $12 \mathrm{~m}$ pulskor en een conventionele wekkerboomkor. Rapport C044/05.

Kals J. Schram E. Mheen van der H., Smaal A.C. en Smit J. (2005). Potentiele soorten voor de Nederlandse Aquacultuur: rapportage deelproject 2. Rapport C073/05.

Vis J.W. van de., Kals J., van Pelt H.M.L., Jansen W. Kruijt-Kloosterboer R.J., Veldman M. en Aalberts C.H.J. (2004). Quality of life and management of living resources programme (19982002): fifth progress report of partner 06. Report 04.018

Kals J. Recirculating aquaculture production systems : an overview of different components, management, economics and technology (2004). Report 04.019

Pelt-Heerschap H. van, Kotterman M.J.J., Shaw N., Kals J. and Vis J.W. van de. (2003). Extraction and characterization of collagen extracted from skin and bones of cod (Gadus 
morhua). In: Proceedings of the First Joined Trans Atlantic Fisheries Technology conference, 10-14 June, Reykjavik, Iceland, Icelandic Fisheries Laboratories, Reykjavik, Iceland, pp. 355356, ISBN 9979-74-005-1, 2003

Kloosterboer R.J., Kals J. Vis J.W. van de., en Aidos I. (2002). Opwaardering bijproducten haringverwerkende industrie. Rapport C014/02

Kals J. Use of pulsed light to extend the shelf life of packed fish and fish products: literature research to explore pulsed light technology and the possibilities for the application of this technology for fish and fish products (2001). Confidential. Rapport 02.015

Vis J.W. van de., Kals J., en Kloosterboer R.J. (2001). Preventie zwartkleuring kokkels: literatuurstudie. Rapport C051/01

Kals J. en Kloosterboer R.J. (2000) Sturing van textuur en verrijking van magere en vette visresten en technical annex. Rapport C024/00.

Kals J. (2000). Er is meer uit vis te halen: focus op reststroomtechnologie. Vleesindustrie, 6(9): 40-41.

Kals J. (2000). Meer uit visafval halen door reststroom-technologie. In Dutch. Visserijnieuws, 8.

Matser A.M., Stegeman D., Kals J. and Bartels P.V. (2000). Effects of high pressure on colour and texture of fish. High Pressure Research, 19: 109-115.

Matser A.M., Stegeman D., Kals J. and Bartels P.V. (1999). Effect of high pressure on colour and texture of fish. Paper read at EHPRG, 9-11 September, Montpellier, France.

Kals J. and Vis J.W. van de. (2000). Comparison of binary-ice (FLO-ICEtm) and flake ice for chilling and storage of yellow gurnard (Trigla lucerna) on a dutch commercial trawlers. In: Proc. 29th WEFTA Meeting 10- 14 October, 1999 - Leptocarya - Pieria, Greece/ ed. by S.A. Georgakis, p. 402-411.

Kals J. Sturing van textuur en verrijking van kabeljauwresten (2000). Rapport 00.014

Kals J. Het gebruik van Flo-ice aan boord van de UK224 (1999). Rapport C051/99

Kals J. Het gebruik van Ultra Hoge Druk voor het elimineren van parasieten uit verse vis (1999). ATO rapport 1999/03/02. Vertrouwelijk. 
Fourmantrouw S. Kals J. Matser A. Bartels P.V. Preliminary experiments of the effect of high pressure on the colour of fish (cod). ATO rapport: January 1999.

Ingen B. Doeveren P. Jonkers J. Kals J. Weitkamp J. Stegeman D. Seo-Mince; Intern rapport bijdrage ATO-DLO in SEO vis onderzoek. ATO Rapport: Mei 1999. Vertrouwelijk.

Kals J., Stegeman D, Schreurs F. Literatuuronderzoek naar de verschillen tussen vis, vlees en gevogelte. ATO rapport 1998-09-14. Vertrouwelijk.

Jonkers J., Kals J. Weitkamp J., Stegeman D. Recente werkzaamheden SEO-vis project. ATO rapport 1998-08-18. Vertrouwelijk.

Kals J. Kamstra A. Van de Vis J.W. (1995). Effects of Killing and processing methods on the quality of African Catfish, Clarias Gariepinus. in Dutch Aquacultuur, 4: 7-15.

Kals J. A Poster presentation: "Effects of slaughter methods on quality of African catfish Clarias Gariepinus. presented at the International Seafood Conference 13-16 November 1995, Noordwijkerhout, The Netherlands 


\section{Colophon}

The research descripted in this thesis was financially supported by the Zeeuwse Tong Project (Zeeland Sole Project, co-financed by the European Fisheries Fund and the Institute for Marine Resources and Ecosystem Studies (IMARES).

Financial support for printing this thesis, from the Aquaculture and Fisheries Group of Wageningen University is gratefully acknowledged.

Cover design: Van Velzen Grafisch Ontwerp, 's-Hertogenbosch

Printed by: Printed by: ProefschriftMaken $\mid$ www.Proefschriftmaken.nl 


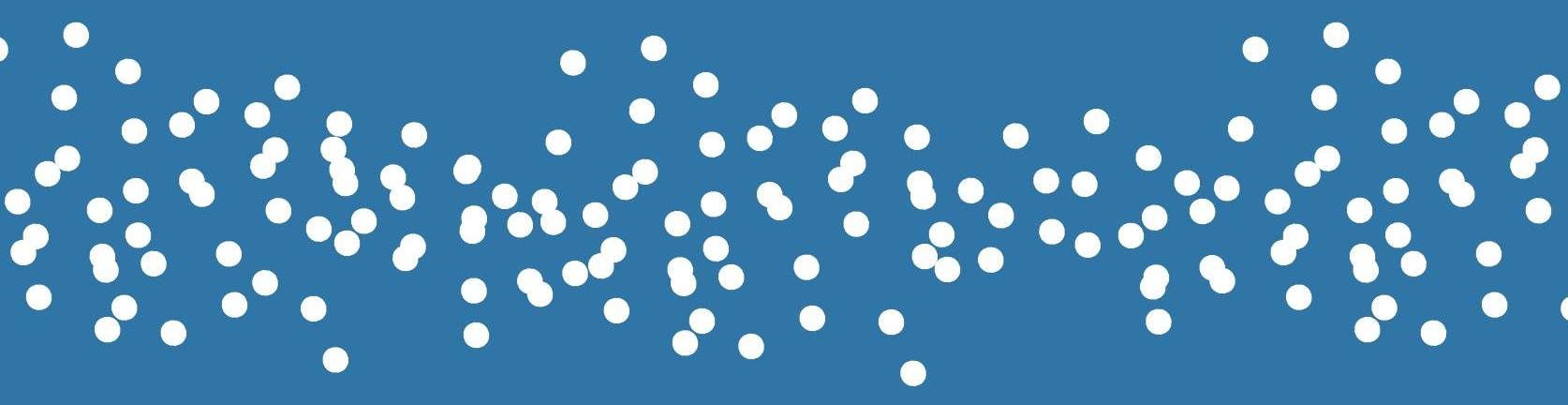

